\title{
WestVirginiaUniversity
}

THE RESEARCH REPOSITORY @ WVU

Graduate Theses, Dissertations, and Problem Reports

2009

\section{Production decline analysis of horizontal well in gas shale reservoirs}

Folarin Adekoya

West Virginia University

Follow this and additional works at: https://researchrepository.wvu.edu/etd

\section{Recommended Citation}

Adekoya, Folarin, "Production decline analysis of horizontal well in gas shale reservoirs" (2009). Graduate Theses, Dissertations, and Problem Reports. 1994.

https://researchrepository.wvu.edu/etd/1994

This Thesis is protected by copyright and/or related rights. It has been brought to you by the The Research Repository @ WVU with permission from the rights-holder(s). You are free to use this Thesis in any way that is permitted by the copyright and related rights legislation that applies to your use. For other uses you must obtain permission from the rights-holder(s) directly, unless additional rights are indicated by a Creative Commons license in the record and/ or on the work itself. This Thesis has been accepted for inclusion in WVU Graduate Theses, Dissertations, and Problem Reports collection by an authorized administrator of The Research Repository @ WVU. For more information, please contact researchrepository@mail.wvu.edu. 


\title{
PRODUCTION DECLINE ANALYSIS OF HORIZONTAL WELL IN GAS SHALE RESERVOIRS
}

\author{
Folarin Adekoya
}

\author{
A Thesis Submitted to the \\ College of Engineering and Mineral Resources at \\ West Virginia University in partial fulfillment of the \\ Requirements for the degree of \\ Master of Science \\ In \\ Petroleum \& Natural Gas Engineering \\ Yueming Cheng, Ph.D., Chair \\ Samuel Ameri, M.S. \\ Ilkin Bilgesu, Ph.D. \\ Daniel E. Della-Giustina, Ph.D. \\ Department of Petroleum \& Natural Gas Engineering \\ West Virginia University \\ Morgantown, West Virginia \\ 2009
}

Keywords: Decline analysis, Shale gas reservoir, Horizontal well, Marcellus shale Copyright 2009 Folarin .O Adekoya 


\section{ABSTRACT \\ PRODUCTION DECLINE ANALYSIS OF HORIZONTAL WELL IN GAS SHALE RESERVOIRS}

Folarin Adekoya

The major factor influencing the increase of natural gas use is the rise in its global demand. Due to the relentlessly increasing demand, there have been improvements in the techniques and technology used in recovering natural gas from shale gas reservoirs, including drilling a horizontal well and hydraulic fracturing. One of the significant challenges associated with gas shale production is that it is difficult to reliably predict ultimate recovery and estimate reserves, leading to great risk in exploitation of these resources. The purpose of this research is to evaluate the current decline curve analysis techniques and provide a more reliable method for production forecast and reserve estimate for hydraulically fractured horizontal wells producing from gas shale reservoirs.

When production data of low permeability reservoirs are analyzed using Arp's equation, the decline exponent $\mathrm{b}$ which is supposed to range between 0 and 1 is usually greater than 1 . The actual decline exponent $b$ value is not easy to come by in the transient period during the life of the well, however, having a decline exponent $b$ value greater than 1 will overestimate the remaining reserves of the well.

In this study, first, decline characteristics for shale gas wells are presented by simulating long-term production performance for a variety of well-reservoir systems, including Dimensionless fracture conductivity change, different fracture stages and fracture half- length; then different current decline analysis methods were evaluated in estimating reserves and predicting future performances. These methods are Conventional Decline Curve Analysis, the Backward Method and the Ilk Method. The evaluation task was done through quantitative comparison of production forecast results from current decline analysis with true simulated recovery. 
Finally, the Backward \& Ilk method was proposed and evaluated. This research work indicates that the Backward \& Ilk method can provide the most suitable and accurate results in estimating reserves and analyzing production data. 


\section{DEDICATION}

I would like to dedicate this work to my family who is my source of strength and stood by me in tough and difficult times. 


\section{ACKNOWLEDGEMENTS}

I would like to thank West Virginia University for giving me the opportunity to do my Masters program in this great University and conduct this research work. I would especially like to thank my mentor and research advisor Dr. Yueming Cheng for guiding me in this research work and sharing her life experiences and knowledge with me. I would also like to thank the other members of my committee Dr. Ilkin Bilgesu, Prof. Samuel Ameri and Dr. Daniel E. Della-Giustina for their guidance and support in completing this work. It has been an intriguing and wonderful learning process.

Finally, I would like to thank the department of Petroleum \& Natural Gas Engineering who gave me the right guidance and nurture from my undergraduate level till now.

I am most grateful to everyone who has helped me throughout this research. Thank you very much for your support. 


\section{TABLE OF CONTENTS}

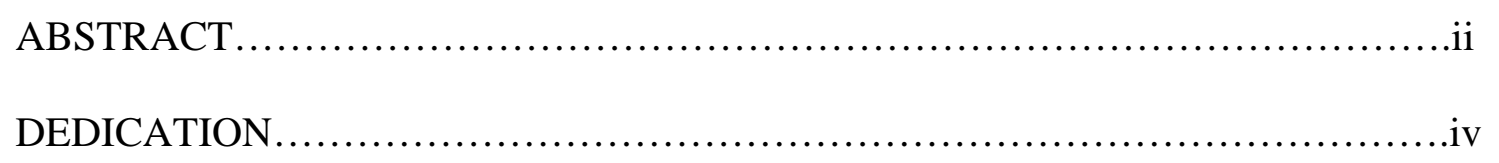

ACKNOWLEDGEMENTS $\ldots \ldots \ldots \ldots \ldots \ldots \ldots \ldots \ldots \ldots \ldots \ldots \ldots \ldots \ldots \ldots \ldots \ldots \ldots$

TABLE OF CONTENTS ..........................................................

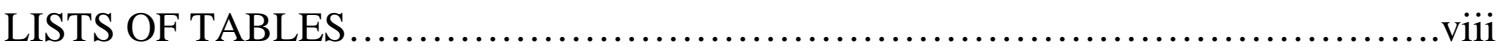

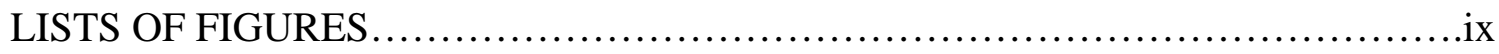

\section{CHAPTER}

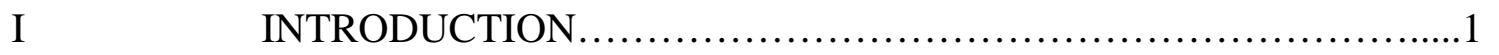

II CHARACTERISTICS OF SHALE GAS RESERVOIRS.................15

$2.1 \quad$ Literature Review...........................................15

$2.2 \quad$ Dual Porosity ...............................................

$2.3 \quad$ Flow Regime................................................18

$2.4 \quad$ Desorption of Adsorbed Gas....................................20

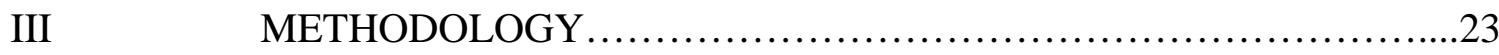

3.1 Model Design...............................................23

3.2 Representative Reservoir Data................................25

3.3 Key Parameters of the Simulated Reservoir........................26

3.4 Flowchart showing the Entire Analysis Process...................27 
3.5 Production Decline Analysis................................28

3.5.1 Convention Decline Curve Analysis Method..............28

3.5.2 Backward Method............................................31

3.5.3 Ilk's Method................................................

3.5.4 Ilk \& Backward Method ...............................33

IV

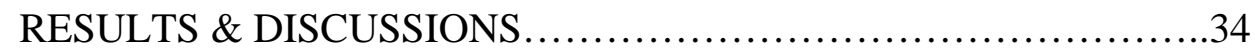

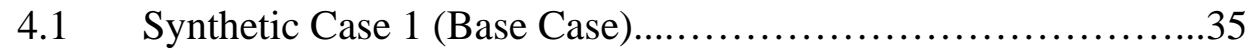

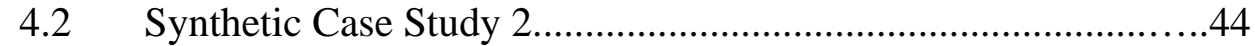

4.3 Synthetic Case Study 3........................................50

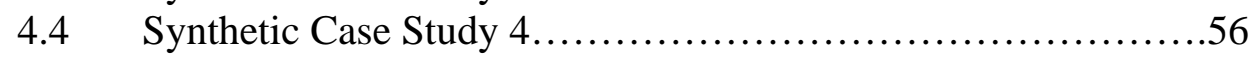

V

SUMMARY \& CONCLUSIONS..................................62

RECOMMENDATION.........................................64

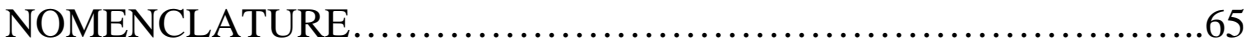

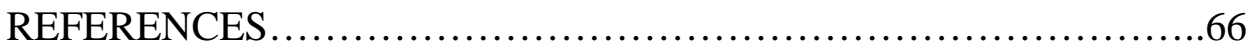




\section{LISTS OF TABLES}

TABLE

PAGE

1 Comparing Horizontal Well versus Vertical Well.........................

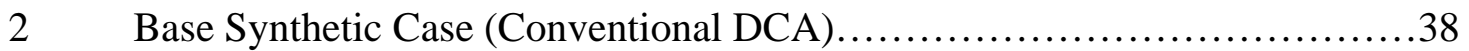

3 Base Synthetic Case (Backwards 10years)..............................40

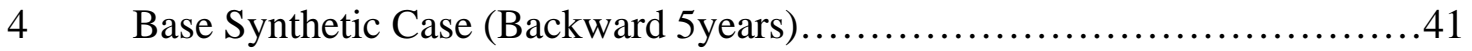

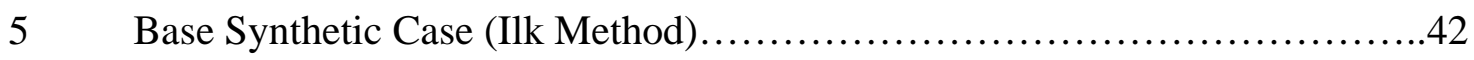

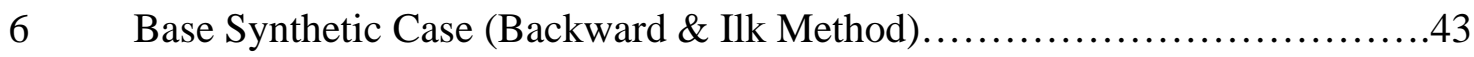

7 Dimensionless fracture conductivity (Conventional DCA).....................45

8 Dimensionless fracture conductivity (Backward 10years) $\ldots \ldots \ldots \ldots \ldots \ldots \ldots \ldots \ldots \ldots . . . .46$

9 Dimensionless fracture conductivity (Backward years) $. . \ldots \ldots \ldots \ldots \ldots \ldots \ldots . . . . . .47$

10 Dimensionless fracture conductivity (Ilk Method) $\ldots \ldots \ldots \ldots \ldots \ldots \ldots \ldots \ldots \ldots . . .48$

11 Dimensionless fracture conductivity (Backward \& Ilk Method).................49

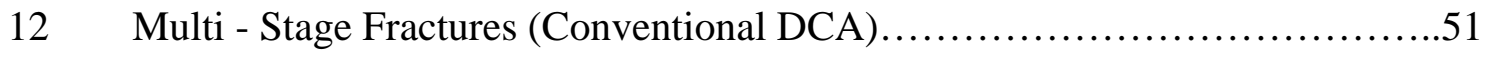

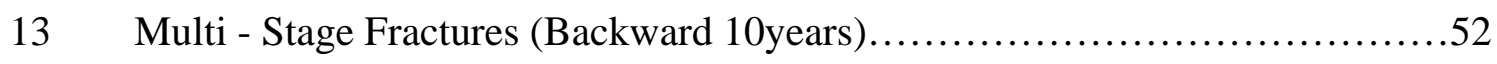

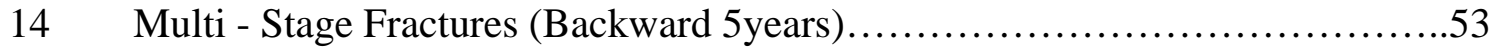

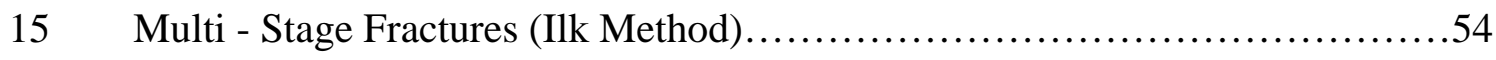

16 Multi - Stage Fractures (Backward \& Ilk Method) ..........................55

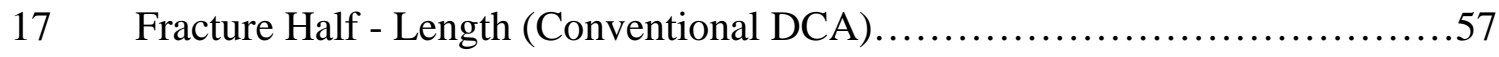

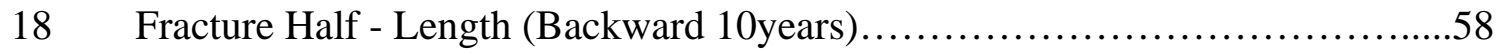

19 Fracture Half - Length (Backwards 5years) ...............................59

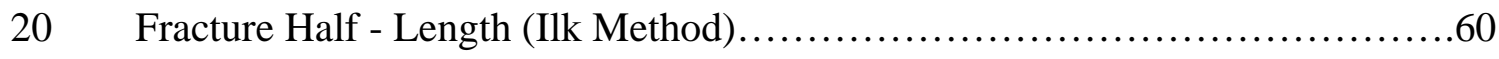

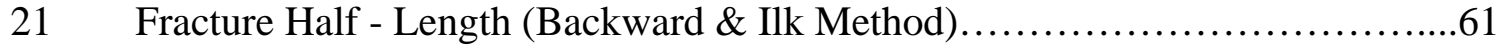




\section{LISTS OF FIGURES}

FIGURE

PAGE

1 A Graph Depicting the Rise of Unconventional Natural Gas Production...........2

2 A Map Showing Marcellus Shale Activity in the Appalachian Basin..............3

3 A Map Showing the Depth and Location of the Marcellus shale in the Appalachian Basin ......................................................4

4 Showing How the Horizontal Well intersects the Marcellus formation............6

5 Gas Production Rate over time of a vertically fractured Marcellus shale well ......8

6 Gas Production Rate over time of a Horizontally Fractured Marcellus shale well .8

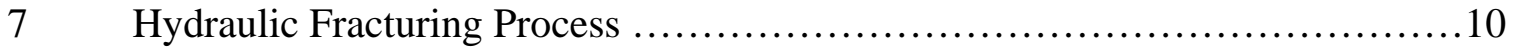

$8 \quad$ Production Rate between and Transverse and Longitudinal

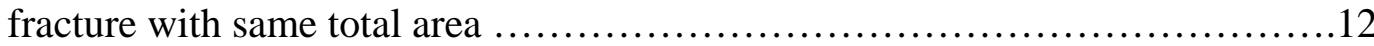

9 Cumulative Production between and Transverse and Longitudinal Fracture with

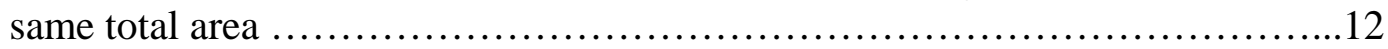

10 Cubed Grid Dual Porosity System........................................17

11 Match-Stick Dual Porosity System.....................................17

12 Slab-Like Dual Porosity System........................................ 17

13 A Pressure Vs Time graph showing the existing time periods ..................19

14 Linear Fracture flow Regime occurs during early time ......................19

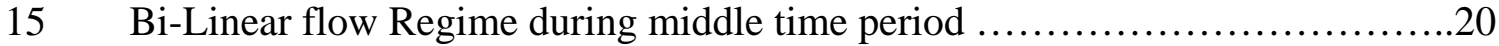

16 Langmuir Isotherm Curve..........................................21

17 Comparison of Gas Content vs. Total Organic Carbon in Two Gas Shale

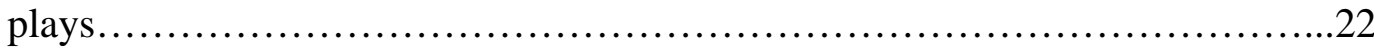


18 Figure 18: Depicts the Position and Location of the Horizontal well in the Shale

Gas Reservoir. .24

19 Flowchart of the entire analysis process.................................27

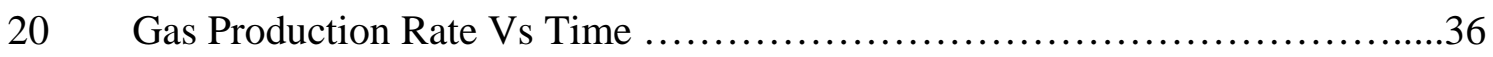

21 Cumulative Production Vs Time for Base Case Study.......................37

22 Semi-log showing the Conventional DCA Method using base case..............39

23 Semi-log showing Backward Method (10years) using base case..............40

24 Semi-log showing Backward Method (5years) using base case................41

25 Semi-log showing Ilk Method using base case $\ldots \ldots \ldots \ldots \ldots \ldots \ldots \ldots \ldots \ldots \ldots . \ldots . \ldots \ldots 2$

26 Semi-log showing Backward \& Ilk Method using base case.................43

27 Semi-log showing Conventional DCA Method

(Using a dimensionless fracture conductivity of 50 )......................45

28 Semi-log showing Backward Method 10years

(Using a dimensionless fracture conductivity of 50).

29 Semi-log showing Backward Method 5years

(Using a dimensionless fracture conductivity of 50).

$30 \quad$ Semi-log showing Ilk Method

(Using a dimensionless fracture conductivity of 50)

$31 \quad$ Semi-log showing Backward \& Ilk Method

(Using a dimensionless fracture conductivity of 50)

32 Figure 32: Semi-log showing Conventional DCA Method

(Using 12 multi-stage fractures)

33 Figure 33: Semi-log showing Backward Method 10years

(Using 12 multi-stage fractures)

34 Figure 34: Semi-log showing Backward Method 5years

(Using 12 multi-stage fractures) .53 
35 Figure 35: Semi-log showing Ilk Method (Using 12 multi-stage fractures)

36 Figure 36: Semi-log showing Backward \& Ilk Method

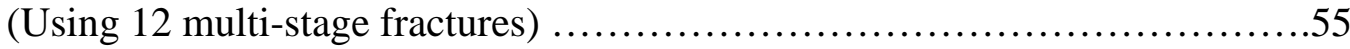

37 Figure 37: Semi-log showing Conventional DCA Method (Using fracture half-length of 271ft)

38 Figure 38: Semi-log showing Backward Method 10years

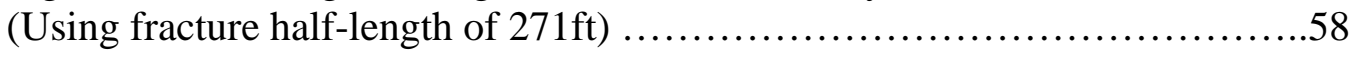

39 Figure 39: Semi-log showing Backward Method 5years

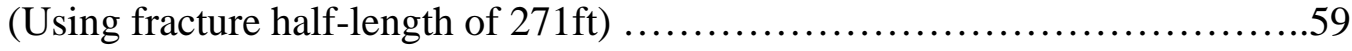

$40 \quad$ Figure 40: Semi-log showing Ilk Method (Using fracture half-length of 271ft)

$41 \quad$ Figure 41: Semi-log showing Conventional Method (Using fracture half-length of 271ft) .61 


\section{CHAPTER I}

\section{INTRODUCTION}

\subsection{Conventional \& Unconventional Reservoirs}

Conventional hydrocarbon reservoirs have been a major supplier of natural gas in the United States for the past years, however, these reservoirs are running out of supply and are becoming extremely difficult to locate and exploit with the present technology and techniques available. Conventional reservoirs are formed when crude oil or natural gas are being pushed upwards by the earth's forces through sips and rock fractures until it gets to a point where it encounters an impervious or impermeable rock (shale) that acts as a trap mechanism. This is then extracted with ease as it is usually accompanied with relatively good permeability by drilling a well. Presently, the continuous increase and persistent demand for crude oil and natural gas has drifted the oil and gas industry towards unconventional reservoirs.

Shale gas reservoirs like coal bed methane and tight sands can be regarded as an unconventional reservoir. Shale gas reservoir possesses the characteristics such as ultralow permeability, no trap mechanism and the gas is tightly absorbed to the rock particle which is the opposite of a conventional reservoir. The United States houses some of the largest shale gas reservoirs in the world which contribute majorly to the total domestic natural gas production in North America like the Barnett Shale of the Fort Worth Basin (1233 mmcf/d), the Lewis Shale of the San Juan Basin (55 mmcf/d), the Antrim Shale of the Michigan Basin (384 mmcf/d) and the Marcellus Shale of the Appalachian Basin (438 mmcf/d) (Sumi $\left.{ }^{28}\right)$. 
Figure 1 shows the rise in trends of unconventional natural gas production from early 1990’s and its predicted estimation through 2030.

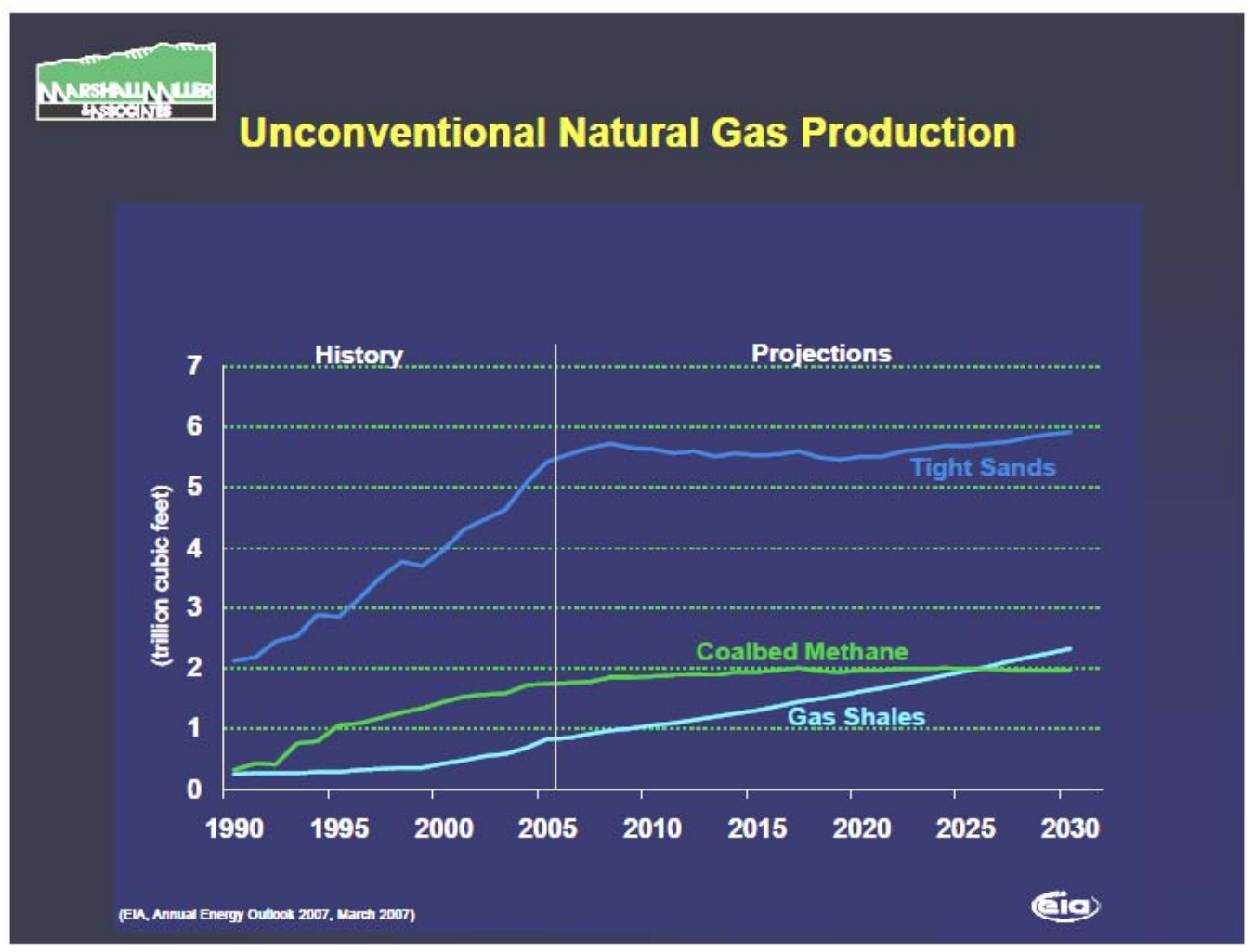

Figure 1: A graph depicting the Rise of Unconventional Natural Gas Production (geology.com ${ }^{20}$ ).

According to Terry Englander, a geoscience professor at Pennsylvania State University, and Gary Lash, a geology professor at the State University of New York at Fredonia, Marcellus shale of the Appalachian Basin was estimated to contain about 500 trillion cubic feet of natural gas in place (geology.com ${ }^{10}$ ). This estimate included that the same technology being used at the Barnett shale of the Fort Worth Basin (horizontal drilling and hydraulic fracturing) are to be applied to this shale reservoir. The Marcellus 
shale is thought to have 50 trillion cubic feet that is recoverable (assuming10\% of gas in place can be recovered with present technology and technique) (geology.com ${ }^{20}$ ).

Exploratory drilling of the Marcellus shale is on the rise and companies like Chesapeake Energy, Exco resources, PetroEdge, Range resources etc. already own large acreage of land containing this shale gas and have started exploiting this type of gas reservoirs. Figure 2 shows the area where Marcellus shale activity is currently producing and commingled with other zones in the Appalachian Basin.

\section{Marcellus Shale Activity}

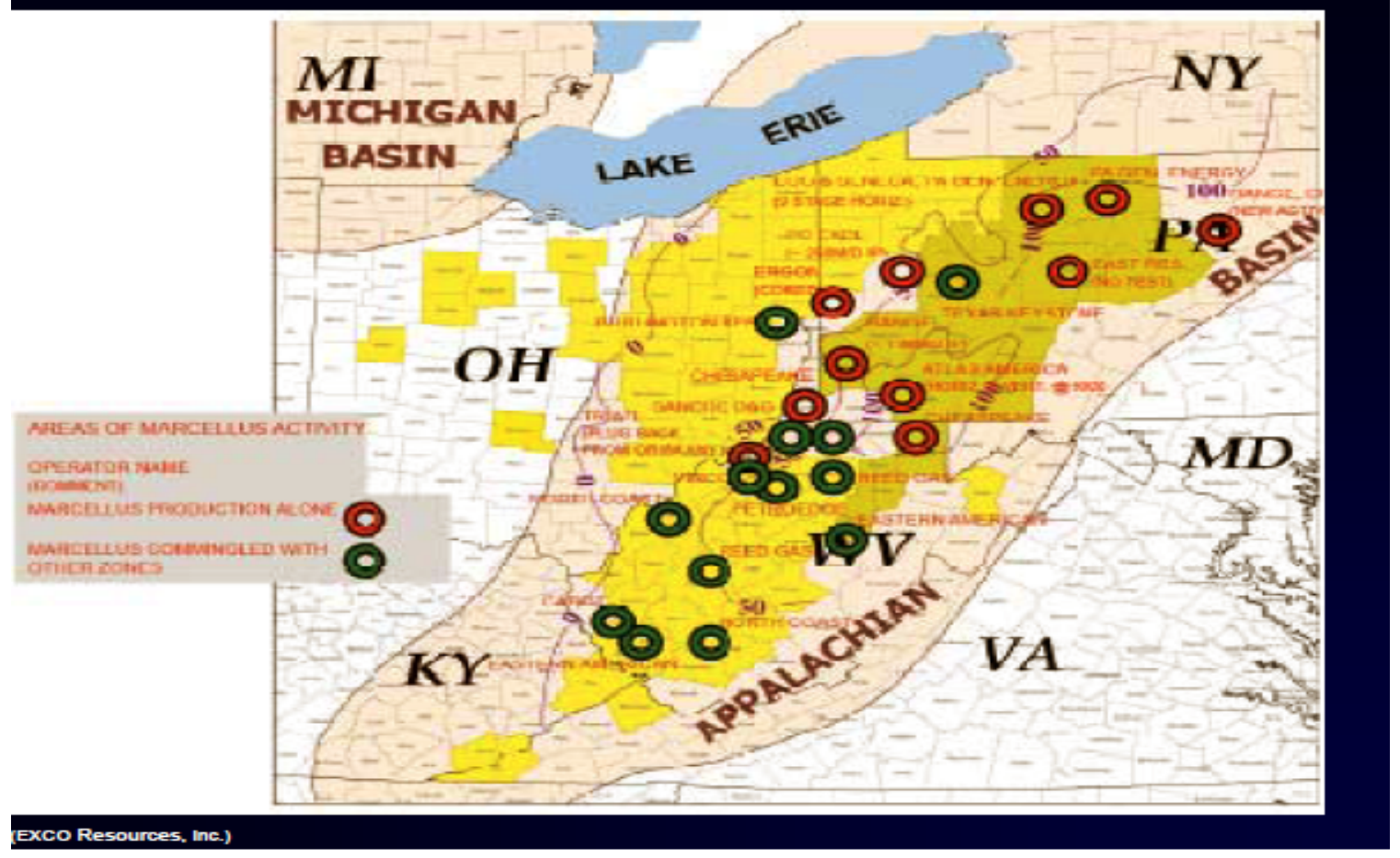

Figure 2: A Map Showing Marcellus Shale Activity in the Appalachian Basin (Miller ${ }^{23}$ ). 


\subsection{History of Marcellus Shale}

The Marcellus shale can be found in the Appalachian region of the United States of America. It is a Middle-Devonian age black shale that dates back to about 400 million years ago. It is organic rich as a result of plants and organisms that died and decayed millions of years ago. It has a low permeability and contains a low density rock. It spans a distance of approximately 600 miles, running from the southern tier of New York, across western and southern Pennsylvania, eastern Ohio, most of West Virginia, through western Maryland and Virginia. Marcellus shale has a true vertical depth of about $3000 \mathrm{ft}-9000 \mathrm{ft}$ (as shown in Figure 3). The thickness of the Marcellus shale is variable depending on the locality. It ranges from about $20 \mathrm{ft}$ to $350 \mathrm{ft}$, it gets thicker eastward and vice-versa westward. The northern part is said to be geopressured and contains less natural fractures compared to the southern part which is underpressured with more natural fractures $\left(\operatorname{Sumi}^{28}\right)$.

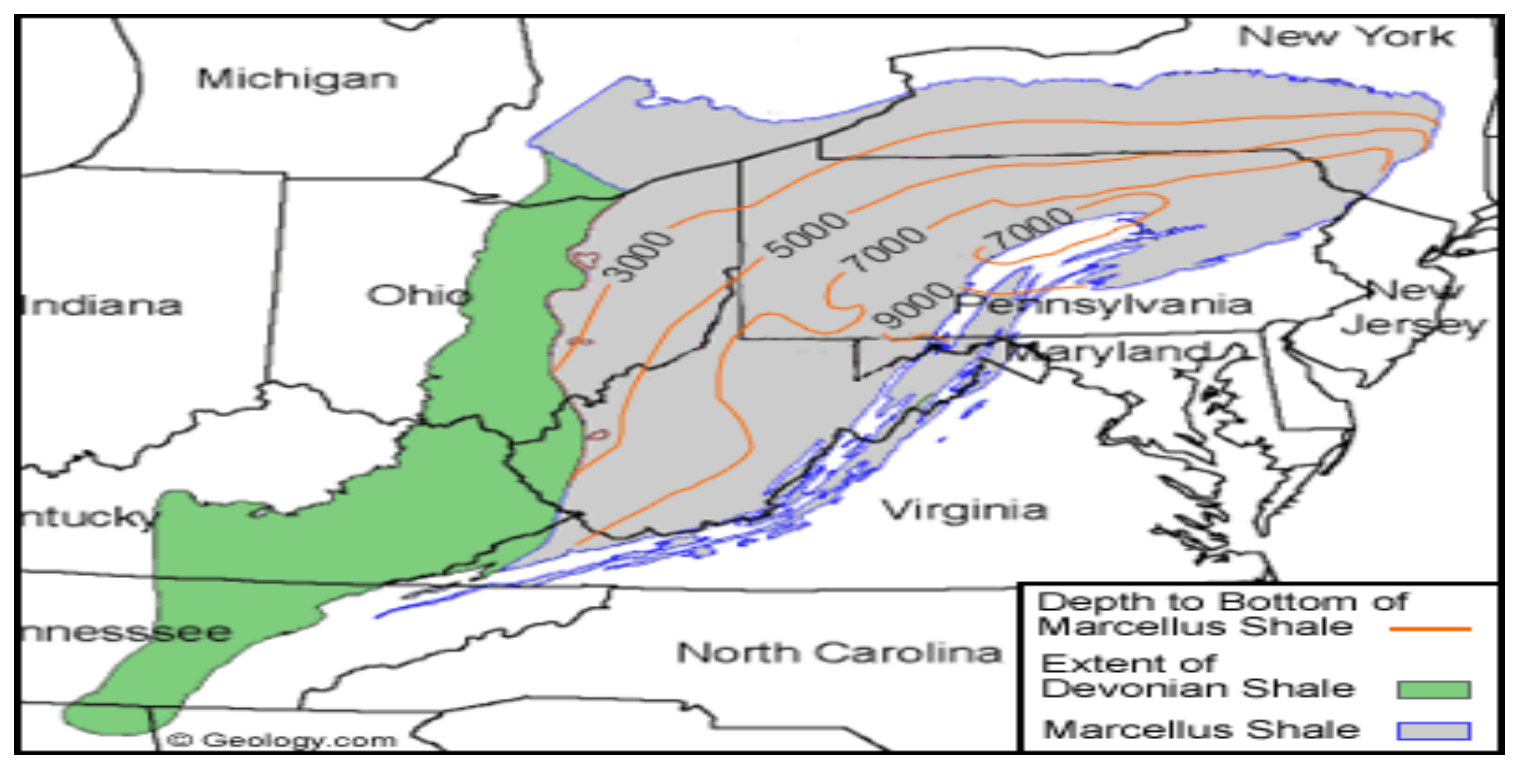

Figure 3: A map showing the depth and location of the Marcellus shale in the Appalachian Basin (geology.com ${ }^{20}$ ). 
In Marcellus gas shale, the natural gas occurs in several ways including as free gas in natural fractures and within the pore spaces of the Marcellus shale and also as an absorbed gas on mineral grains and kerogen within the shale matrix. The grains in Marcellus shale are compacted together as a result, Marcellus shale possesses very tiny, poorly connecting and low permeability pores, and the movement of fluid is very restricted. Most of the gases that are recoverable in this shale are usually contained in the pore spaces.

In order for natural gas in a Marcellus shale to be produced in economical (commercial) quantities, it must either have natural fractures, or hydrofraced (create hydraulic fractures). Identification and characterization of natural fractures is typically done at the surface through outcrop studies or in-situ through the use of geophysical logs or core.

There are two major techniques that will be incorporated into getting economical amount of natural gas from Marcellus shale. They are horizontal drilling and hydraulic fracturing. These techniques are currently been used in the Fort Worth Basin in extracting crude oil and gas from the Barnett shale.

\subsection{Horizontal Drilling}

Drilling a horizontal well can be achieved when a vertical hole is deviated to a horizontal direction so that it penetrates a maximum number of vertical rock fractures and penetrate a maximum distance of gas-bearing rock. Figure 4 illustrates how a horizontal well penetrates a number of hydraulic fractures in a Marcellus zone. Horizontal wells are preferred to vertical wells when drilling in a Marcellus shale reservoir which is going to 
be hydrofraced. This is because the natural fractures that exist in Marcellus shale are vertical and when a vertical well is drilled in this reservoir, very few vertical fractures are intersected; however, the horizontal well intersects many of the vertical fractures. Another major reason is that a hydraulically fractured horizontal well will most likely outperform a hydraulically fractured vertical well in a shale reservoir.

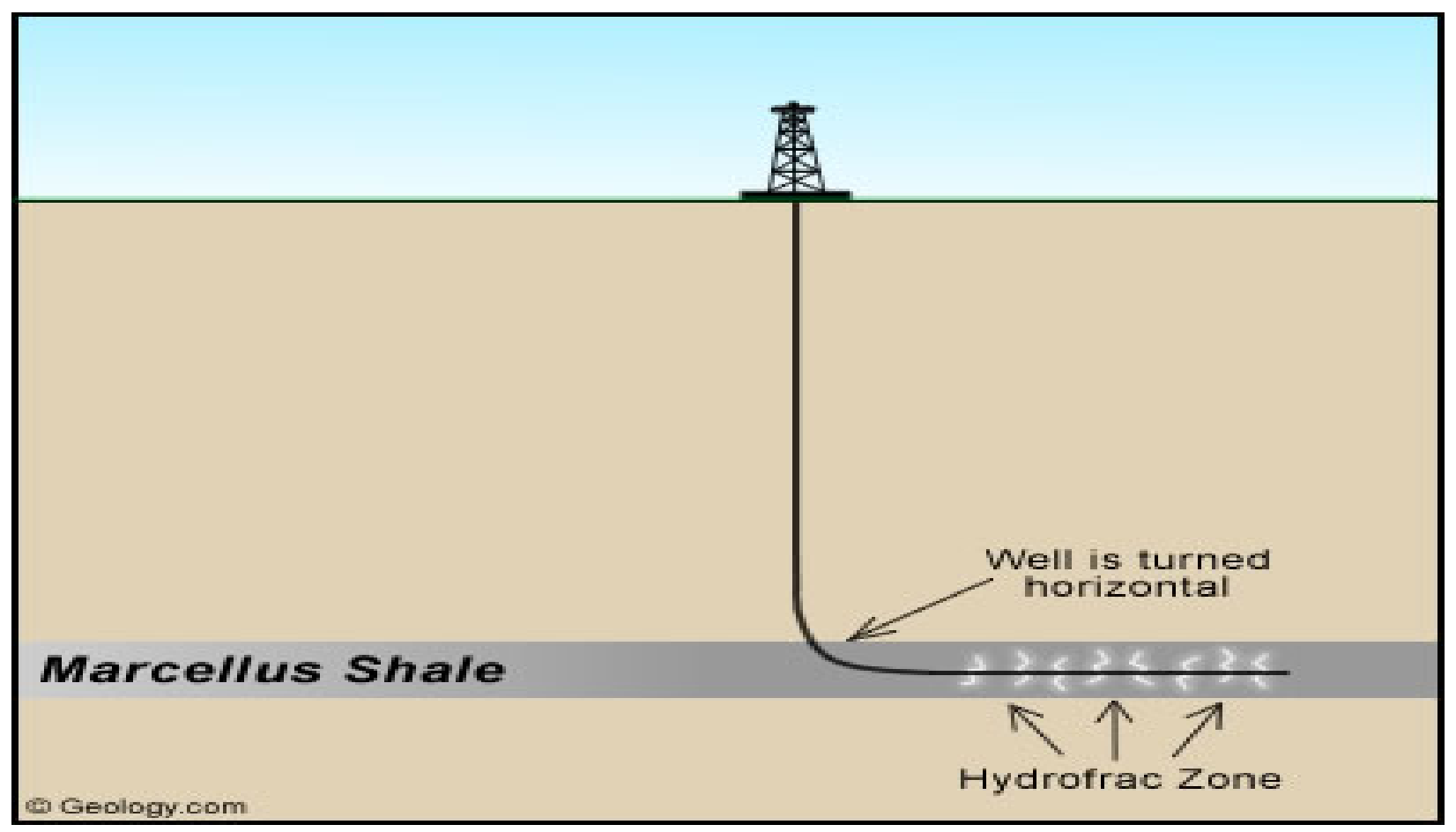

Figure 4: Showing how the horizontal well intersects the Marcellus formation (geology.com ${ }^{20}$ ).

Although, horizontal wells are preferred to vertical wells for the Marcellus formation, it is important to know that they are more expensive than vertical wells. An average newly drilled horizontal well costs about 1.5 to 2.5 times more than a vertical well $\left(\operatorname{Joshi}^{15}\right)$. On the other hand, the productivity of the horizontal well is 2 to 5 times larger than the vertical well $\left(\mathrm{Joshi}^{15}\right)$. Thus, for the given economic gas rate limit, 
horizontal wells could be produced with up to half to one-third reservoir pressure as compared to the reservoir pressure required for economic production from a vertical well (Joshi $^{15}$ ).

Below is a typical example of Devonian shale that was drilled both vertically and horizontally with the same well drainage area, thickness, gas content and total gas-inplace. Despite the fact that both the vertical and horizontal wells are quite similar, the horizontal well outperforms the vertical well by more than double as seen in Table 1 and Figures $5 \& 6$.

Table 1: Comparing Horizontal well versus vertical well (Miller ${ }^{23}$ ).

\begin{tabular}{|c|c|c|c|c|c|c|}
\hline Well Type & $\begin{array}{c}\text { Well Unit } \\
\text { (acres) }\end{array}$ & $\begin{array}{c}\text { Shale } \\
\text { Thickness } \\
\text { (feet) }\end{array}$ & $\begin{array}{c}\text { Gas } \\
\text { Content } \\
\text { (Mcf/af) }\end{array}$ & $\begin{array}{c}\text { Gas In } \\
\text { Place } \\
\text { (MMcf) }\end{array}$ & $\begin{array}{c}\text { Recovery } \\
\text { Factor } \\
(\%)\end{array}$ & $\begin{array}{c}\text { Gas } \\
\text { Resource } \\
\text { (MMcf) }\end{array}$ \\
\hline Horizontal & 80 & 150 & 100 & 1,200 & 60 & 720 \\
\hline Vertical & 80 & 150 & 100 & 1,200 & 25 & 300 \\
\hline
\end{tabular}




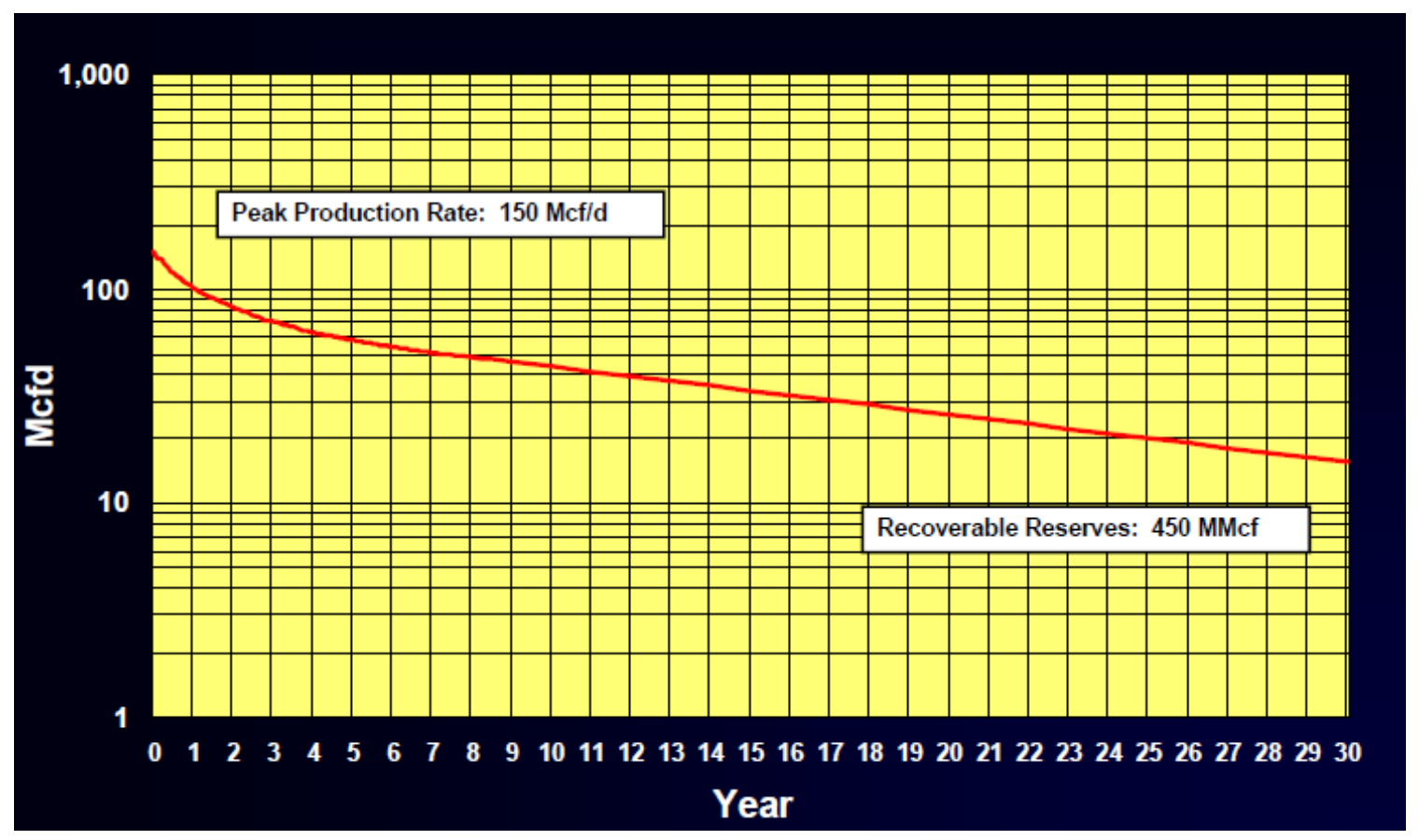

Figure 5: Gas production rate over time of a vertically fractured Devonian shale well $\left(\right.$ Miller $\left.^{23}\right)$.

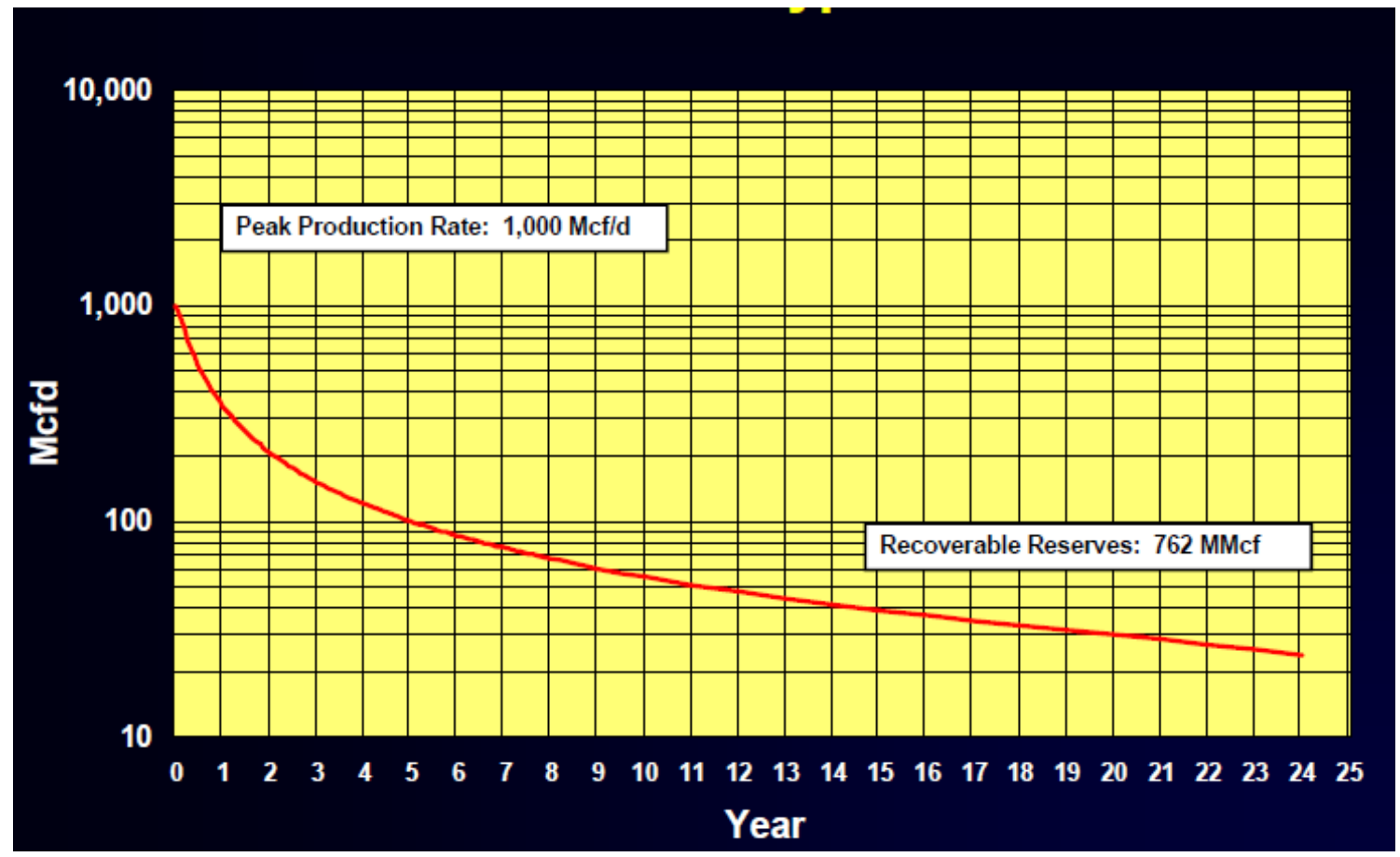

Figure 6: A graph showing the gas production rate over time of a horizontally fractured Devonian shale well (Miller ${ }^{23}$ ). 


\subsection{Hydraulic Fracturing}

Nowadays, many petroleum companies conduct well stimulation for various reasons including:

- Increase hydrocarbon production rate

- Increase reserves

- Increase well economical production life

- Maximize the monetary value on their investment on well (Drilling \& Completion)

Well stimulation is a well intervention performed on a gas and oil well to increase production by improving the flow of hydrocarbon from reservoir to wellbore. There are mainly two well stimulation methods, namely Matrix Acidizing and Hydraulic Fracturing. Matrix Acidizing is a stimulation technique in which acid solution (HCL, mixture of HCL \& HF) is injected into a formation to dissolve some minerals present.

The process of hydraulic fracturing is very vital in unconventional reservoirs (For example, Marcellus shale) if it is to be commercially produced. Hydraulic fracturing is used to create a flow path in a gas reservoir that can facilitate the fluid flow of natural gas to a producing well.

Marcellus shale has restricted pore volume and low connectivity that impedes the flow of natural gas through the reservoir. Therefore, it is usually fractured by injecting a fluid containing sand or other proppant under specified pressure to efficiently create fractures in the rock through which the natural gas can easily flow. 
According to Schlumberger, slickwater ( a low viscosity water based fluid) and proppant can be used for deeper higher-pressured Marcellus shale with increased production, while nitrogen foamed fracturing fluid is better used for shallower lowpressured shale. Caution is necessary to contain the fractures within the specified gas reservoir to avoid intersecting adjoining aquifers that would introduce excess water into the gas producing zone. In order to increase the success rate of the hydraulic fracture significantly and have an effective stimulation, a long and conductive fracture will have to be created. This is because the reservoir we are dealing with has an ultra low permeability. Figure 7 shows and explains the process of how hydraulic fracturing is implemented.

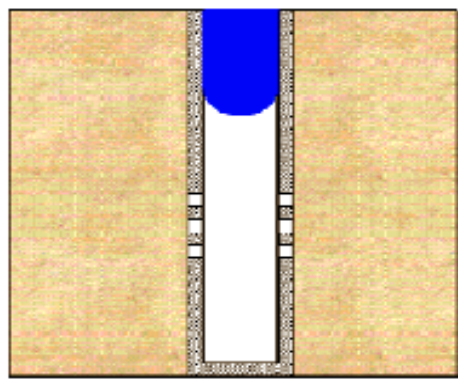

a. Fluid is pumped down well.

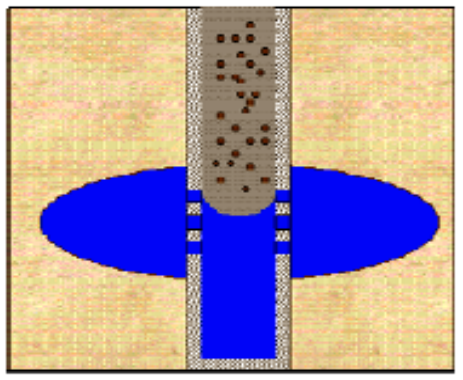

d. Proppant is transported with viscous fluid into fracture.

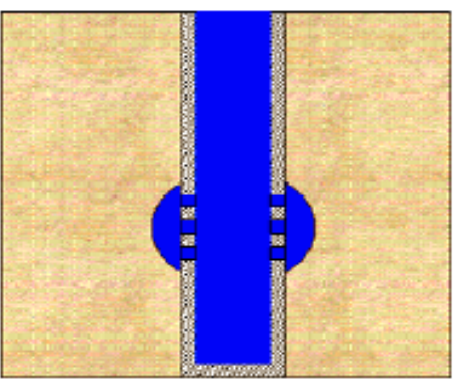

b. Hydraulic pressure of fluid initiates a fracture in the reservoir.

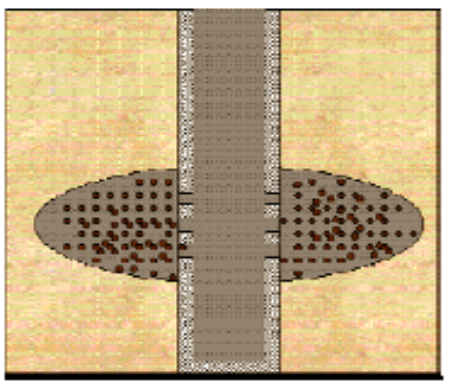

e. Viscous fluid uniformly transports fluid deeply into the fracture.

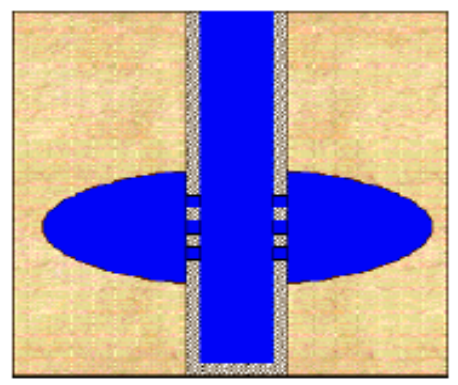

c. Fracture begins propagating into reservoir.

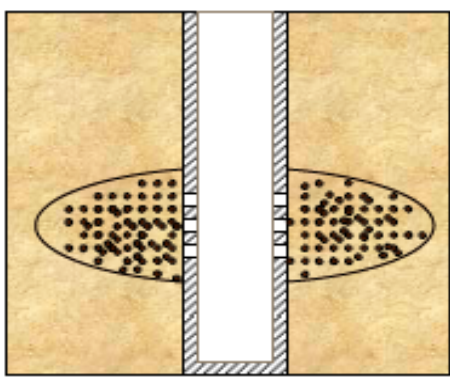

f. Viscous fluid breaks and is allowed to flow back out of well. The formation closes upon proppants resulting in a long conductive fracture.

Figure 7: The diagram above explains a Hydraulic Fracturing Process (Tschirhart ${ }^{31}$ ). 
There are two different types of hydraulic fractures that can be created in a reservoir. These fractures are mostly determined by the direction of the stress field (vertical or normal to the horizontal minimum stress) in the producing formation. If the horizontal well is drilled parallel to the minimum horizontal stress, it is expected that the fractures created will be perpendicular to the horizontal well, thereby, creating a transverse well while, the other limiting case can be generated if a horizontal well is drilled perpendicular to the minimum horizontal stress, creating a longitudinal fracture. Here, the fractures created usually are parallel to the horizontal well.

Longitudinal fractured wells perform massively in high permeability reservoirs, however, for Marcellus shale reservoirs, transverse fractured horizontal well are very attractive as they are more productive than longitudinal fractured horizontal well when compared with one another in the same reservoir and conditions. Figures 8 \& 9 show the comparison of the production rate and cumulative production between transverse and longitudinal fractures, respectively. 


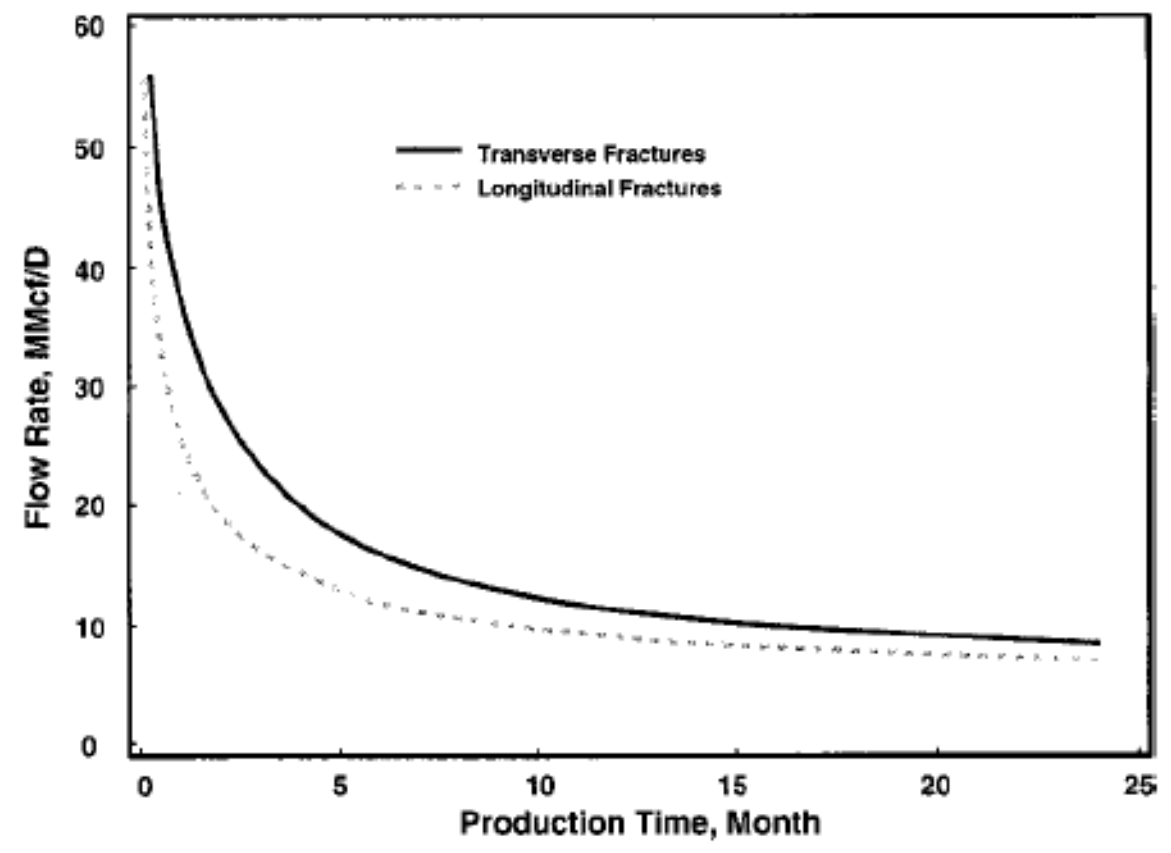

Figure 8: Comparison of Production rate between transverse and longitudinal fractures with the same total area (Soliman ${ }^{27}$ ).

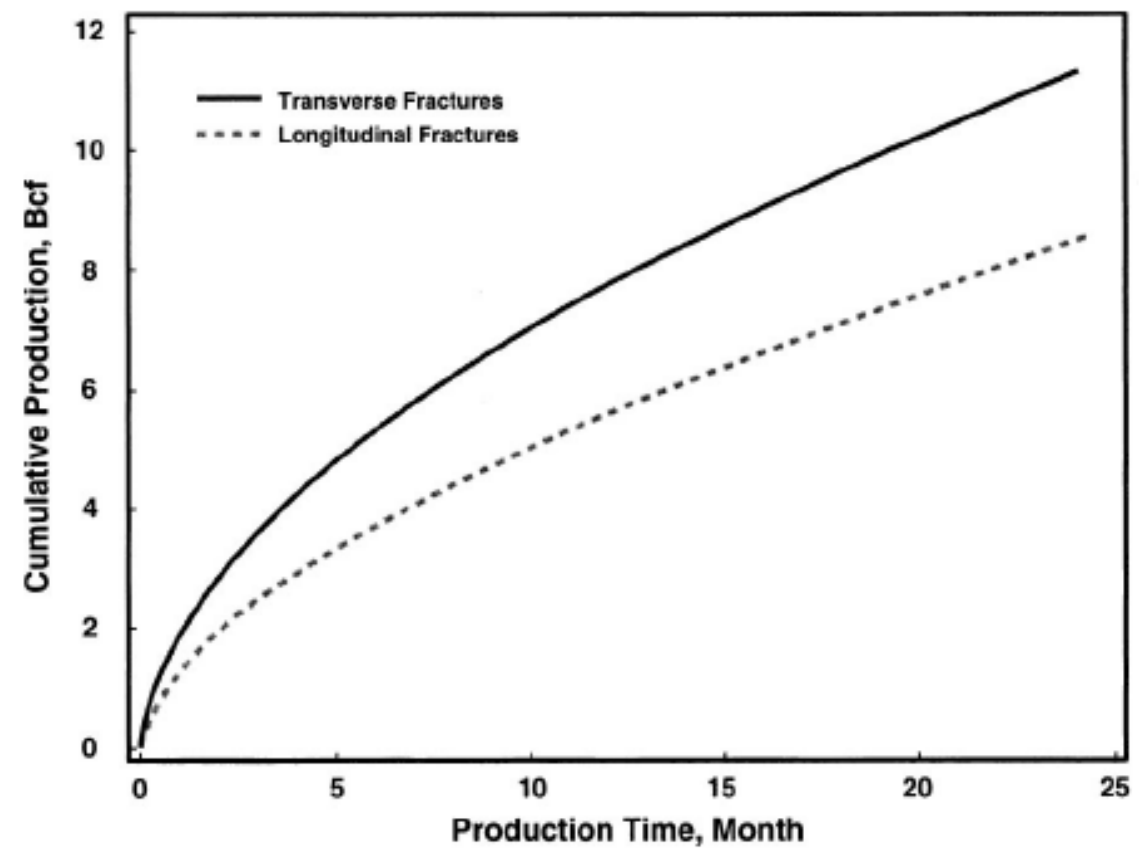

Figure 9: Cumulative production between transverse and longitudinal fractures with same the total area (Soliman ${ }^{27}$ ). 


\subsection{Objectives}

It is difficult to reliably predict ultimate recovery and estimate reserves for gas shales, leading to great risk in exploitation of these resources. The objectives of the research are to evaluate the current decline curve analysis methods and provide a more reliable method for production forecast and reserve estimate for hydraulically fractured horizontal wells producing from gas shale reservoirs.

\subsection{Research Tasks}

Literature review to determine reservoir parameters for a Marcellus formation such as:

- $\quad$ Reservoir Permeability

- $\quad$ Reservoir Porosity

- $\quad$ Formation Depth and Thickness (Pay-zone)

- $\quad$ Reservoir Temperature

Using Schlumberger’s Eclipse Software simulate a Marcellus shale reservoir, considering:

- $\quad$ Simulation of transverse fractures in a hydraulically fractured horizontal reservoir with multistage fractures

- $\quad$ Use of dual porosity model (matrix and fracture systems).

- $\quad$ Incorporation of desorption of adsorbed gas.

- $\quad$ Generation of data for four different reservoir-well systems. 
Using four different production decline analysis methods, the following steps are to be taken;

- $\quad$ Perform forecast on the production data from eclipse

- $\quad$ Quantify errors in reserve estimates from decline analysis

- $\quad$ Characterize the decline behavior

- $\quad$ Compare all four different approaches

- $\quad$ Estimate reserves 


\section{CHAPTER II}

\section{CHARACTERISTICS OF SHALE GAS RESERVOIRS}

\subsection{Literature Review}

The placement of a horizontal well in the formation can impact the stimulation of the well significantly. In reality, lateral wells are not exactly horizontal. These horizontal wells slant about 75 to 85 degree angles using the upward or downward dips and assume the trend of the formation. Certain variables are very important when talking about producing from a hydraulically fractured horizontal well like reservoir permeability, reservoir pressure, wellbore length, well drainage area and fracture orientation (in-situ stress and fracture direction).

Hydraulic fracturing is often used in reservoirs with low permeability that is not capable of reaching economic production rates. This is very different in character to the naturally fractured reservoirs that are classified as having a dual porosity. Hydraulic fractures are generally characterized by four variables: fracture half-length $\left(\mathrm{X}_{\mathrm{f}}\right.$, fracture width (w), proppant pack permeability (kf) and formation permeability (k). These four variables make up the dimensionless Dimensionless fracture conductivity. Dimensionless fracture conductivity along with fold of increase (FOI) in productivity are two very important factors to be considered when creating a hydraulic fracture. Dimensionless fracture conductivity less than 10 is considered poor, while that between 10-50 is considered good and anything beyond 50 is considered to have excellent Dimensionless fracture conductivity (Gidley ${ }^{10}$ ). 


$$
C_{f D}=\frac{k_{f} w}{k x_{f}}
$$

Eq 1

Unlike natural fractures, hydraulic fractures are almost entirely vertical generally and they cut through the thickness of a reservoir, thereby, increasing the chances of hitting the pay zone.

\subsection{Dual Porosity}

Dual porosity model consists of two different media. These two media are fracture system and matrix system. The fracture system contains very little fluid (gas/oil) with low storage capacity but possesses a high conductive path for fluid compared to the matrix system. The other medium which is the matrix system has a high storage capacity but a poor fluid conductive path. Presently, there are many models that characterize natural fractures already existing in reservoir and artificial hydraulic fractures based on dual porosity. These somewhat different models are usually different in the way they connect the relationship between the fracture and matrix systems. They also, differ in the way their fracture and matrix systems are shaped.

For example: Figures $10-12$ are matrix and fracture systems with three different shapes. Figure 10 shows a Cubed (Grid) like shaped matrix and fracture system. It is usually computed in three dimensions $(\mathrm{x}, \mathrm{y}, \mathrm{z})$. Figure 11 shows a Match Stick like matrix and fracture system. It is usually computed in two dimensions $(\mathrm{x}, \mathrm{y})$. Figure 12 shows a Slab like matrix and fracture system. It is usually computed in one dimension (x or y direction). 

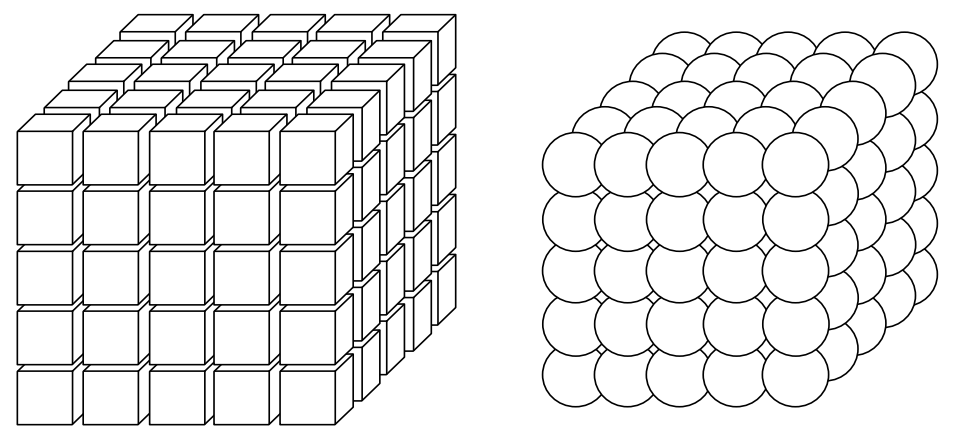

Figure 10- Cubed Grid Dual Porosity System.
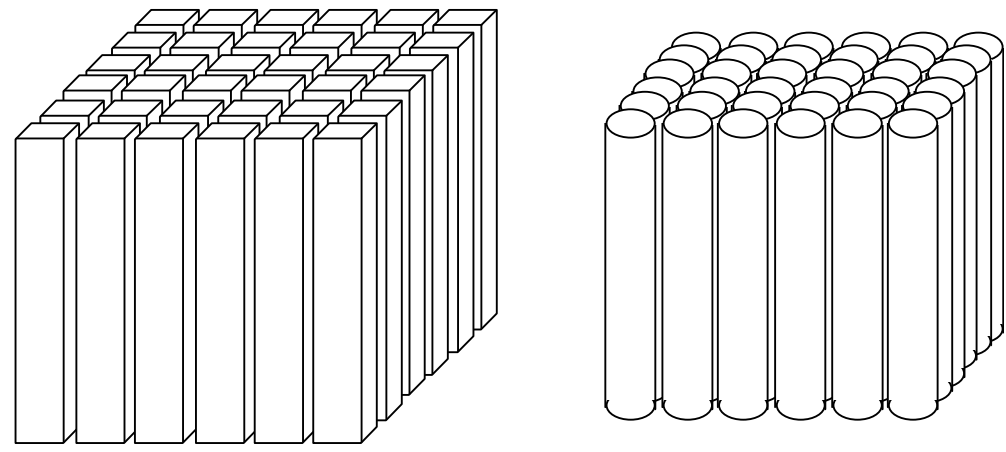

Figure 11- Match-Stick Dual Porosity System.
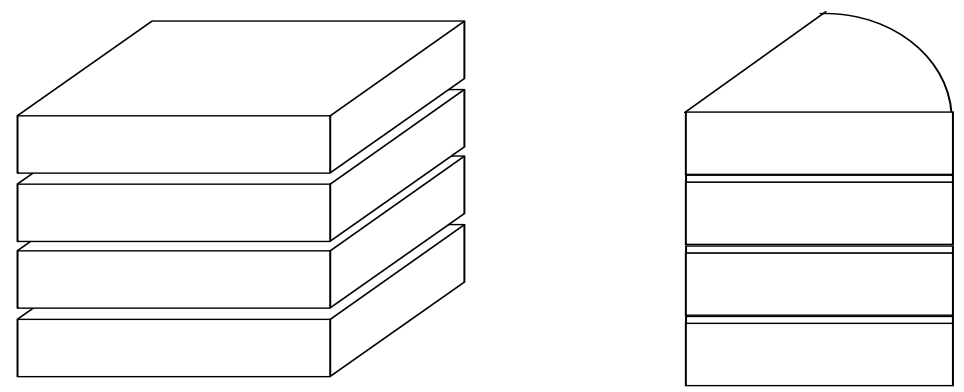

Figure 12- Slab-Like Dual Porosity System. 
These models (slabs, match-sticks, and cubes) are that the results produced by these different models are usually similar as far as the flow regime between the media is a transient flow. The only difference between these media models occurs during transitional flow regime (www.fekete.com ${ }^{9}$ ).

When characterizing a dual porosity model into software, one has to assume what type of flow is to be created between the media (matrix and fracture systems). This flow type between the media could either be a transient flow or pseudo steady state flow.

\subsection{Flow regime}

There are four different flow regimes that can occur in a hydraulically fractured reservoir which are fracture linear flow, bilinear flow, reservoir linear flow and pseudoradial flow (www.fekete.com ${ }^{9}$ ). Figure 13 shows different time periods that exist in the life of the shale gas reservoir.

The flow regime starts out early with a fracture linear flow as shown in Figure 14, which lasts for a very short time before advancing to the bilinear flow during the midtime in the reservoir. During the bilinear flow regime, two linear flows occur simultaneously where one flow is a linear flow within the fracture and the other is a linear flow from the formation toward the fracture (www.fekete.com ${ }^{9}$ ). The bilinear flow regime gives an estimate of Dimensionless fracture conductivity. Figure 15 illustrates the bilinear flow regime. The reservoir linear flow toward the fracture occurs when fracture has infinite conductivity. The pseudo- radial flow regime takes a long period of time to occur and only does if there is no boundary effect. The pseudo-radial analysis provides an estimation of formation permeability in the radial direction. 
Finally, pseudo steady state flow appears when pressure transient reaches the outer boundaries and the outer boundaries are no flow boundaries.

Legends:

E.T: Early Time

Middle Time

Transition period

Late Time: Pseudo steady state (P.S.S) or Steady State (S.S)

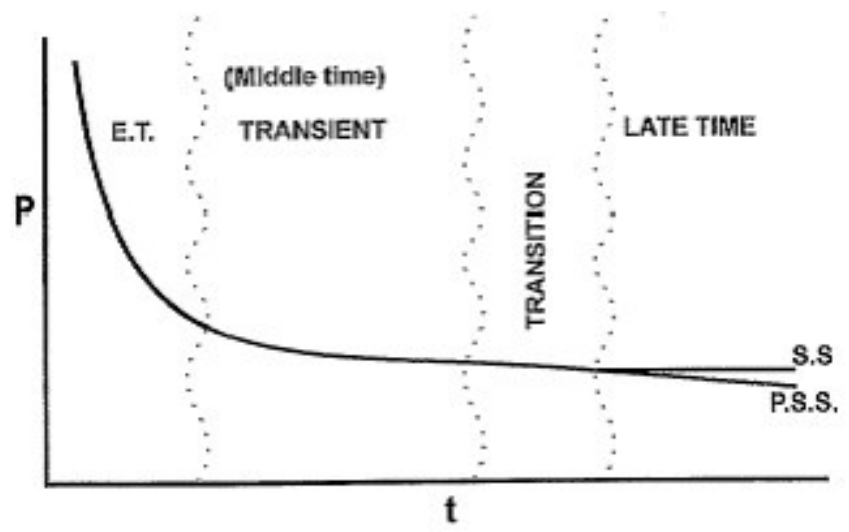

Figure 13- A pressure versus time graph showing the existing time periods (www.fekete.com ${ }^{9}$ ).

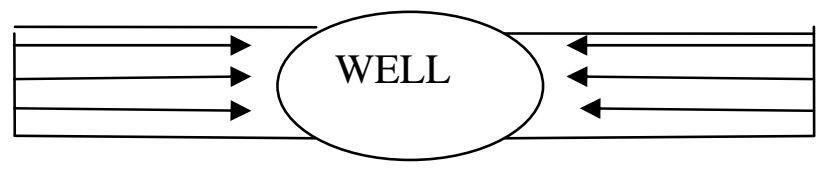

Figure 14: Fracture linear flow regime occurs during early time (www.fekete.com ${ }^{9}$ ). 


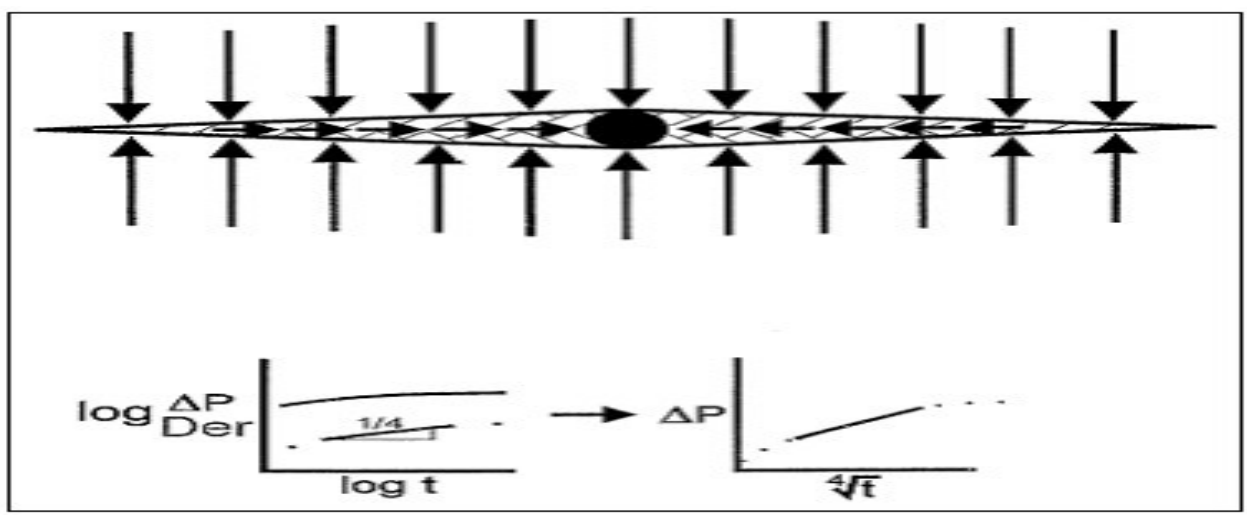

Figure 15: Bi-linear flow regime during middle time period (www.fekete.com ${ }^{9}$ ).

\subsection{Desorption of adsorbed Gas}

Another factor that was taken into consideration in Marcellus shale was adsorption of gas into the shale. This character which is often associated with coal beds, also exists in Marcellus shale and the mechanism of desorption of sorbed gas can be considered in the simulator.

The Langmuir isotherm was developed by Irving Langmuir in 1916 to describe the relationship that existed between the surface coverage of an adsorbed gas and the pressure of the gas above the surface at a fixed temperature. After Langmuir's development, many other types of isotherm like Temkin isotherm and Freundlich isotherm surfaced. Whilst the Langmuir isotherm is one of the oldest and straight-forward isotherms, it still provides a useful insight into the pressure dependence of the extent of surface adsorption.

Adsorption molecules of one substance become attached to the surface of another. Adsorption is different from absorption as it is a reversible process interconnected by weak attracting forces in this case, shale and natural gas. 
Langmuir's Equation:

$V(P)=\frac{V_{L} P}{P_{L}+P}$

$\mathrm{V}(\mathrm{P})=$ Gas Content

$V_{L}=$ Langmuir Volume

$P_{L}=$ Langmuir Pressure

$\mathrm{P}=$ Pressure $(\mathrm{psi})$

$V_{L}$ is the maximum amount of gas that can be adsorbed on the shale at infinite pressure

$P_{L}$ affects the curvature of the isotherm and corresponds to the pressure at which half of the Langmuir volume is adsorbed.

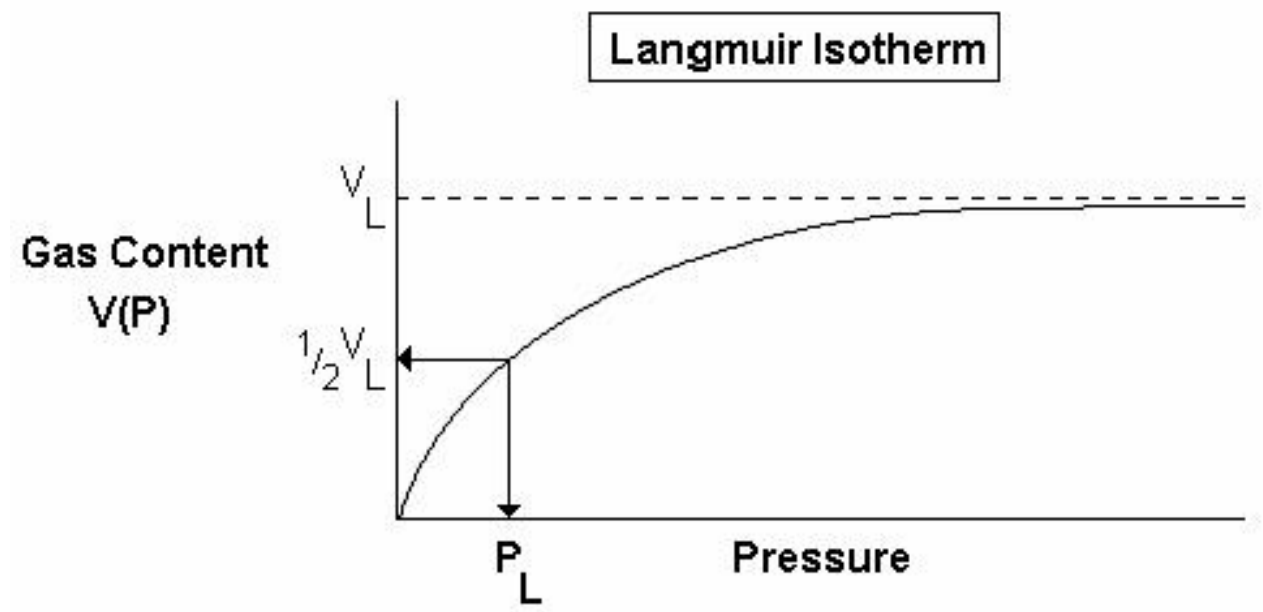

Figure 16: A Langmuir Isotherm Curve: Gas Content plotted against Pressure. (www.fekete.com ${ }^{9}$ ). 
Marcellus shale like other shale contains organic material which has the ability to adsorb natural gas. The process of adsorption is controlled by properties such as the amount of organic carbon present, the thermal maturity of the kerogen, reservoir temperature, reservoir pressure, in-situ moisture of the shale and gas composition $\left(\mathrm{Hill}^{11}\right)$. According to Hill, there is a linear proportionality between the Total Organic Carbon (TOC) and total gas content in shale gas, that is, as latter increases so does the other and vice-versa. Two correlations of gas content and TOC from two different types of shale were compared with one another, one from Antrim shale in the Michigan Basin and the other from the New Albany shale in the Illinois Basin $\left(\right.$ Hill $\left.^{11}\right)$.

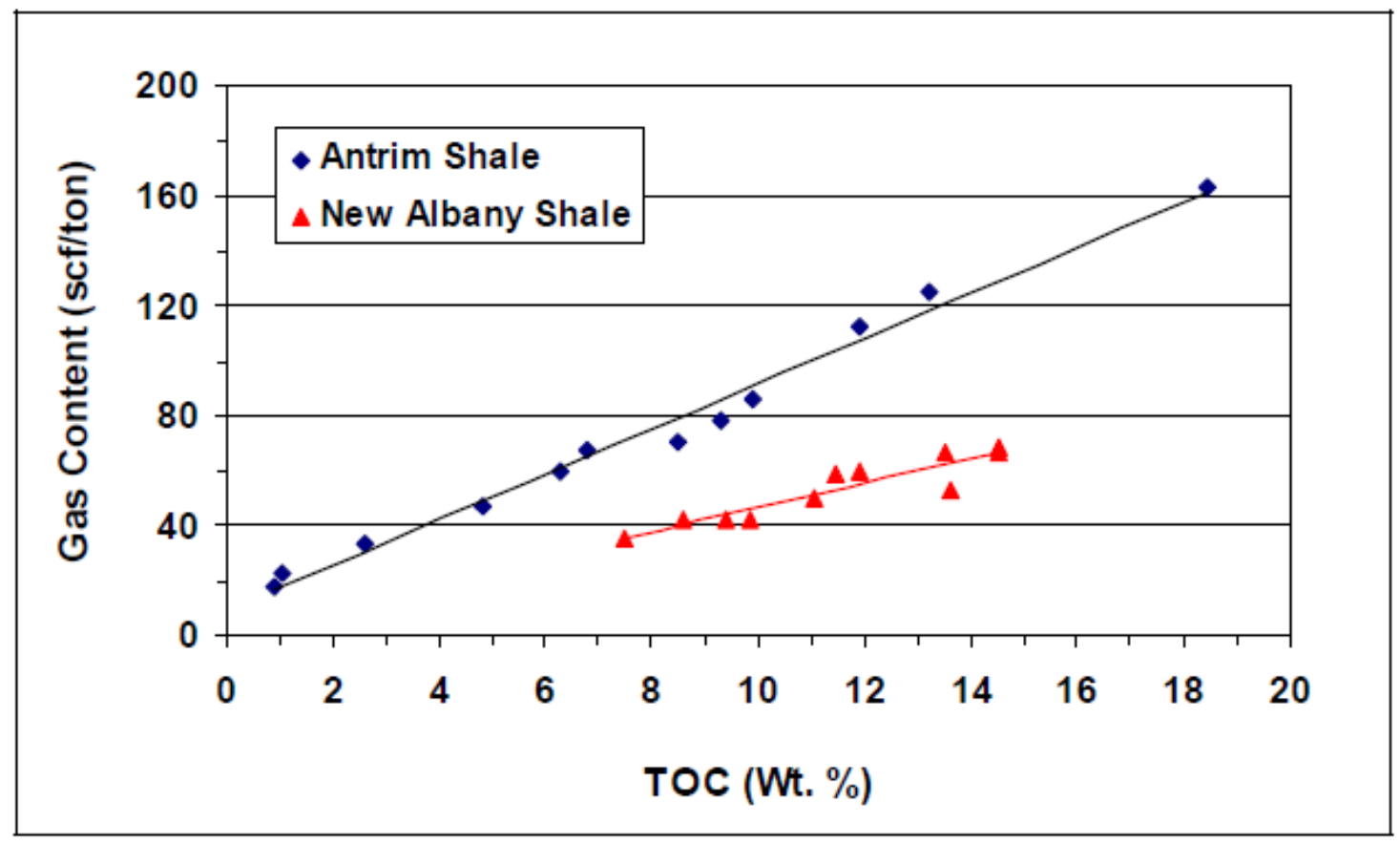

Figure 17: Comparison of Gas Content versus Total Organic Carbon in Two Gas Shale plays $\left(\right.$ Hill $\left.^{11}\right)$. 


\section{CHAPTER III}

\section{METHODOLOGY}

In this research, the following tasks were performed and described in more details below:

- $\quad$ Model Design

- $\quad$ Representative Reservoir data

\subsection{Model Design}

In this study, Schlumberger's Eclipse software was the reservoir simulator used for modeling. This simulator was used to model a horizontal well which was hydraulically fractured in multi - stages. The multi - stage fractures created are transverse to the lateral well as they connect more with pay zone, thereby increasing the probability of having a good flow path for the natural gas. Afterwards, production data were produced from the simulator. In simulated cases, dual porosity model was used and desorption of adsorbed gas were incorporated for more accurate results. Desorption of adsorbed gas was included in this simulation because Marcellus shale contains adsorbed gas and the typical properties of Marcellus shale reservoir were used in simulation models.

The established simulation model represents a reservoir with characteristics of Marcellus shale. The simulated reservoir encompasses a well drainage area of 160 acres with a grid system of $26 \times 25 \times 6$ and the dimensions of $138.5 \mathrm{ft}$ by $77.5 \mathrm{ft}$ by $20 \mathrm{ft}$ for 
each grid block. The horizontal well trajectory is located in the center of the reservoir as illustrated in Figure 18. Local Grid Refinement (LGR) is used to characterize the variation of permeability and conductivity of hydraulic fractures.

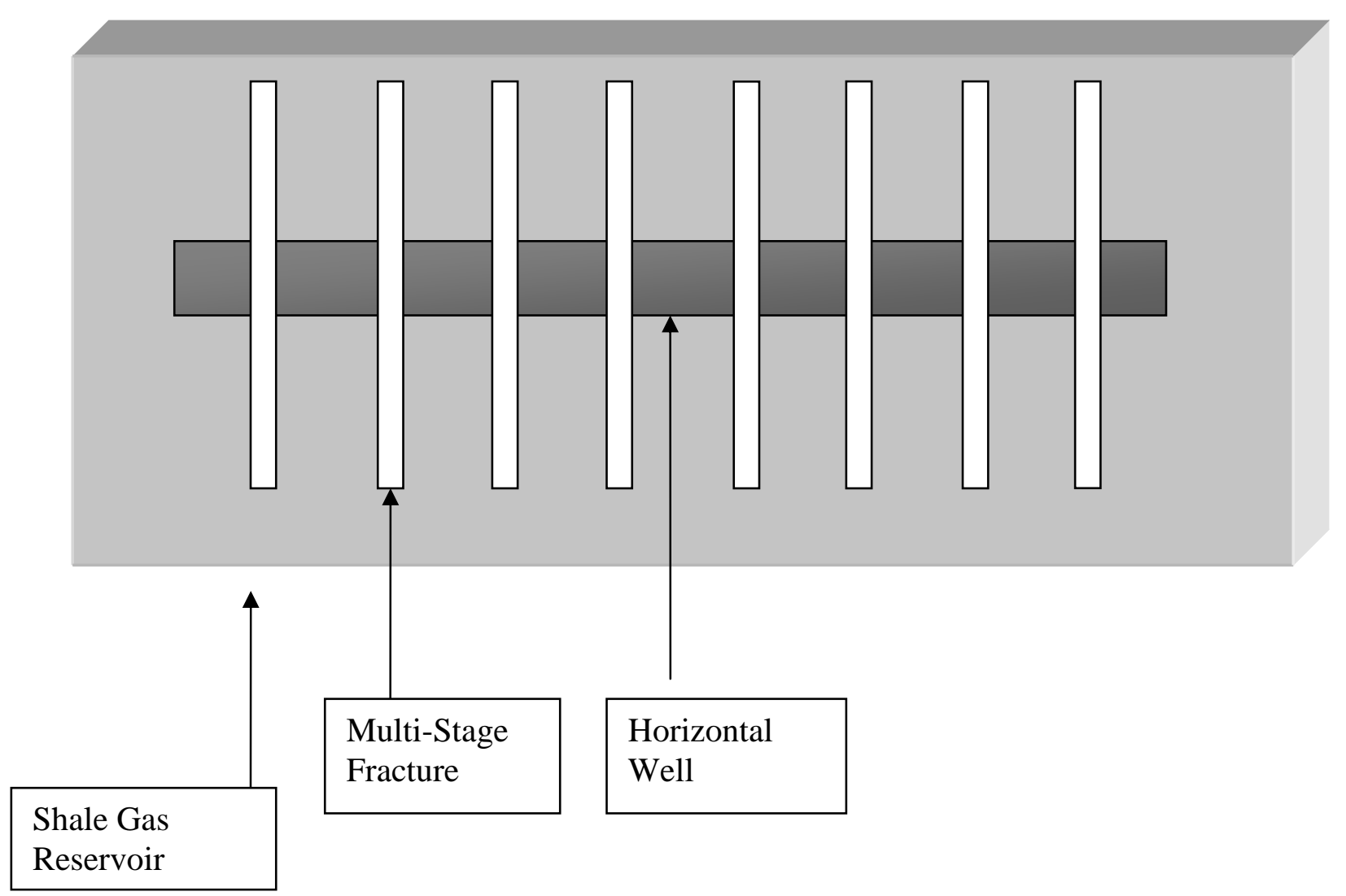

Figure 18: The position and location of the horizontal well in the shale gas reservoir. 


\subsection{Representative Reservoir Data}

The efficacy of any result(s) got from a simulator has a lot to do with the representative reservoir data as it contains the main intangibles based on what has been simulated. For this research, based on the representative reservoir data, multiple synthetic cases are generated including one base case as well as three other case studies to support the accuracy of the research results. The base synthetic case was based on a well with 8 multi-stage hydraulic transverse fractures with a fracture spacing of $381 \mathrm{ft}$, dimensionless Dimensionless fracture conductivity of 10, fracture half-length of $504 \mathrm{ft}$ and a total wellbore length of about $3050 \mathrm{ft}$, producing natural gas for a period of 60 years. 


\subsection{Key Parameters of the Simulated Reservoir}

These parameters were used for all case studies including the base synthetic case.

Well Drainage Area: 160 Acres

Reservoir Pressure: 2880 psi

Pressure Gradient: 0.433 psi/ft

Matrix Permeability: 0.0005 md

Matrix Porosity: 8\%

Net pay thickness: $120 \mathrm{ft}$

Depth (TVD): $6600 \mathrm{ft}$

Reservoir Temperature: $125^{0} \mathrm{~F}$

Langmuir Pressure: 473 psi

Langmuir Volume: 74.4 scf/ton

Bulk Density: 2.5 g/cc

Gas in Place: 17.96 Bcf

Free Gas: 14.13 Bcf

Adsorbed Gas: 3.83 Bcf 


\subsection{Flowchart of the Entire Analyzing Process}

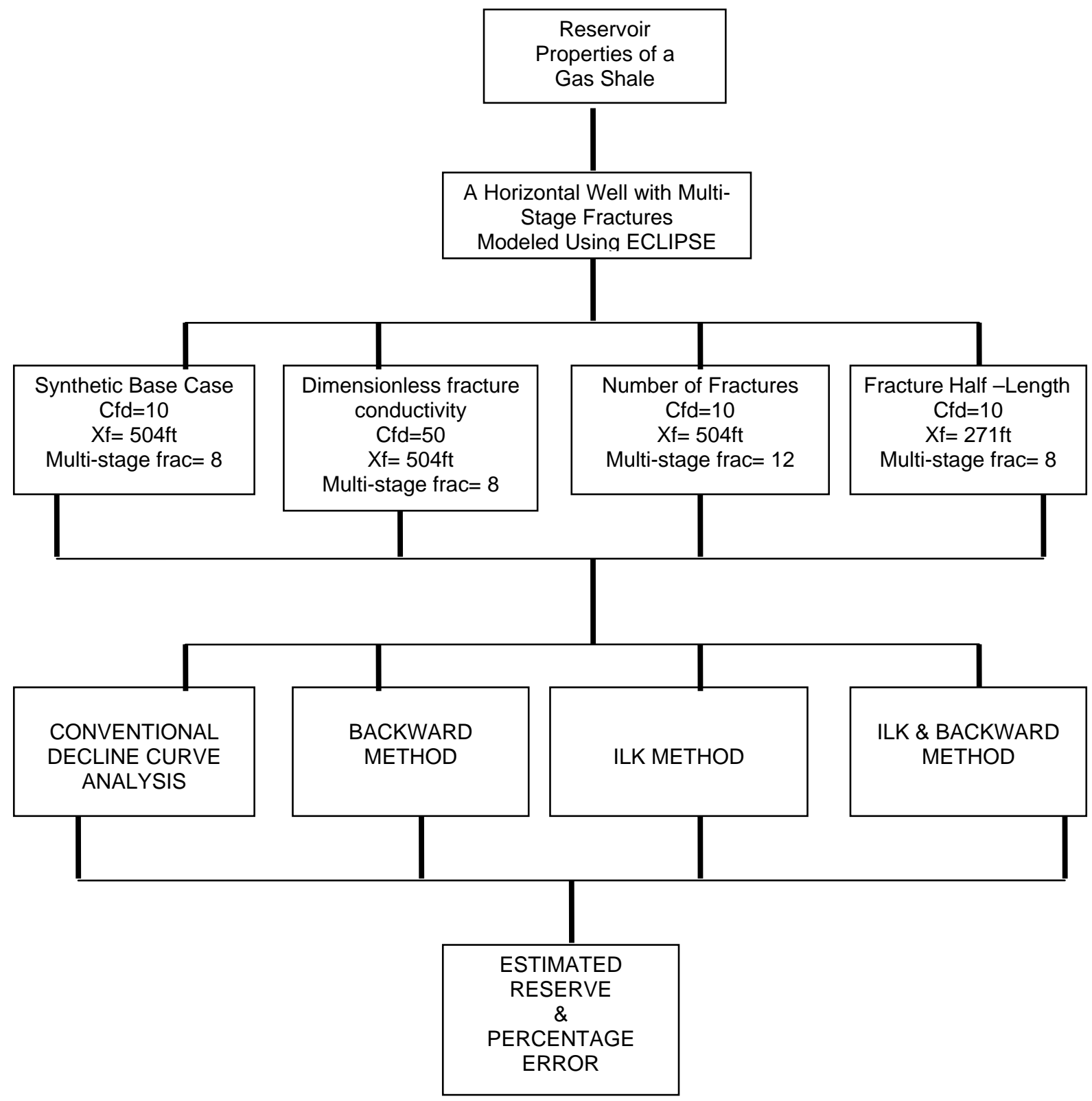

Figure 19: Flowchart of the entire analysis process.

The flowchart in Figure 19 briefly explains how methodologically the whole process was carried out starting from the collecting of data for the shale gas until the end result (estimated reserves with error analysis). 


\subsection{Production Decline Analysis}

\subsubsection{Conventional Decline Curve Analysis Method}

Conventional Decline Curve Analysis (DCA) is a graphical examination of the production data given. It consists of fitting a mathematically modeled curve with a plot of flow rate vs. time. Several equations may be used to model a decline curve, such as hyperbolic equation, exponential equation, and harmonic equation. This technique was developed by Arps in the 50's. The purpose of DCA is to come up with a prediction of future production performance and forecast reserves of the life of a well. Arps decline curve equation was basically empirical and was proven to be related to fluid properties and production conditions in a well by Fetkovich (Fetkovich ${ }^{7}$ ).

Decline curves which are plots of a well's producing rate versus production time can also be used to estimate ultimate recovery of the well. They are usually plotted on semi-log graphs and extrapolated to give an estimate of the production rate. This method of estimating reserves is one of the most commonly applied methods in the petroleum

industry (Thompson ${ }^{30}$ ) and it generally yields good results when production data during pseudo-steady state flow are available. 
Arps decline curve equation $\left(\operatorname{Arps}^{1}\right)$ is

$$
q(t)=\frac{q_{i}}{\left(1+b D_{i} t\right)^{\frac{1}{b}}}
$$

Eq 3

Equation 3 is usually called the hyperbolic model, where b is the decline exponent and ranges between 0 and $1 . \mathrm{q}(\mathrm{t})$ is the production rate at time $\mathrm{t}, q_{i}$ is the initial production rate and $D_{i}$ is the initial decline rate.

When $\mathrm{b}$ is zero, equation 3 becomes exponential model

$$
\mathrm{q}(\mathrm{t})=\mathrm{q}_{\mathrm{i}} \mathrm{e}^{-\mathrm{Dt}}
$$

When b is unitary or 1 in equation 3 , harmonic model is obtained

$$
\mathrm{q}(\mathrm{t})=\frac{q_{i}}{\left(1+D_{i} t\right)}
$$

Cumulative production for hyperbolic decline is

$$
\mathrm{Np}=\frac{q_{i}^{b}}{(1-b) D_{i}}\left[q_{i}^{1-b}-q^{1-b}\right]
$$

Where Np is cumulative production.

Cumulative production for exponent decline is

$$
\mathrm{Np}=\frac{q_{i-} q}{D_{i}}
$$

Cumulative production for harmonic decline is

$$
\mathrm{Np}=\frac{q_{i}}{D_{i}} \ln \left(q_{i} / q\right)
$$


Relative error:

$\%$ Error $=\frac{\text { Calculated Cum. Prod. }- \text { Actual Cum. Prod. }}{\text { Actual Cum. Prod. }} \times 100$

As stated above, when b approaches zero the model is exponential, when it approaches 1 the model is harmonic. The model is hyperbolic when $\mathrm{b}$ falls between 0 and 1. A well is assumed to be multi-layered (comingled) or heterogeneous if the decline exponent $\mathrm{b}$ is higher than 0.5. The decline exponent (b) plays an important part in the forecast of long-term production of a well through Arp's equation. An increase in b causes an increase in the life of a well and also the remaining reserves in the well.

Decline curve analysis based on Arps equations has always been known to be effective for conventional oil and gas wells. However, estimating the reserves of comingled hydraulically fractured tight gas wells using conventional decline curve analysis has been problematic (Cheng ${ }^{2}$ ). This problem arises due to transient effects and changes in flow regimes in different layers.

The ultra low permeability known to exist in gas shale reservoirs makes it very difficult to accurately estimate its future production performance and forecast its reserves with conventional decline curve analysis because a very long time is required to attain a stabilized flow. Because of this factor, Arps' decline exponent b which is supposed to have a range between 0 and 1 is usually surpassed. The decline exponent b is more often greater than 1 in shale signifying, that the future production performance and forecasted reserves have been over estimated. 


\subsubsection{Backward Method:}

In order to deal with problems like transient flow, changed operation conditions and reliability of decline curve analysis, the backward method was developed. In this research work, two scenarios were considered. For the first scenario, the production data are available only for the first ten years, and then the most recent years of data were used for history matching and prediction, such as the most recent five years $\left(10^{\text {th }}-9^{\text {th }}\right.$ year, $10^{\text {th }}$ $8^{\text {th }}$ year until $10^{\text {th }}-5^{\text {th }}$ year). For the second scenario, production data are available only for the first five years, and then regression was performed with the data for the last three years $\left(5^{\text {th }}-4^{\text {th }}\right.$ year, $5^{\text {th }}-3^{\text {rd }}$ year and $5^{\text {th }}-2^{\text {nd }}$ year $)$.

Using the parameters generated by doing regression for the most recent years of production data, future performances were predicted. For the first scenario, the future performance was predicted for the next 50 years using the most recent five years of production data $\left(10^{\text {th }}-9^{\text {th }}\right.$ year, $10^{\text {th }}-8^{\text {th }}$ year until $10^{\text {th }}-5^{\text {th }}$ year $)$ while for the second scenario, the future performance was predicted for the next 55years using the most recent three years production data $\left(5^{\text {th }}-4^{\text {th }}\right.$ year, $5^{\text {th }}-3^{\text {rd }}$ year and $5^{\text {th }}-2^{\text {nd }}$ year $)\left(C h e n{ }^{29}\right)$.

\subsubsection{Ilk Method:}

The Ilk method is a method that was developed by Ilk from Texas A\&M University, this approach focuses on using the "power law loss ratio" rate relation to match production rate functions much better than the hyperbolic rate decline relation for tight gas and shale gas applications (Ilk D. et al ${ }^{14}$ ), while the "Power law exponential decline” is derived from only tight gas and shale gas performances. 
The power law loss ratio can be used to model transient, transitional and boundary flow regimes and many well cases even in a hydraulically fractured shale gas well $\left(\right.$ Ilk D. et $a l^{14}$ ). For the power law loss ratio, the $D_{\infty}$ parameter is first set to zero and then later adjusted to give the best fit during the boundary flow regime as it only affects the late portion of the power law loss ratio equations. The $D_{\infty}$ parameter dominates at very large times and provides a lower bound for the estimated reserves.

The "power law loss ratio rate decline" equation was used just like the hyperbolic model to estimate reserves in this research. The $t^{n}$ parameter in this equation dominates the transient and transition flow regimes in both fractured and unfractured wells yielding good matches of the production data used (Ilk D. et $a{ }^{14}$ ).

Rate loss ratio:

$\mathrm{D}=\frac{1}{q} \times \frac{d q}{d t}$

Eq 10

Power law loss ratio:

$\mathrm{D}=D_{\infty}+D_{1} t^{-(1-n)}$

Power law loss ratio rate decline:

$\mathrm{q}=q_{i} \exp \left[-D_{\infty} t-D_{i} t^{n}\right]$

Where:

$q_{i}=$ Rate $\mathrm{q}(\mathrm{t}=0)$ [this parameter differs from initial rate]

$D_{1}=$ Decline constant at 1 time unit $\mathrm{D}(\mathrm{t}=1$ day $)$

$D_{\infty}=$ Decline constant at "infinite time” $\mathrm{D}(\mathrm{t}=$ infinite $)$ 
$D_{i}=$ Decline constant where $D_{i}=D_{1} / \mathrm{n}$

$\mathrm{n}=$ Time exponent

\subsubsection{Backward \& Ilk Method}

This is simply just the combination of two very good reserve estimation methods that could be very viable when used for shale gas reservoirs. This method encompasses the backward approach which deals with analyzing and doing regression with the most recent production data in a backwards fashion in combination with the Ilk method which uses the "power law loss ratio" rate decline in predicting future reserves. 


\section{CHAPTER IV}

\section{RESULTS AND DISCUSSIONS}

The main objective of this research is to evaluate three current production decline analysis methods by quantitative comparison of errors in reserve estimate in different reservoir - well systems, and to propose a new method to provide more reliable production forecast and reserve estimate for gas shale reservoirs.

These approaches will be compared based on error analysis of the remaining reserves using the estimated future performances and forecasted reserves. The four methods to be compared are the conventional decline curve analysis method, the backward method, the Ilk's method and the proposed new method which is the combination of backward \& Ilk method.

Four synthetic cases are generated using a commercial reservoir simulator "Eclipse” for evaluation of the decline curve analysis methods. These four synthetic cases illustrated the decline behaviors of a hydraulically fractured horizontal well in different well- reservoir systems. 


\subsection{Synthetic Case 1 - Base Case}

In this case, gas produced from a horizontal well hydraulically fractured in a single-layer shale gas reservoir. Basic reservoir, fracture and fluid properties are listed below:

$\underline{\text { Reservoir and Fracture Properties }}$

Reservoir temperature $=125^{0} \mathrm{~F}$

Initial reservoir pressure $=2880 \mathrm{psi}$

Net-pay thickness $=120 \mathrm{ft}$

Matrix porosity $=8 \%$

Matrix permeability $=0.0005 \mathrm{md}$

Fracture half-length $=504 \mathrm{ft}$

Dimensionless fracture conductivity $=9.9$

Bottom-hole flowing pressure $=500$ psi

Well drainage area $=160$ acre (3600ft x 1938ft)

\section{$\underline{\text { Fluid Properties }}$}

Gas gravity $=0.65$

Initial gas viscosity $=0.0209 \mathrm{cp}$

Initial gas compressibility $=3.11 \times 10^{-4} \mathrm{psi}^{-1}$

Initial gas production rate $=2646$ Mscf/Day 
Production forecast was performed as illustrated in Figures 20 and 21. These figures show forecasts of gas production rate and cumulative production of the shale gas reservoir. The graph of gas production rate versus time starts at a peak point and then production declines drastically before gaining stabilization in the middle and late time of the life of the well. The life of the wells was simulated for a period of about 22000 days or 60 years. The cumulative production increases with time and reaches almost 6 Bcf after 60 year production.

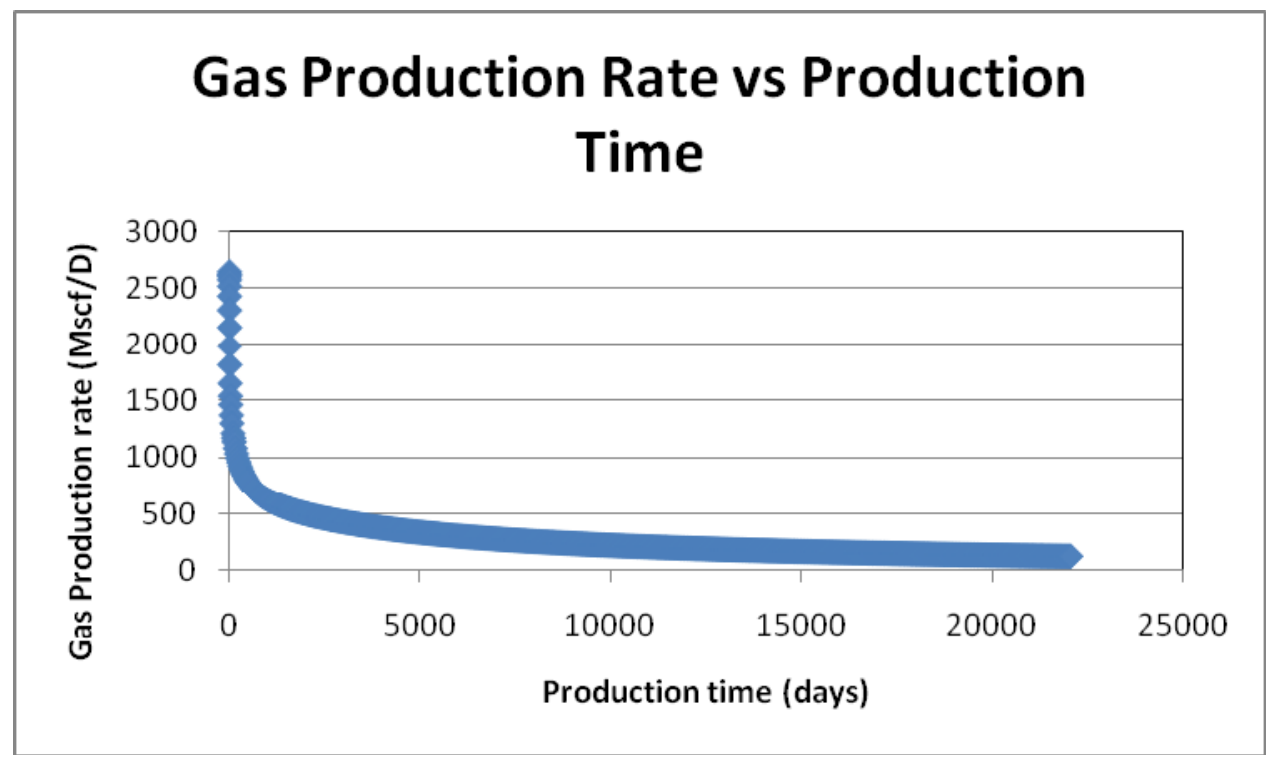

Figure 20: Gas Production Rate versus Time. 


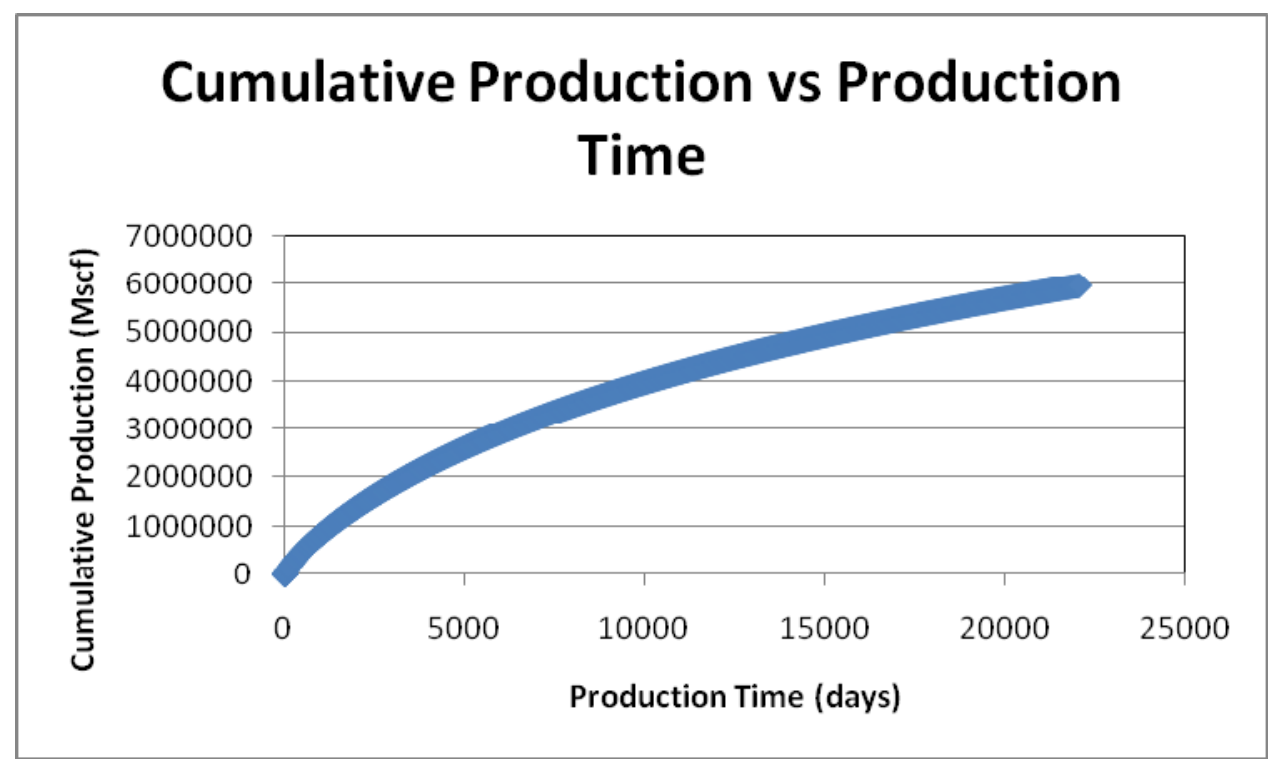

Figure 21: Cumulative Production versus Time.

In this research, an assumption was made that the production data for the first five or ten years are readily available, these production data were used in conventional decline curve analysis to forecast the estimated reserves for the future production of the horizontal well.

We consider two scenarios. In the first scenario we assume that only the production data for the first ten years of the wells life are available for decline curve analysis. In the second scenario, only the production data for the first five years are available for analysis. Table 2 shows the corresponding $\mathrm{q}_{i}, D_{i}$, b, cumulative production and relative error for the times used for reserve estimation. In scenario one, we need to forecast the performance for the remaining 50 years; while in scenario two we need to forecast the production performance for the remaining 55 years. The cumulative 
production and relative error are used in this evaluation to determine the accurate method in estimating the remaining reserves and predicting the wells future performance.

The true remaining cumulative production given by the simulator for the first ten years and first five years scenarios were given respectively to be 3844707 Mscf and 4664879 Mscf which is clearly overestimated by the conventional decline curve analysis method to be 6018251 Mscf for (1-10 years) and 7660304 Mscf for (1-5 years). This overestimation occurs because the $b$ value which is supposed to range between 0 and 1 is within a range of $3.85-4.26$. The overestimation can also be seen in Figure 22 where both (1-5 years) and (1-10 years) rise above the Field Gas Production Rate (FGPR) which is the simulated production rate. It is also because this is a shale gas reservoir which has ultra low permeability. History matching (HM) is done for the amount of years for which production data is available. This is used to predict future performances in different case studies.

Table 2: Base synthetic case (Conventional DCA)

\begin{tabular}{|l|l|l|l|l|l|l|}
\hline HM, yr & (Mscf/D) & $D_{i}$ & $\mathrm{~b}$ & $\begin{array}{l}\text { CUM_cal } \\
\text { (Mscf) }\end{array}$ & $\begin{array}{l}\text { CUM_true } \\
\text { (Mscf) }\end{array}$ & Error \\
(Fraction) \\
\hline $1-10$ & 2533 & 0.060492 & 3.849 & $6,018,251$ & $3,844,707$ & 0.56 \\
\hline $1-5$ & 2562 & 0.083749 & 4.268 & $7,660,304$ & $4,664,879$ & 0.64 \\
\hline
\end{tabular}




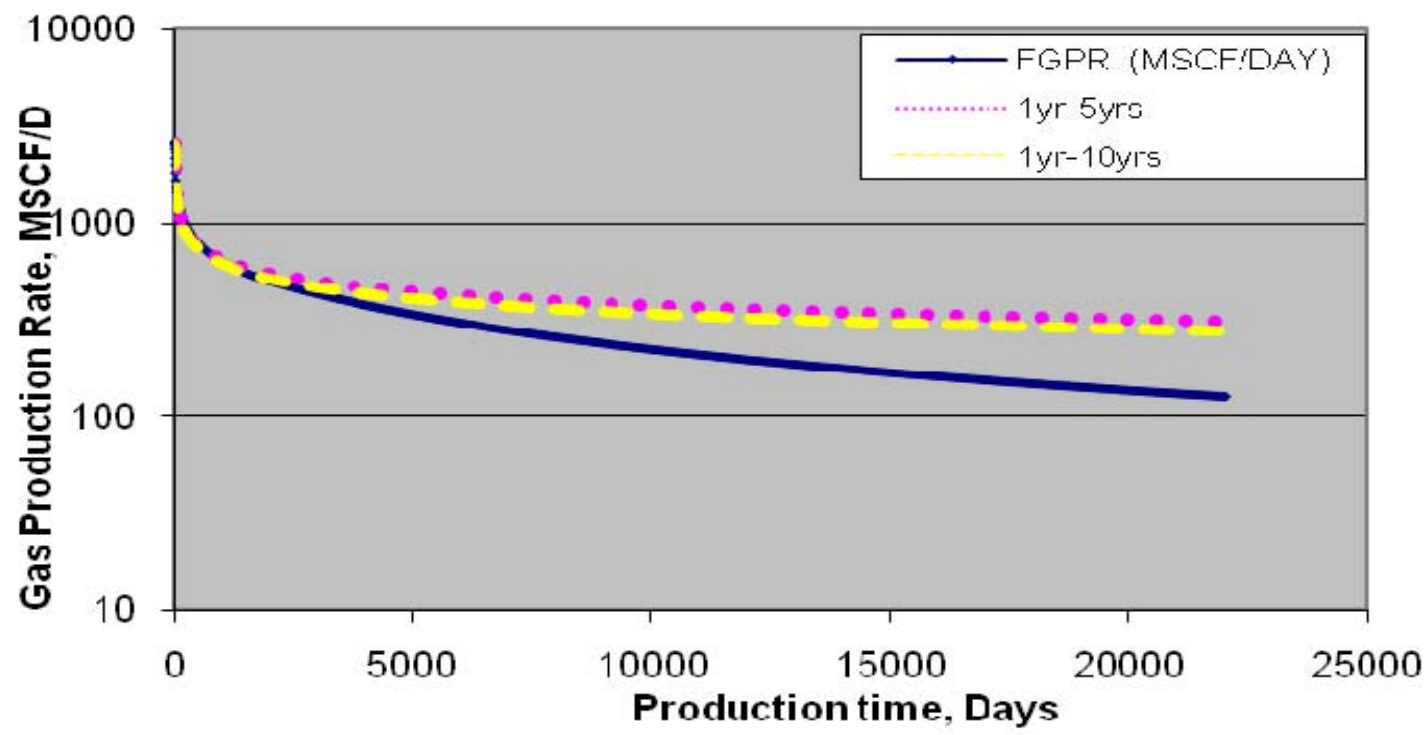

Figure 22: Semi-log showing the Conventional Decline Curve Analysis Method (base case).

The $D_{i}$ and b values for the first and second scenarios in Tables $3 \& 4$ are very close to one another and have a trend of descending slowly from the most recent years to the later years. One could make an assumption that the $D_{i}$ and b values are close to that generated by the simulator due to the little change observed in the decline rate and decline exponent of the production time that was history matched.

Tables $3 \& 4$ and Figures $23 \& 24$ also show that the more recent the production data, the lower the relative error both for the first (5 years) and the second (10 years) scenario. The predicted reserve estimation and future performance are also closer to the simulated one from the most recent years and backwards. The positive value in the error signifies that the estimated reserve is overestimated. 
Table 3: Base synthetic case (Backwards 10 years)

\begin{tabular}{|l|l|l|l|l|l|l|}
\hline HM, yr & (Mscf/D) & $D_{i}$ & $\mathrm{~b}$ & $\begin{array}{l}\text { CUM_cal } \\
\text { (Mscf) }\end{array}$ & $\begin{array}{l}\text { CUM_true } \\
\text { (Mscf) }\end{array}$ & Error \\
\hline $9-10$ & 3200 & 0.012258 & 2.196 & $4,397,370$ & $3,844,707$ & 0.14 \\
\hline $8-10$ & 3199 & 0.013312 & 2.246 & $4,444,872$ & $3,844,707$ & 0.15 \\
\hline $7-10$ & 3198 & 0.015202 & 2.329 & $4,523,472$ & $3,844,707$ & 0.17 \\
\hline $6-10$ & 3195 & 0.01738 & 2.412 & $4,602,743$ & $3,844,707$ & 0.19 \\
\hline $5-10$ & 3190 & 0.020259 & 2.510 & $4,694,510$ & $3,844,707$ & 0.22 \\
\hline
\end{tabular}

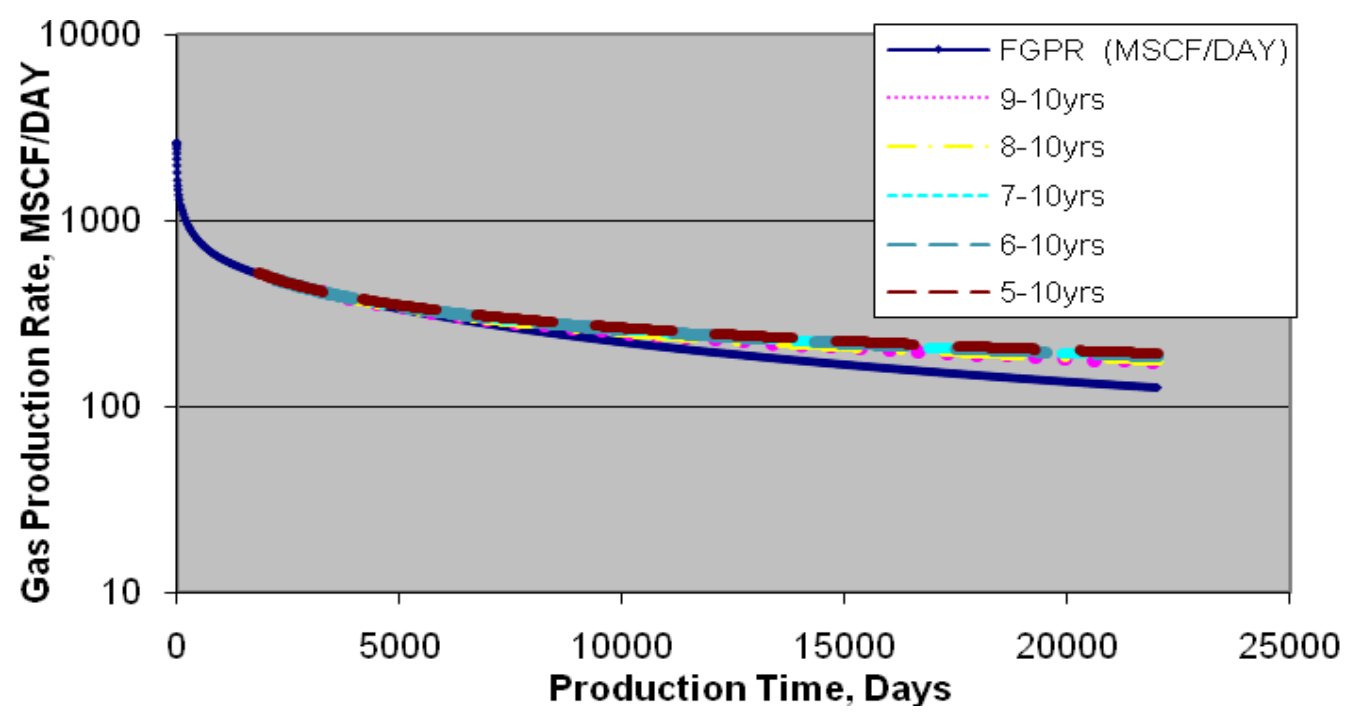

Figure 23: Semi-log showing Backward Method (10 years) using base case. 
The relative errors in Table 4 are very close to one another and can be seen to be matched up close together in Figure 24.

Table 4: Base synthetic case (Backward 5years)

\begin{tabular}{|c|c|c|c|c|c|c|c|}
\hline $\begin{array}{l}\text { Start } \\
\text { HM, yr }\end{array}$ & $\begin{array}{l}\text { End } \\
\mathrm{HM}, \mathrm{yr}\end{array}$ & $\begin{array}{l}q_{i} \\
(\mathrm{Mscf} / \mathrm{D})\end{array}$ & $D_{i}$ & b & $\begin{array}{l}\text { CUM_cal } \\
\text { (Mscf) }\end{array}$ & $\begin{array}{l}\text { CUM_true } \\
\text { (Mscf) }\end{array}$ & $\begin{array}{l}\text { Error } \\
\text { (Fraction) }\end{array}$ \\
\hline 4 & 5 & 2865 & 0.02973 & 2.981 & $6,037,421$ & $4,664,879$ & 0.29 \\
\hline 3 & 5 & 2863 & 0.034446 & 3.092 & $6,567,901$ & $5,074,155$ & 0.29 \\
\hline 2 & 5 & 2861 & 0.038785 & 3.184 & $6,904,769$ & $5,309,976$ & 0.30 \\
\hline
\end{tabular}

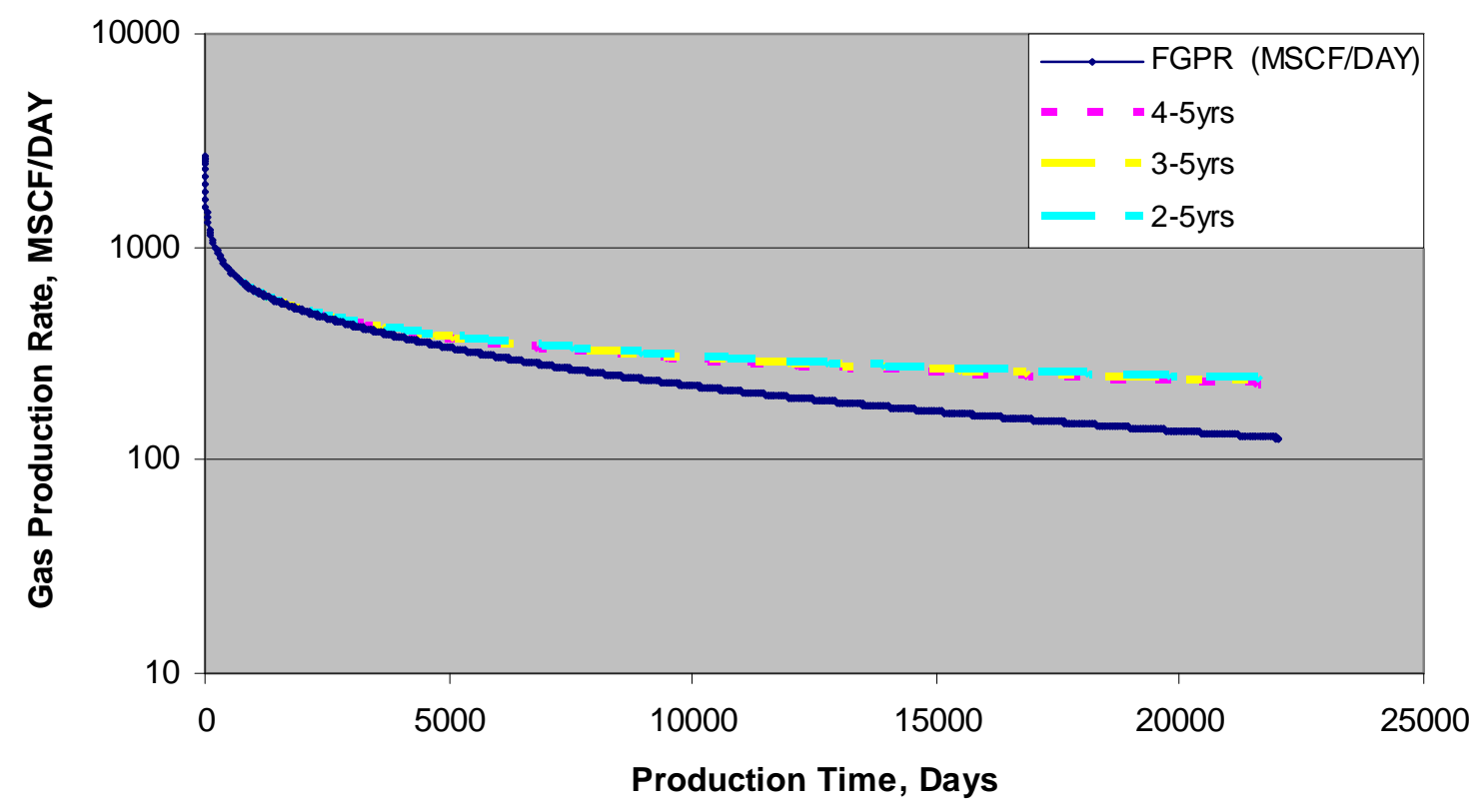

Figure 24: Semi-log showing Backward Method (5 years) using base case. 
Using the production data from the first five years and the first ten years, the estimated reserves of the horizontal well was predicted for the Ilk method. In Table 5, the negative sign in the error shows that the calculated cumulative production data was less than the simulated cumulative production data while, Figure 25 shows how the (1-5years) and (1-10years) are slightly below the Field Gas Production Rate (FGPR).

Table 5: Base synthetic case (Ilk Method)

\begin{tabular}{|l|l|l|l|l|l|l|l||l|}
\hline \hline Start & End & $q_{i}$ & & & & CUM_cal & CUM_true & Error \\
HM, yr & HM, yr & (Mscf/D) & $D_{i}$ & $n$ & D infi & (Mscf) & (Mscf) & (Fraction) \\
\hline 1 & 5 & 2882 & 0.269176 & 0.251 & $1 \mathrm{E}-08$ & $3,972,017$ & $4,664,879$ & -0.14 \\
\hline 1 & 10 & 2930 & 0.295931 & 0.236 & $6.69 \mathrm{E}-07$ & $3,700,140$ & $3,844,707$ & -0.03 \\
\hline
\end{tabular}

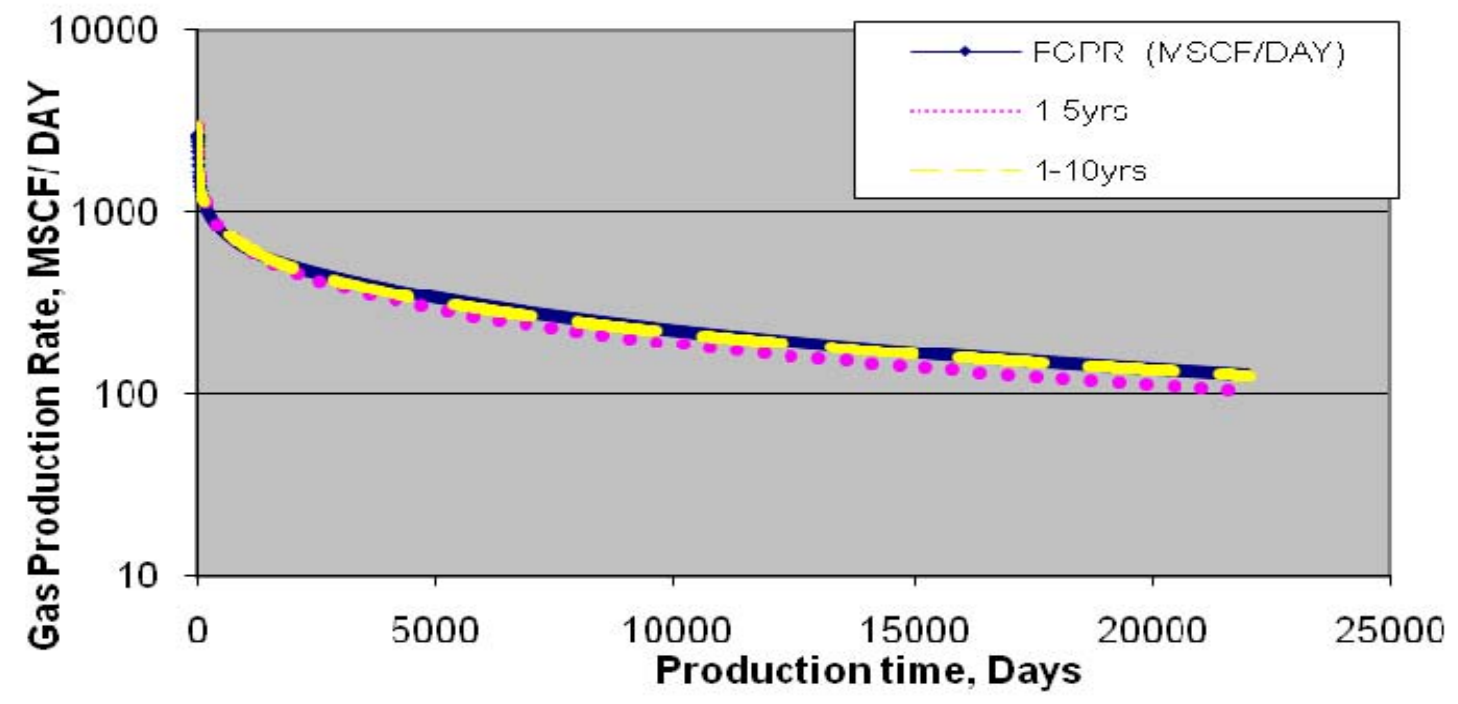

Figure 25: Semi-log showing Ilk Method using base case. 
Looking at table 6 and Figure 26, this method is clearly the most accurate compared to the other three (backward, conventional DCA and Ilk method) discussed previously. This method generates a very good estimate of the future reserve with little error to account for when compared to the one generated by the simulator.

Table 6: Base synthetic case (Backward \& Ilk Method)

\begin{tabular}{|l|l|l|l|l|l|l|l|l|}
\hline Start & End & & & & & & \\
HM, & HM, & $q_{i}$ & & & & CUM_cal & CUM_true Error \\
yr & yr & (Mscf/D) & $D_{i}$ & n & D infi & (Mscf) & (Mscf) & (Fraction) \\
\hline 4 & 5 & 2871 & 0.403908 & 0.190 & 0.00001 & $5,125,802$ & $4,664,879$ & 0.09 \\
\hline 9 & 10 & 2924 & 0.342375 & 0.213 & 0.00001 & $3,956,864$ & $3,844,707$ & 0.02 \\
\hline
\end{tabular}

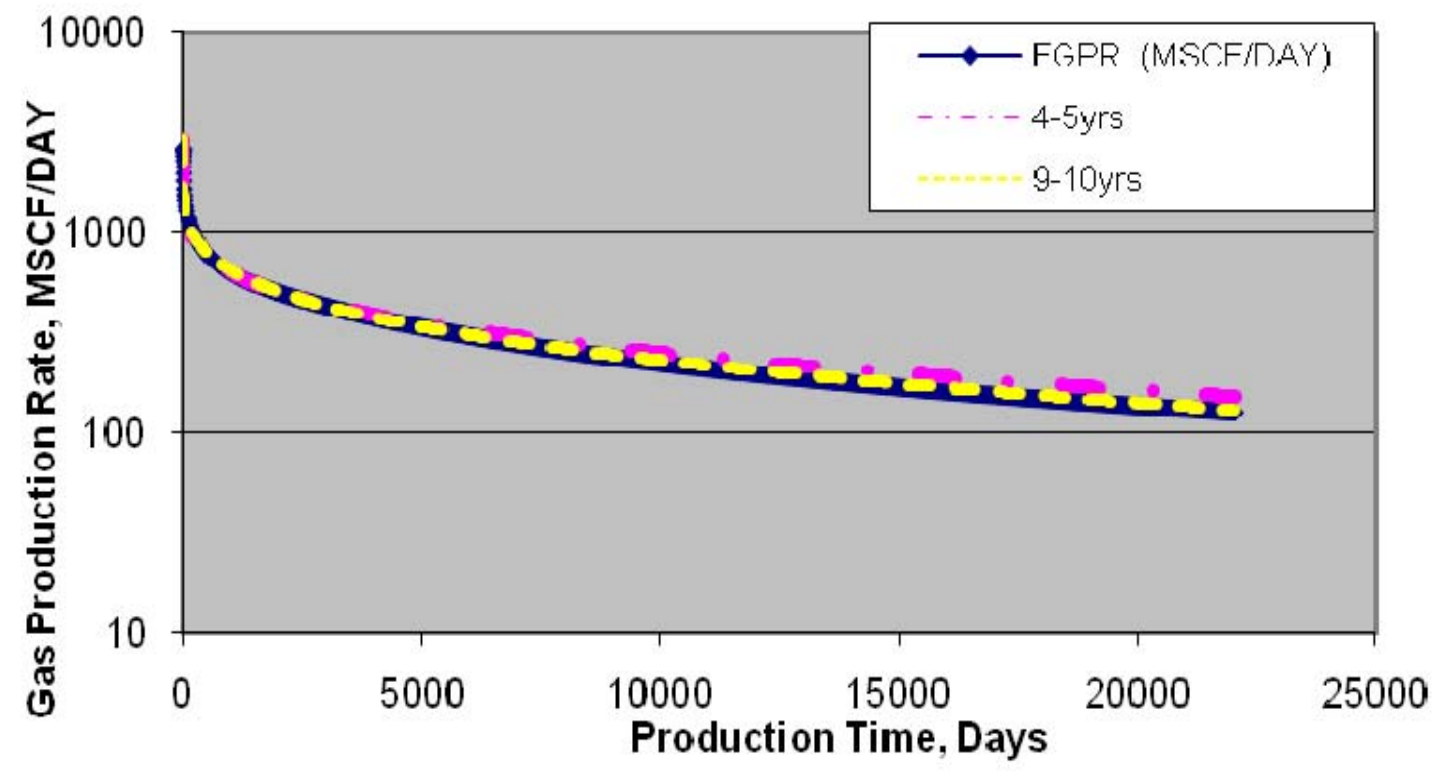

Figure 26: Semi-log showing Backward \& Ilk Method using base case. 


\subsection{Synthetic Case Study 2}

The second case study has similar key parameters compared to the base case; however, there is only one key noticeable parameter which was altered in order to know how this change could affect the effective production of natural gas in this shale reservoir. This case study helps in validating if the results and conclusion in the base synthetic case can vary.

All the main parameters of the shale reservoir remained constant other than the dimensionless fracture conductivity which is been altered from 10 to 50. Altering the dimensionless fracture conductivity from 10 to 50 increased the relative errors in all methods when compared to the base case study. Furthermore, contrary to my expectations, this case study showed that the accuracy of predicted estimated reserves is not necessarily improved with increased production history. This can be seen when the backward method is done using a duration of 5years.

In comparison to the base case, the true cumulative production of this case study is overwhelmingly greater. This shows the dimensionless fracture conductivity plays an important role production from hydraulic fractured wells. While other methods were increasing in relative error, the Backward \& Ilk method was an exception as it recorded relative errors of 0.06 and 0.01 as seen in Table 11 and Figure 31 for (4-5 years) and (910 years) respectively. 
Tables 7 through 10 shows a high relative error and this difference can also be seen in Figures 27 through 30 as there is a huge gap between the FGPR and years that were history matched when compared to the base synthetic case.

Table 7: Dimensionless fracture conductivity (Conventional DCA)

\begin{tabular}{|l|r|l|l|l|l|l|}
\hline HM, yr & \multicolumn{1}{l|}{$\begin{array}{l}q_{i} \\
(\mathrm{Mscf} / \mathrm{D})\end{array}$} & \multicolumn{1}{l|}{$D_{i}$} & $\mathrm{~b}$ & $\begin{array}{l}\text { CUM_cal } \\
\text { (Mscf) }\end{array}$ & $\begin{array}{l}\text { CUM_true } \\
\text { (Mscf) }\end{array}$ & $\begin{array}{l}\text { Error } \\
\text { (Fraction) }\end{array}$ \\
\hline $1-10$ & 8825 & 0.103208 & 2.712 & $8,352,152$ & $4,337,061$ & 0.92 \\
\hline $1-5$ & 8887 & 0.123308 & 2.960 & $11,431,249$ & $5,507,119$ & 1.07 \\
\hline
\end{tabular}

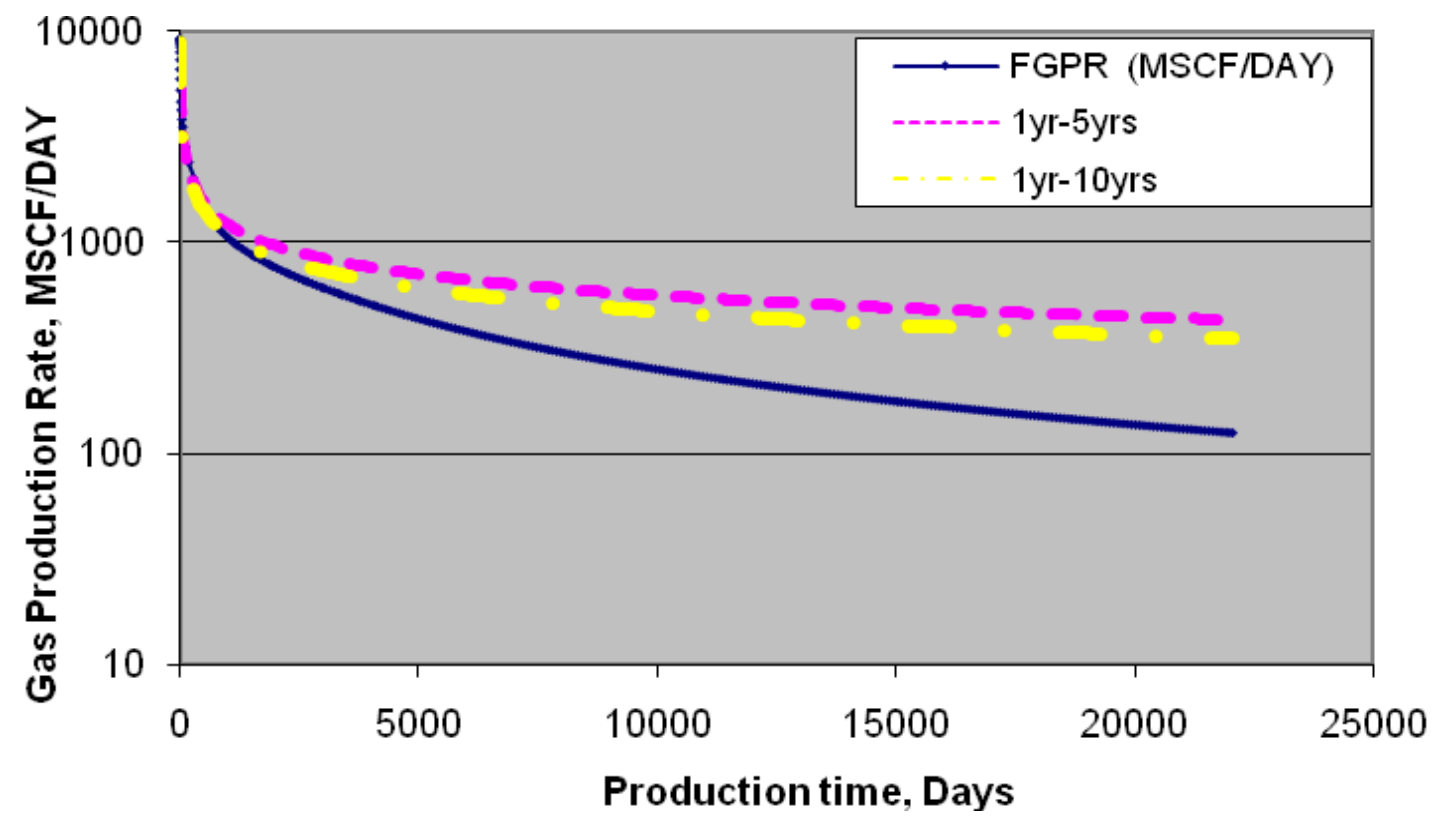

Figure 27: Semi-log showing Conventional Method (Using a dimensionless fracture conductivity of 50). 
Table 8: Dimensionless fracture conductivity (Backward 10 years)

\begin{tabular}{|l|r|l|r|r|r|r|}
\hline $\mathrm{HM}, \mathrm{yr}$ & $(\mathrm{Mscf} / \mathrm{D})$ & \multicolumn{1}{|l|}{$D_{i}$} & $\mathrm{~b}$ & $\begin{array}{l}\text { CUM_cal } \\
(\mathrm{Mscf})\end{array}$ & $\begin{array}{l}\text { CUM_true } \\
(\text { Mscf })\end{array}$ & $\begin{array}{l}\text { Error } \\
\text { (Fraction) }\end{array}$ \\
\hline $9-10$ & 11101 & 0.053153 & 1.970 & $5,712,576$ & $4,385,345$ & 0.30 \\
\hline $8-10$ & 11092 & 0.053541 & 1.979 & $5,769,610$ & $4,385,345$ & 0.31 \\
\hline $7-10$ & 11089 & 0.054134 & 1.986 & $5,797,749$ & $4,385,345$ & 0.32 \\
\hline $6-10$ & 11055 & 0.054985 & 2.003 & $5,877,806$ & $4,385,345$ & 0.34 \\
\hline $5-10$ & 11020 & 0.055393 & 2.017 & $5,903,571$ & $4,385,345$ & 0.35 \\
\hline
\end{tabular}

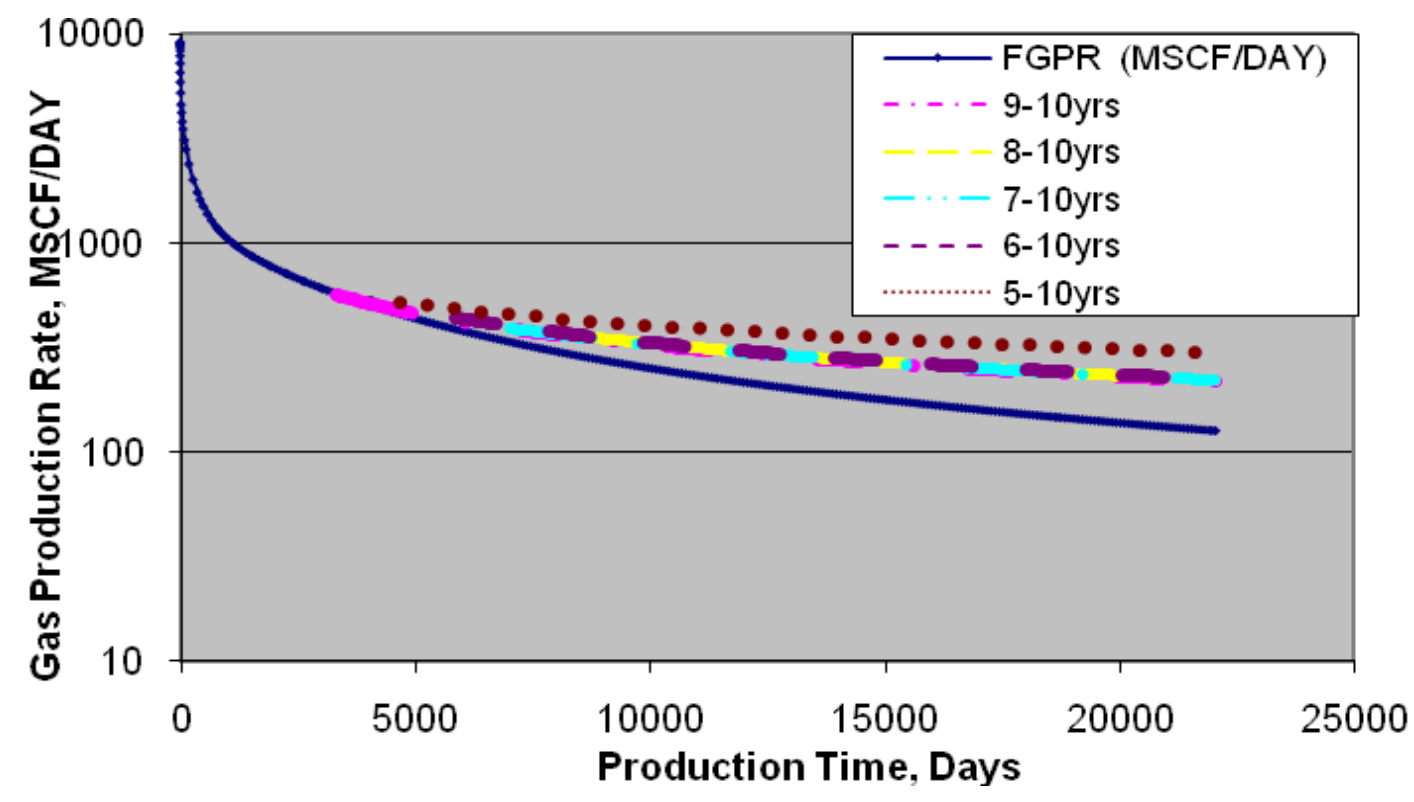

Figure 28: Semi-log showing Backward Method 10years (Using a dimensionless fracture conductivity of 50). 
Table 9: Dimensionless fracture conductivity (Backward 5 years)

\begin{tabular}{|r|l|r|l|r|r|l|r|}
\hline $\begin{array}{l}\text { Start } \\
\mathrm{HM}, \mathrm{yr}\end{array}$ & $\begin{array}{l}\text { End } \\
\mathrm{HM}, \mathrm{yr}\end{array}$ & $\begin{array}{l}q_{i} \\
\text { (Mscf/D) }\end{array}$ & \multicolumn{1}{l|}{$D_{i}$} & $\mathrm{~b}$ & $\begin{array}{l}\text { CUM_cal } \\
\text { (Mscf) }\end{array}$ & $\begin{array}{l}\text { CUM_true } \\
\text { (Mscf) }\end{array}$ & $\begin{array}{l}\text { Error } \\
\text { (Fraction) }\end{array}$ \\
\hline 4 & 5 & 10020 & 0.055559 & 2.123 & $7,507,928$ & $5,578,171$ & 0.34 \\
\hline 3 & 5 & 10031 & 0.055753 & 2.123 & $8,149,580$ & $6,234,332$ & 0.31 \\
\hline 2 & 5 & 10041 & 0.05451 & 2.110 & $8,511,877$ & $6,643,666$ & 0.28 \\
\hline
\end{tabular}

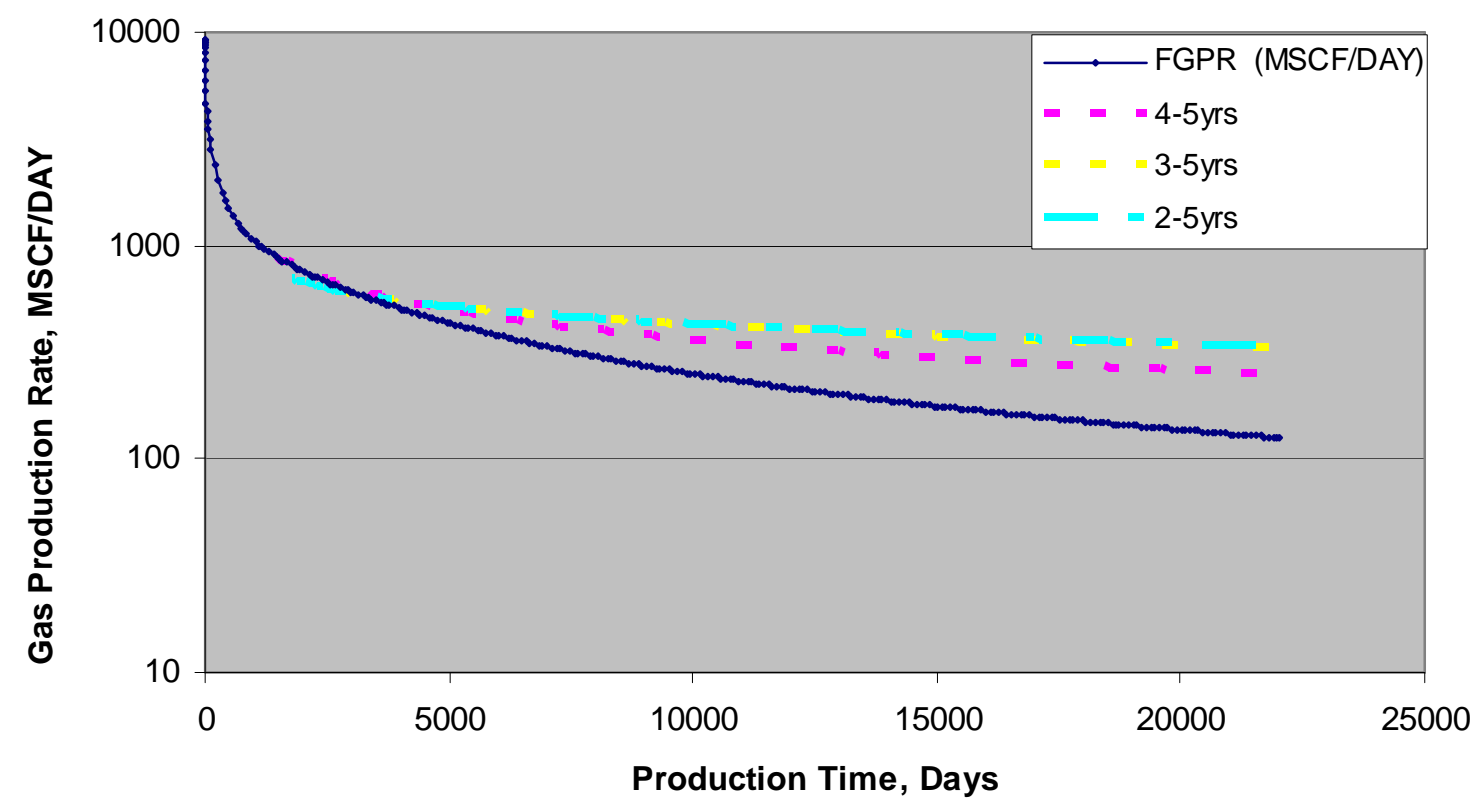

Figure 29: Semi-log showing Backward Method 5years (Using a dimensionless fracture conductivity of 50). 
Table 10: Dimensionless fracture conductivity (Ilk Method)

\begin{tabular}{|r|l|r|l|l|l|l|l|l|}
\hline $\begin{array}{l}\text { Start } \\
\mathrm{HM}, \mathrm{yr}\end{array}$ & $\begin{array}{l}\text { End } \\
\mathrm{HM}, \mathrm{yr}\end{array}$ & \multicolumn{1}{l|}{$\begin{array}{l}q_{i} \\
(\mathrm{Mscf} / \mathrm{D})\end{array}$} & \multicolumn{1}{l|}{$D_{i}$} & $\mathrm{n}$ & Dinfi & $\begin{array}{l}\text { CUM_cal } \\
\text { (Mscf) }\end{array}$ & $\begin{array}{l}\text { CUM_true } \\
\text { (Mscf) }\end{array}$ & $\begin{array}{l}\text { Error } \\
\text { (Fraction) }\end{array}$ \\
\hline 1 & 5 & 9935 & 0.268814 & 0.250 & 0.000001 & $2,654,483$ & $5,507,119$ & -0.51 \\
\hline 1 & 10 & 10057 & 0.315796 & 0.282 & 0.000001 & $2,461,755$ & $4,337,061$ & -0.43 \\
\hline
\end{tabular}

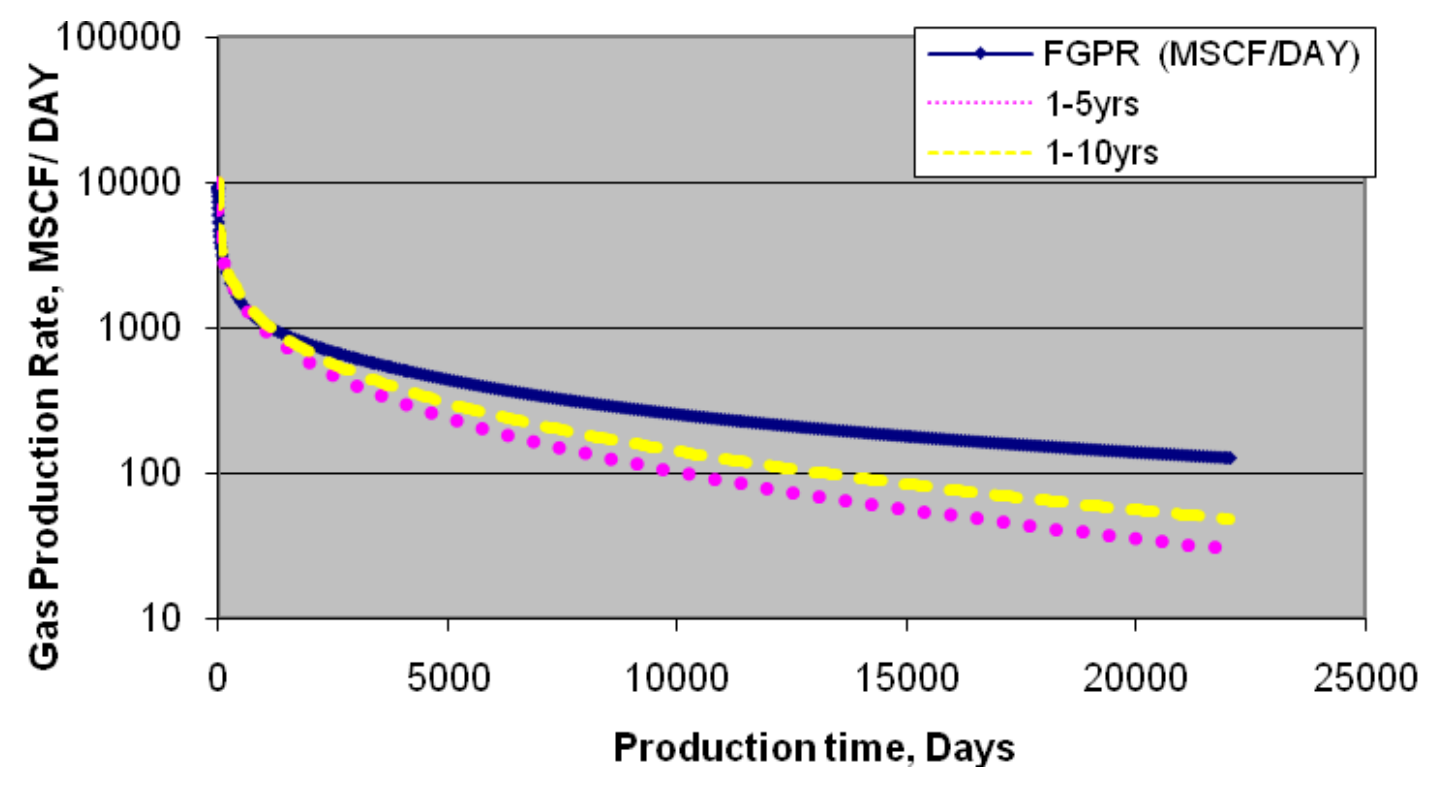

Figure 30: Semi-log showing Ilk Method (Using a dimensionless fracture conductivity of $50)$. 
Table 11: Dimensionless fracture conductivity (Backward \& Ilk Method)

\begin{tabular}{|c|c|c|c|c|c|c|c|c|}
\hline $\begin{array}{l}\text { Start } \\
\mathrm{HM}, \mathrm{yr}\end{array}$ & $\begin{array}{l}\text { End } \\
\mathrm{HM}, \mathrm{yr}\end{array}$ & $\begin{array}{l}q_{i} \\
(\mathrm{Mscf} / \mathrm{D})\end{array}$ & $D_{i}$ & $\mathrm{n}$ & Dinfi & $\begin{array}{l}\text { CUM_cal } \\
\text { (Mscf) }\end{array}$ & $\begin{array}{l}\text { CUM_true } \\
\text { (Mscf) }\end{array}$ & $\begin{array}{l}\text { Error } \\
\text { (Fraction) }\end{array}$ \\
\hline 4 & 5 & 6408 & 0.372433 & 0.228 & $1 \mathrm{E}-05$ & $5,865,913$ & $5,507,119$ & 0.06 \\
\hline 9 & 10 & 8819 & 0.459038 & 0.218 & $9.81 \mathrm{E}-06$ & $4,384,878$ & $4,337,061$ & 0.01 \\
\hline
\end{tabular}

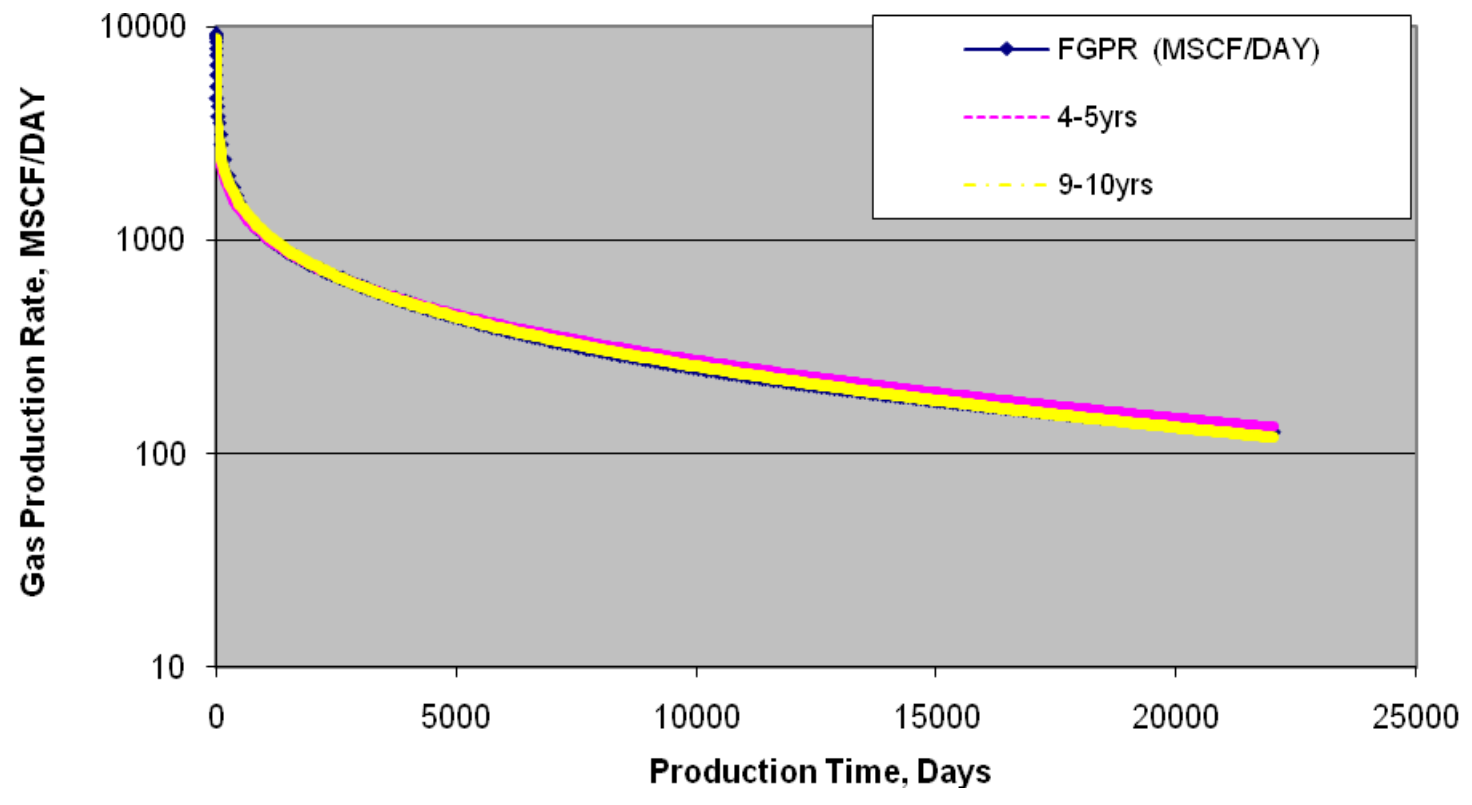

Figure 31: Semi-log showing Backward \& Ilk Method (Using a dimensionless fracture conductivity of 50). 


\subsection{Synthetic Case Study 3}

For the next case study, the variable changed was the number of multi-stage fractures from 8 to 12 while other variables were kept constant. The results from this study indicate that increasing the number of multi-stage fractures from 8 to 12 has tremendous up-side (high cumulative production) with a very low error difference.

When comparing the backward method in this case study with that of all other cases, this case study has the lowest decline exponent (b) and decline rate $\left(D_{i}\right)$ values. This case study also has the best predicted future performances in regards to the others. While all other methods thrived in this case study, the conventional DCA was an exception with high errors as shown in Table 12 and Figure 32. This study affirms that the conventional decline curve analysis method is not a good analysis for estimating reserves of shale gas reservoirs because the other methods (Backward method, Ilk method and Ilk \& Backward method) show lower error as seen in Tables 13, 14,15 \& 16 and Figures 33, 34, 35 \& 36 when compared to Table 12 and Figure 32. 
Table 12: Multi - stage fractures (Conventional DCA)

\begin{tabular}{|l|r|l|l|l|l|l|}
\hline HM, yr & \multicolumn{1}{l|}{$\begin{array}{l}q_{i} \\
(\mathrm{Mscf} / \mathrm{D})\end{array}$} & $D_{i}$ & $\mathrm{~b}$ & $\begin{array}{l}\text { CUM_cal } \\
\text { (Mscf) }\end{array}$ & $\begin{array}{l}\text { CUM_true } \\
\text { (Mscf) }\end{array}$ & $\begin{array}{l}\text { Error } \\
\text { (Fraction) }\end{array}$ \\
\hline $1-10$ & 3806 & 0.062758 & 3.684 & $8,269,637$ & $4,151,237$ & 0.99 \\
\hline $1-5$ & 3856 & 0.092422 & 4.309 & $11,449,760$ & $5,180,704$ & 1.21 \\
\hline
\end{tabular}

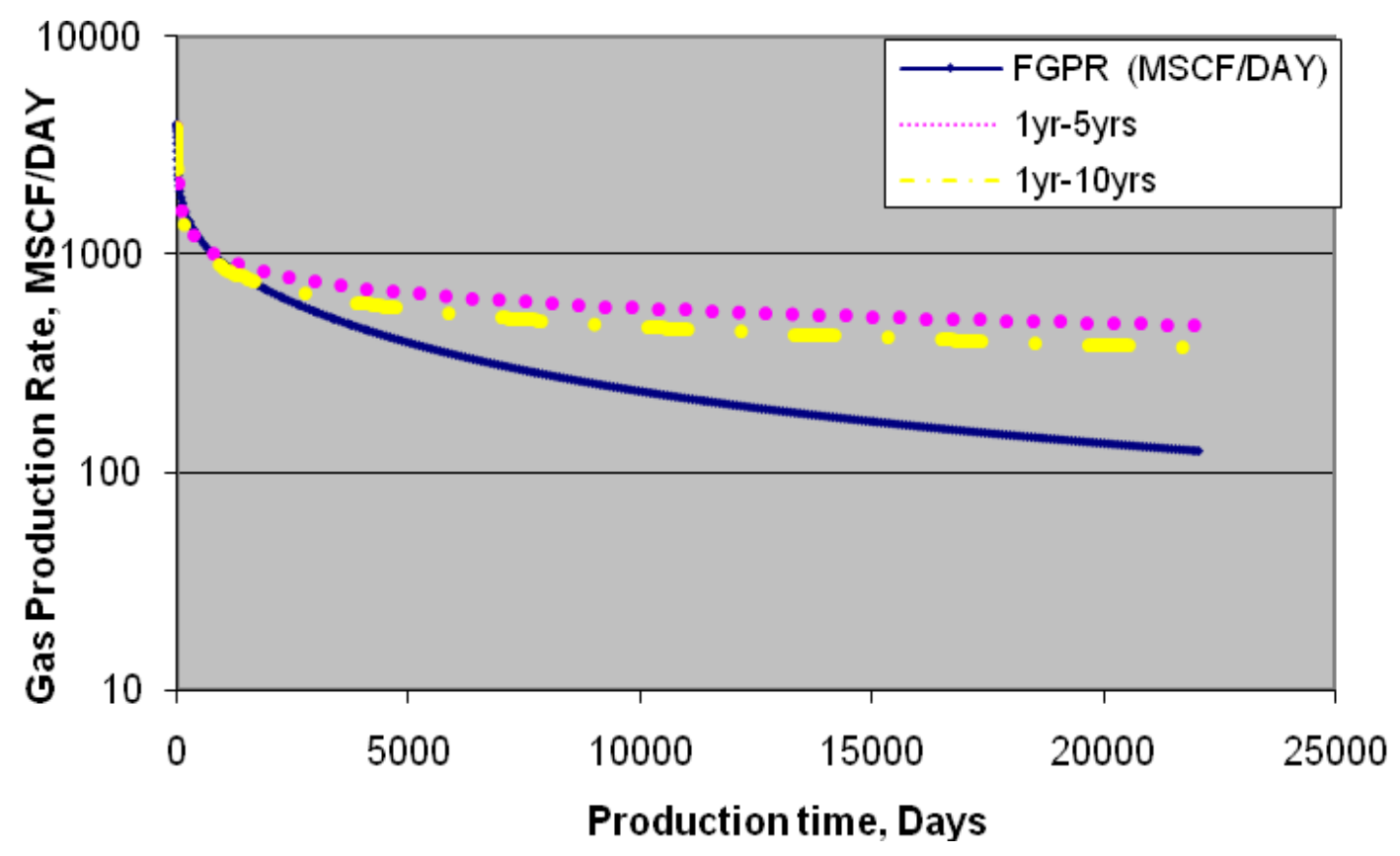

Figure 32: Semi-log showing Conventional Method (Using 12 multi-stage fractures). 
Table 13: Multi - stage fractures (Backward 10years)

\begin{tabular}{|c|c|c|c|c|c|c|}
\hline $\mathrm{HM}, \mathrm{yr}$ & $\begin{array}{l}q_{i} \\
(\mathrm{Mscf} / \mathrm{D})\end{array}$ & $D_{i}$ & b & $\begin{array}{l}\text { CUM_cal } \\
\text { (Mscf) }\end{array}$ & $\begin{array}{l}\text { CUM_true } \\
\text { (Mscf) }\end{array}$ & $\begin{array}{l}\text { Error } \\
\text { (Fraction) }\end{array}$ \\
\hline $9-10$ & 3985 & 0.004604 & 1.574 & $4,556,191$ & $4,151,237$ & 0.09 \\
\hline $8-10$ & 3986 & 0.004846 & 1.607 & $4,613,274$ & $4,151,237$ & 0.11 \\
\hline $7-10$ & 3986 & 0.005194 & 1.653 & $4,693,608$ & $4,151,237$ & 0.13 \\
\hline $6-10$ & 3989 & 0.005613 & 1.704 & $4,784,111$ & $4,151,237$ & 0.15 \\
\hline $5-10$ & 4128 & 0.006611 & 1.773 & $4,903,549$ & $4,151,237$ & 0.18 \\
\hline
\end{tabular}

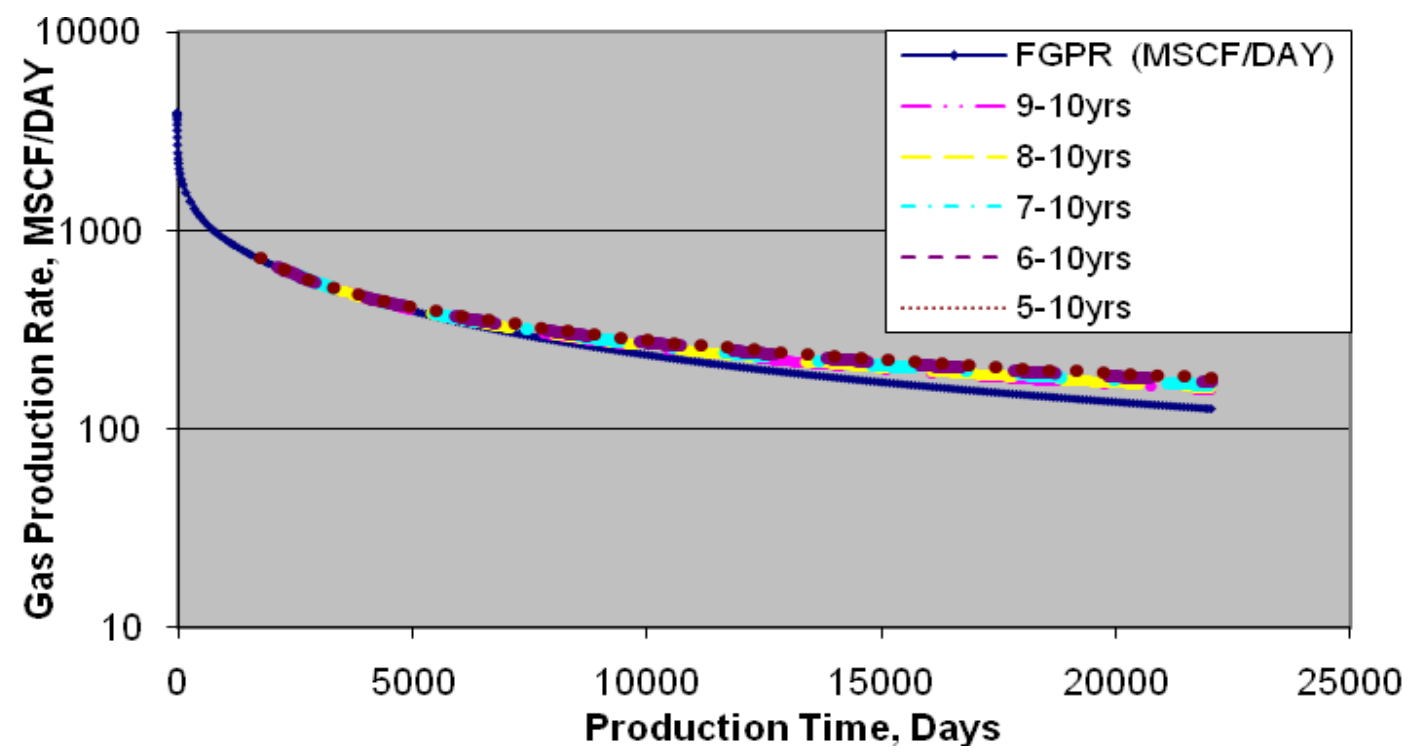

Figure 33: Semi-log showing Backward Method 10years (Using 12 multi-stage fractures). 
Table 14: Multi - stage fractures (Backward 5years)

\begin{tabular}{|c|c|c|c|c|c|c|c|}
\hline $\begin{array}{l}\text { Start } \\
\mathrm{HM}, \mathrm{yr}\end{array}$ & $\begin{array}{l}\text { End } \\
\mathrm{HM}, \mathrm{yr}\end{array}$ & $\begin{array}{l}q_{i} \\
(\mathrm{Mscf} / \mathrm{D})\end{array}$ & $D_{i}$ & b & $\begin{array}{l}\text { CUM_cal } \\
\text { (Mscf) }\end{array}$ & $\begin{array}{l}\text { CUM_true } \\
\text { (Mscf) }\end{array}$ & $\begin{array}{l}\text { Error } \\
\text { (Fraction) }\end{array}$ \\
\hline 4 & 5 & 4057 & 0.010352 & 2.135 & $6,762,485$ & $5,221,030$ & 0.29 \\
\hline 3 & 5 & 4061 & 0.011952 & 2.245 & $7,579,412$ & $5,802,300$ & 0.30 \\
\hline 2 & 5 & 4062 & 0.014658 & 2.408 & $8,283,852$ & $6,153,267$ & 0.34 \\
\hline
\end{tabular}

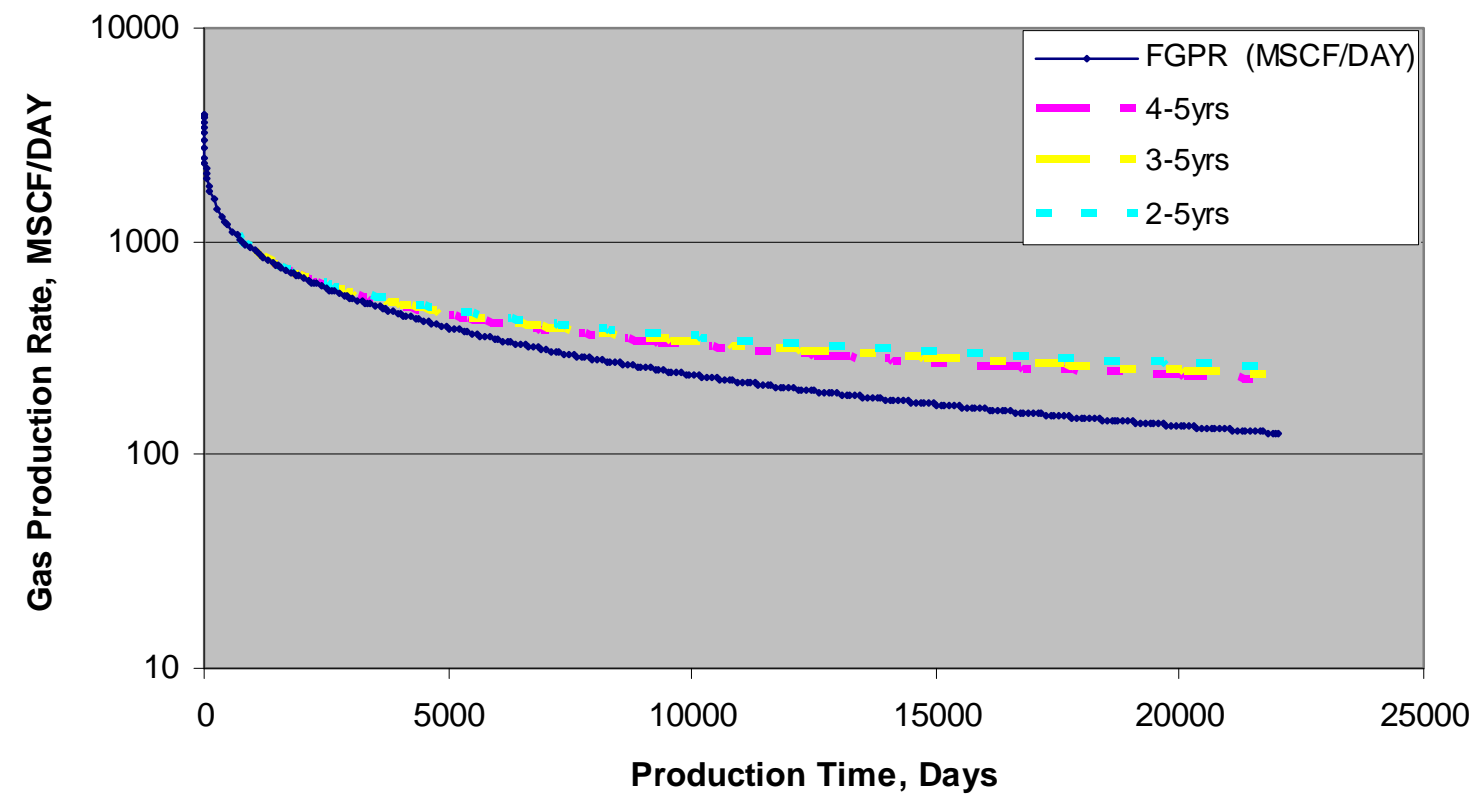

Figure 34: Semi-log showing Backward Method 5years (Using 12 multi-stage fractures). 
Table 15: Multi - stage fractures (Ilk Method)

\begin{tabular}{|r|l|l|l|l|l|l|l|l|}
\hline $\begin{array}{l}\text { Start } \\
\mathrm{HM}, \mathrm{yr}\end{array}$ & $\begin{array}{l}\text { End } \\
\mathrm{HM}, \mathrm{yr}\end{array}$ & $\begin{array}{l}q_{i} \\
\text { (Mscf/D) }\end{array}$ & \multicolumn{1}{l|}{$D_{i}$} & $\mathrm{n}$ & Dinfi & $\begin{array}{l}\text { CUM_cal } \\
\text { (Mscf) }\end{array}$ & $\begin{array}{l}\text { CUM_true } \\
\text { (Mscf) }\end{array}$ & $\begin{array}{l}\text { Error } \\
\text { (Fraction) }\end{array}$ \\
\hline 1 & 5 & 4268 & 0.248307 & 0.265 & 0.000001 & $5,168,023$ & $5,221,030$ & -0.01 \\
\hline 1 & 10 & 4283 & 0.253498 & 0.261 & $2.51 \mathrm{E}-06$ & $4,312,140$ & $4,151,237$ & 0.03 \\
\hline
\end{tabular}

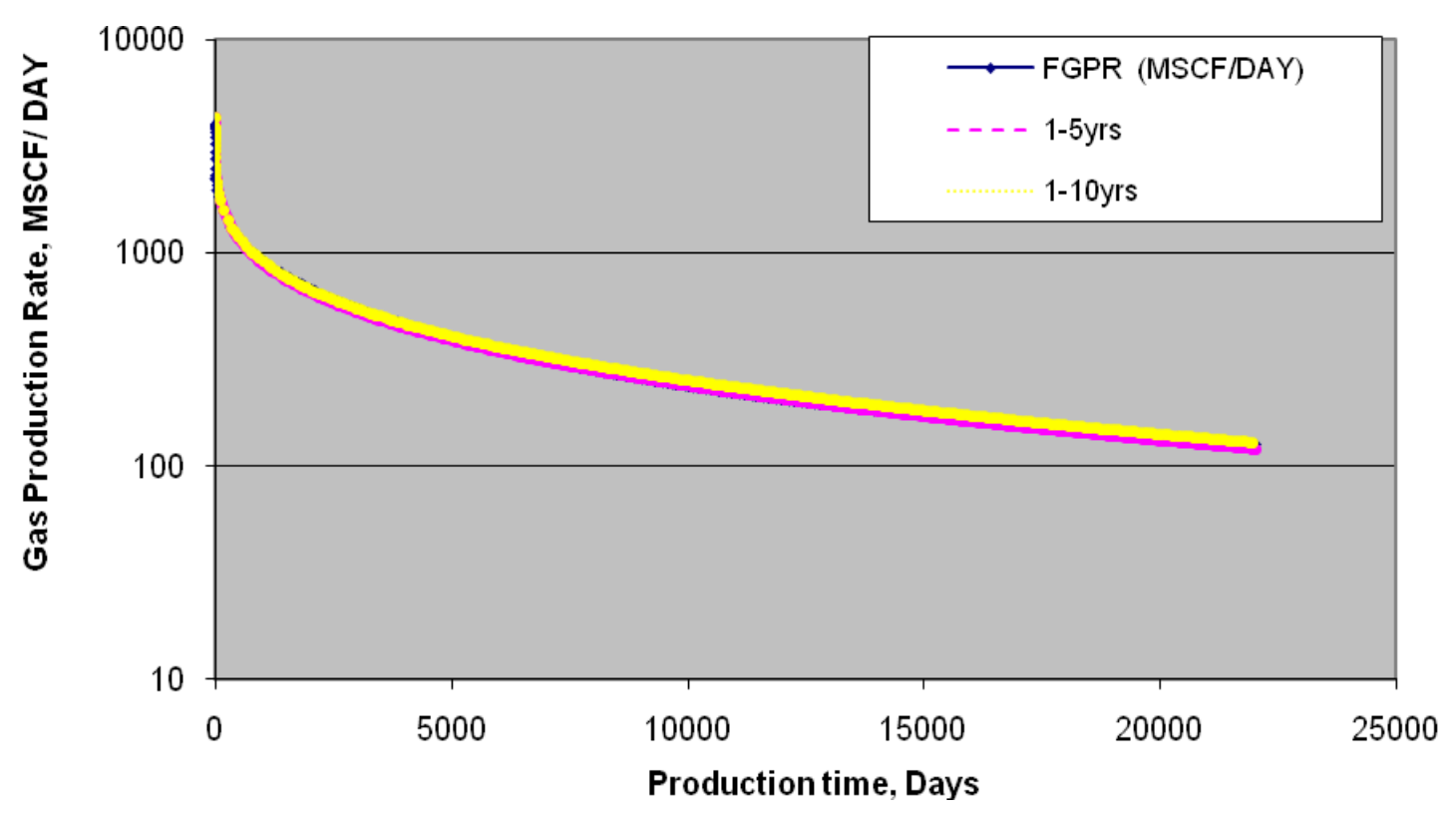

Figure 35: Semi-log showing Ilk Method (Using 12 multi-stage fractures). 
Table 16: Multi - stage fractures (Backward \& Ilk Method)

\begin{tabular}{|c|c|c|c|c|c|c|c|c|}
\hline $\begin{array}{l}\text { Start } \\
\mathrm{HM}, \mathrm{yr}\end{array}$ & $\begin{array}{l}\text { End } \\
\mathrm{HM}, \mathrm{yr}\end{array}$ & $\begin{array}{l}q_{i} \\
(\mathrm{Mscf} / \mathrm{D})\end{array}$ & $D_{i}$ & $\mathrm{n}$ & Dinfi & $\begin{array}{l}\text { CUM_cal } \\
\text { (Mscf) }\end{array}$ & $\begin{array}{l}\text { CUM_true } \\
\text { (Mscf) }\end{array}$ & $\begin{array}{l}\text { Error } \\
\text { (Fraction) }\end{array}$ \\
\hline 4 & 5 & 4075 & 0.245341 & 0.260 & 1E-05 & $5,378,472$ & $5,221,030$ & 0.03 \\
\hline 9 & 10 & 3994 & 0.215477 & 0.275 & 1.01E-05 & $4,038,784$ & $4,151,237$ & -0.02 \\
\hline
\end{tabular}

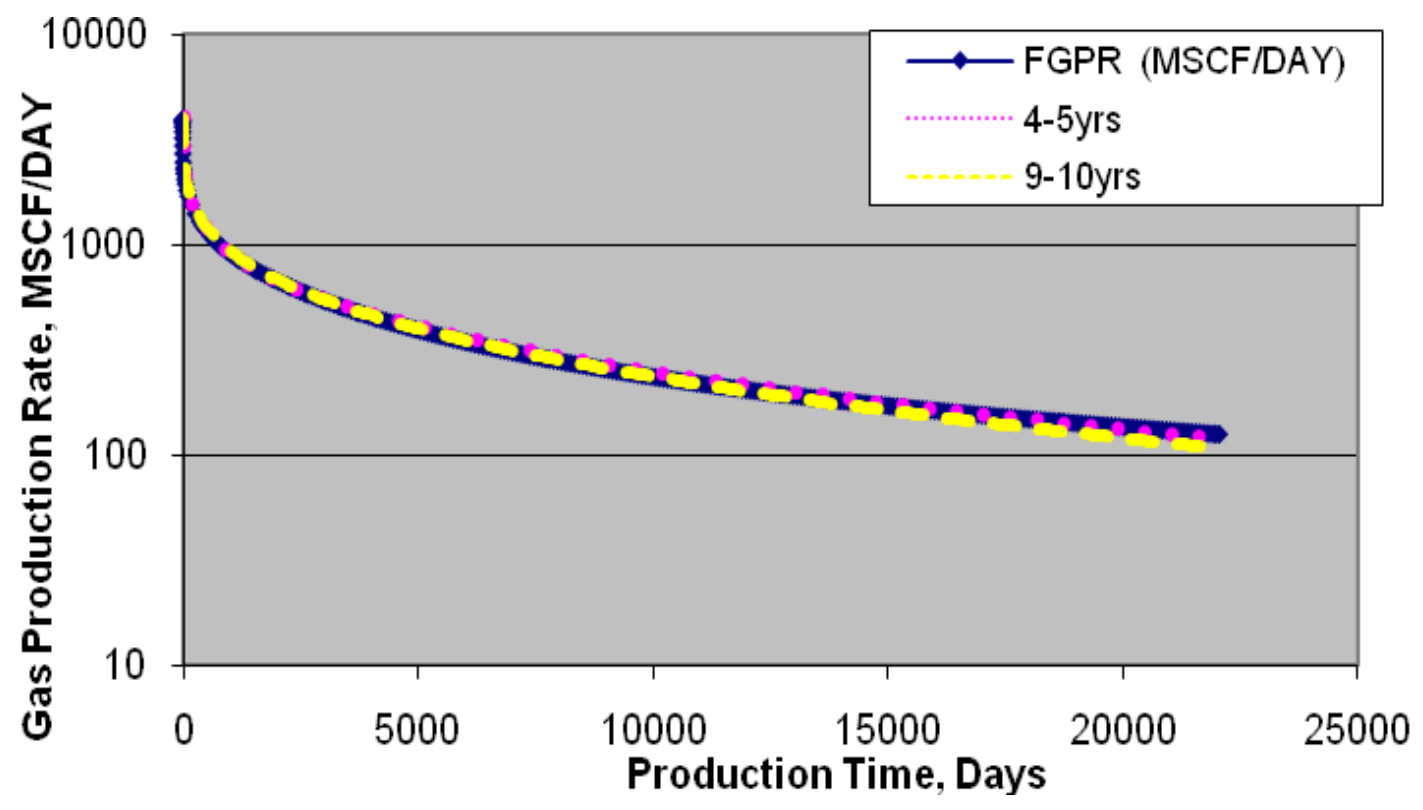

Figure 36: Semi-log showing Backward \& Ilk Method (Using 12 multi-stage fractures). 


\subsection{Synthetic Case Study 4}

For the final case study, the fracture half-length was reduced from $504 \mathrm{ft}$ to $271 \mathrm{ft}$ keeping all other parameters constant. A reduction in the fracture half-length resulted in a simultaneous reduction in the cumulative production but there was also a drop in relative error using the conventional DCA, backward method (5 \& 10 years) and the backward and Ilk method when put side by side with the base case. The reduction in cumulative production occurred because for shale gas reservoirs, long and narrow fractures are needed for high production rate but when the long fracture was shortened to almost half of its initial size, production is thereby affected adversely.

For case study 4, all three methods other than the Ilk method are close to that of the base case. This is another case where the Ilk method shows its inconsistency in reserve estimation. The first is in case study 2 when the Dimensionless fracture conductivity was increased to 50. In this study, the Ilk method gives a high relative error of -0.27 and -0.37 as shown in Table 20 and the space between the history matched curve and the can be seen in Figure 40. Although, the Ilk method was still lower in relative error compared to the conventional DCA method as seen in Table 17 \& Figure 37, it is not a good reserve estimator for short fracture half- length and very high Dimensionless fracture conductivity. Tables 18, 19 \& 21 with their respective Figures which are 38, 39 \& 41 show similar trends when compared to the first three scenarios. It is necessary to address that Ilk \& Backward method is a much better method. 
Table 17: Fracture half - length (Conventional DCA)

\begin{tabular}{|l|l|l|l|l|l|l|}
\hline & \multicolumn{1}{|l|}{$q_{i}$} & & & CUM_cal & CUM_true & Error \\
HM, yr & $(\mathrm{Mscf} / \mathrm{D})$ & $D_{i}$ & $\mathrm{~b}$ & $($ Mscf) & $($ Mscf) & (Fraction) \\
\hline $1-10$ & 2534 & 0.059818 & 3.288 & $4,478,335$ & $2,970,796$ & 0.50 \\
\hline $1-5$ & 2552 & 0.073148 & 3.600 & $5,843,072$ & $3,604,367$ & 0.62 \\
\hline
\end{tabular}

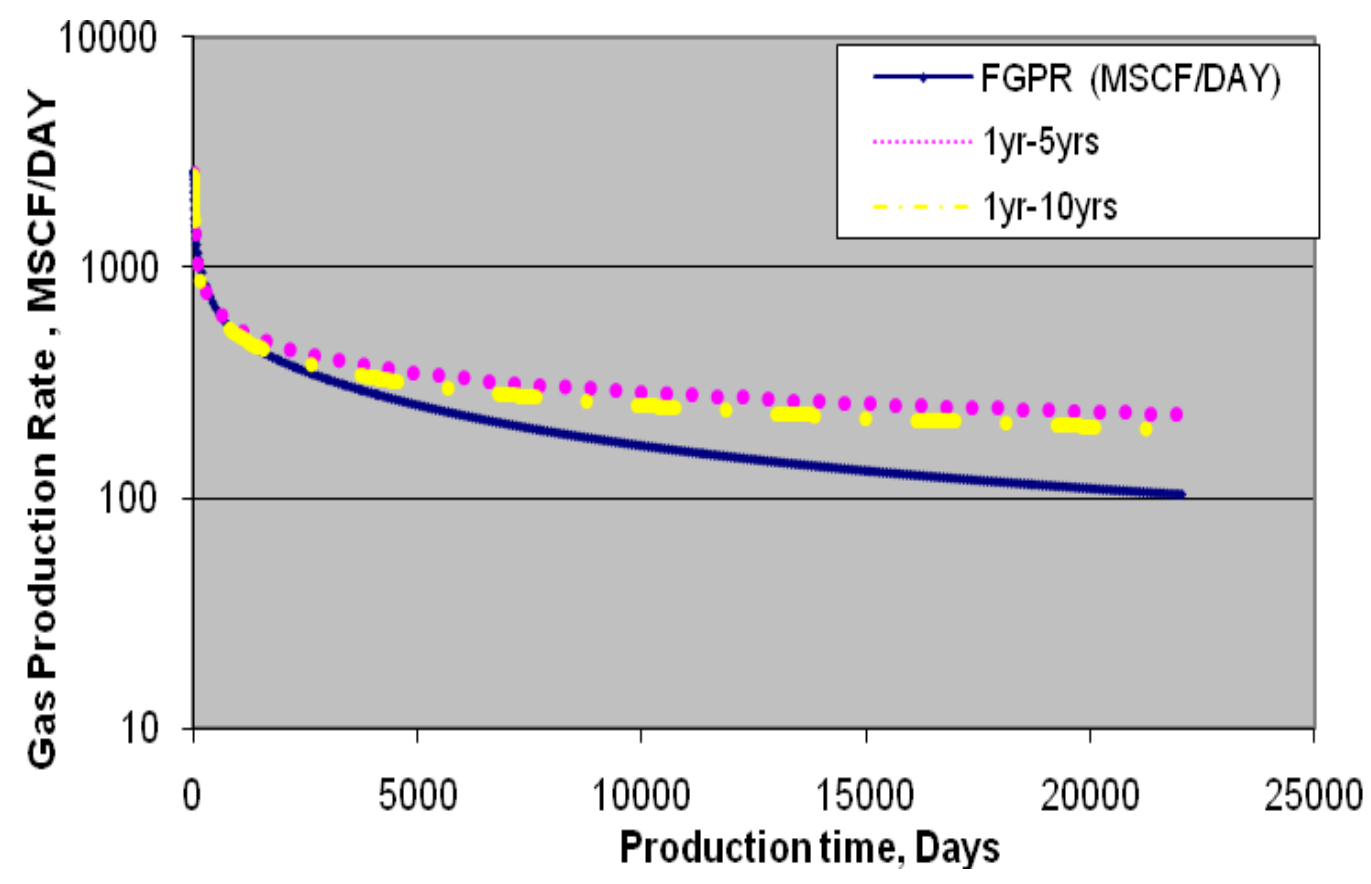

Figure 37: Semi-log showing Conventional Method (Using fracture half-length of 271ft). 
Table 18: Fracture half - length (Backward 10years)

\begin{tabular}{|l|r|l|r|r|r|r|}
\hline $\mathrm{HM}, \mathrm{yr}$ & $(\mathrm{Mscf} / \mathrm{D})$ & \multicolumn{1}{l|}{$D_{i}$} & $\mathrm{~b}$ & $\begin{array}{l}\text { CUM_cal } \\
(\mathrm{Mscf})\end{array}$ & $\begin{array}{l}\text { CUM_true } \\
(\text { Mscf })\end{array}$ & $\begin{array}{l}\text { Error } \\
\text { (Fraction) }\end{array}$ \\
\hline $9-10$ & 3002 & 0.015974 & 2.087 & $3,255,604$ & $2,970,796$ & 0.09 \\
\hline $8-10$ & 3155 & 0.018994 & 2.123 & $3,284,208$ & $2,970,796$ & 0.10 \\
\hline $7-10$ & 3199 & 0.020453 & 2.147 & $3,302,266$ & $2,970,796$ & 0.11 \\
\hline $6-10$ & 3216 & 0.023285 & 2.210 & $3,353,862$ & $2,970,796$ & 0.12 \\
\hline $5-10$ & 3220 & 0.026605 & 2.280 & $3,411,170$ & $2,970,796$ & 0.14 \\
\hline
\end{tabular}

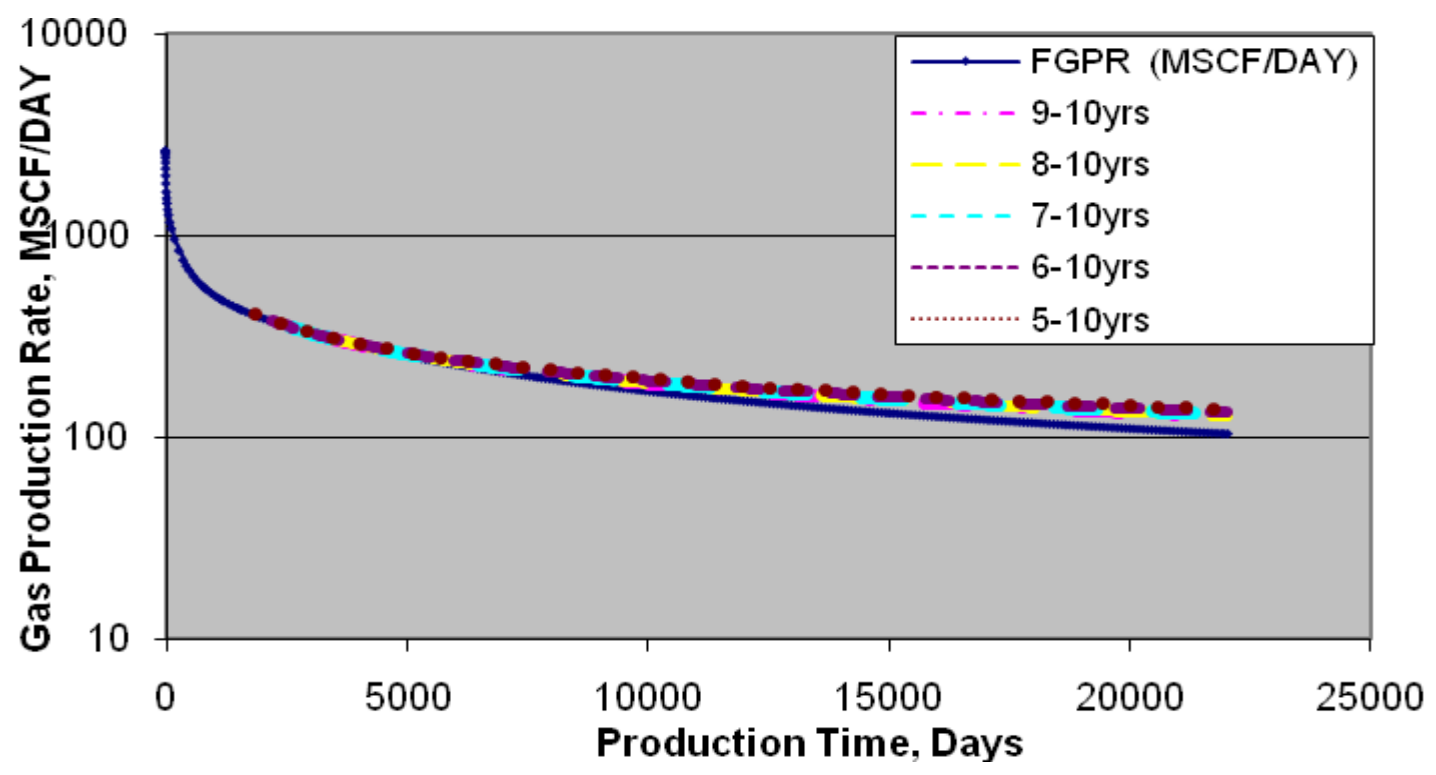

Figure 38: Semi-log showing Backward Method 10years (Using fracture half-length of 271ft). 
Table 19: Fracture half - length (Backwards 5years)

\begin{tabular}{|c|c|c|c|c|c|c|c|}
\hline $\begin{array}{l}\text { Start } \\
\mathrm{HM}, \mathrm{yr}\end{array}$ & $\begin{array}{l}\text { End } \\
\mathrm{HM}, \mathrm{yr}\end{array}$ & $\begin{array}{l}q_{i} \\
(\mathrm{Mscf} / \mathrm{D})\end{array}$ & $D_{i}$ & b & $\begin{array}{l}\text { CUM_cal } \\
\text { (Mscf) }\end{array}$ & $\begin{array}{l}\text { CUM_true } \\
\text { (Mscf) }\end{array}$ & $\begin{array}{l}\text { Error } \\
\text { (Fraction) }\end{array}$ \\
\hline 4 & 5 & 2868 & 0.033228 & 2.586 & $4,346,842$ & $3,604,367$ & 0.20 \\
\hline 3 & 5 & 2866 & 0.03565 & 2.632 & $4,717,691$ & $3,930,626$ & 0.20 \\
\hline 2 & 5 & 2864 & 0.035054 & 2.622 & $4,896,867$ & $4,125,484$ & 0.18 \\
\hline
\end{tabular}

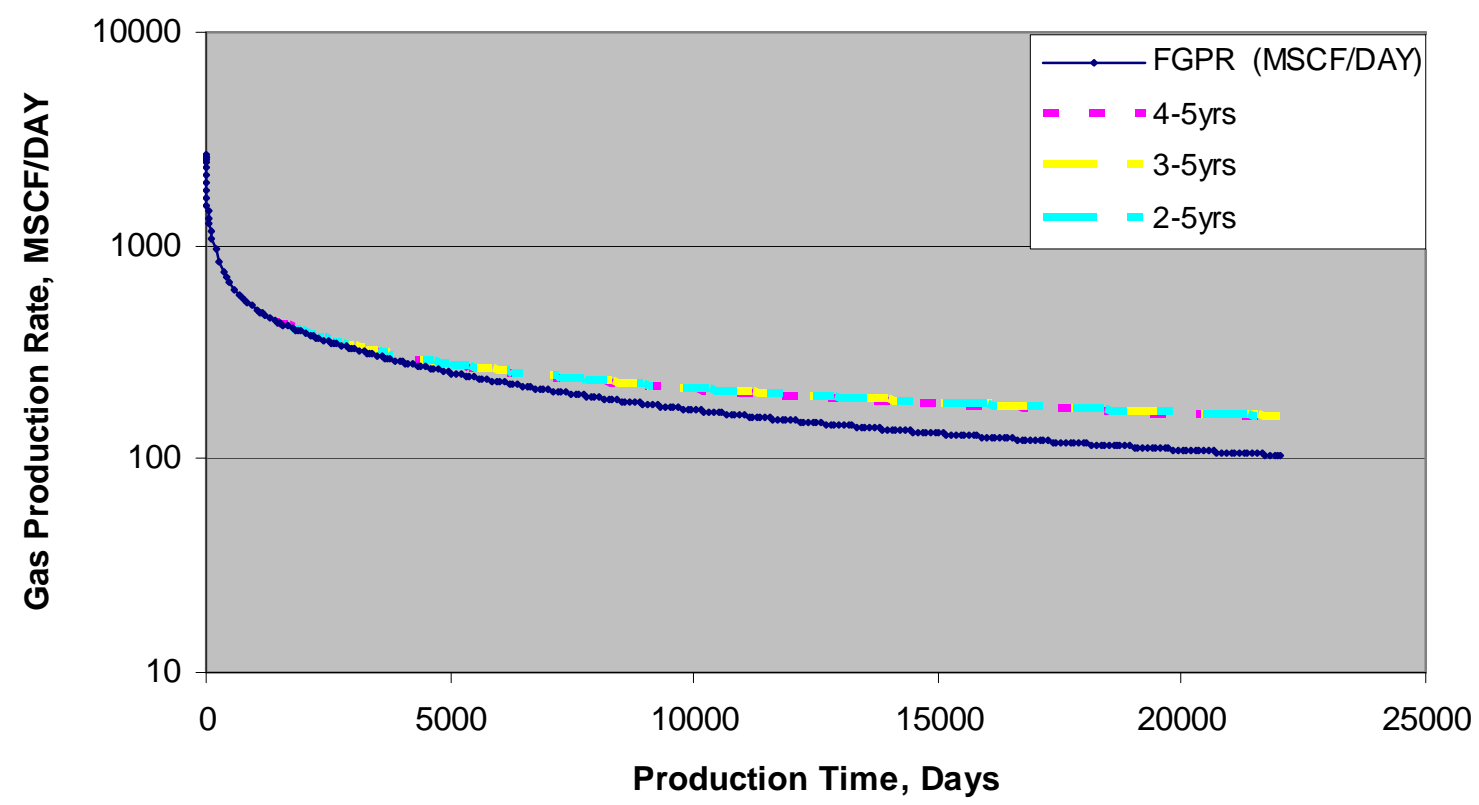

Figure 39: Semi-log showing Backward Method 5years (Using fracture half-length of 271ft). 
Table 20: Fracture half - length (Ilk Method)

\begin{tabular}{|r|l|l|l|l|l|l|l|l|}
\hline $\begin{array}{l}\text { Start } \\
\mathrm{HM}, \mathrm{yr}\end{array}$ & $\begin{array}{l}\text { End } \\
\mathrm{HM}, \mathrm{yr}\end{array}$ & $\begin{array}{l}q_{i} \\
(\mathrm{Mscf} / \mathrm{D})\end{array}$ & $D_{i}$ & $\mathrm{n}$ & Dinfi & $\begin{array}{l}\text { CUM_cal } \\
\text { (Mscf) }\end{array}$ & $\begin{array}{l}\text { CUM_true } \\
\text { (Mscf) }\end{array}$ & $\begin{array}{l}\text { Error } \\
\text { (Fraction) }\end{array}$ \\
\hline 1 & 5 & 2833 & 0.241108 & 0.285 & 0.000001 & $2,237,964$ & $3,604,367$ & -0.37 \\
\hline 1 & 10 & 2871 & 0.261982 & 0.269 & 0.000001 & $2,144,366$ & $2,970,796$ & -0.27 \\
\hline
\end{tabular}

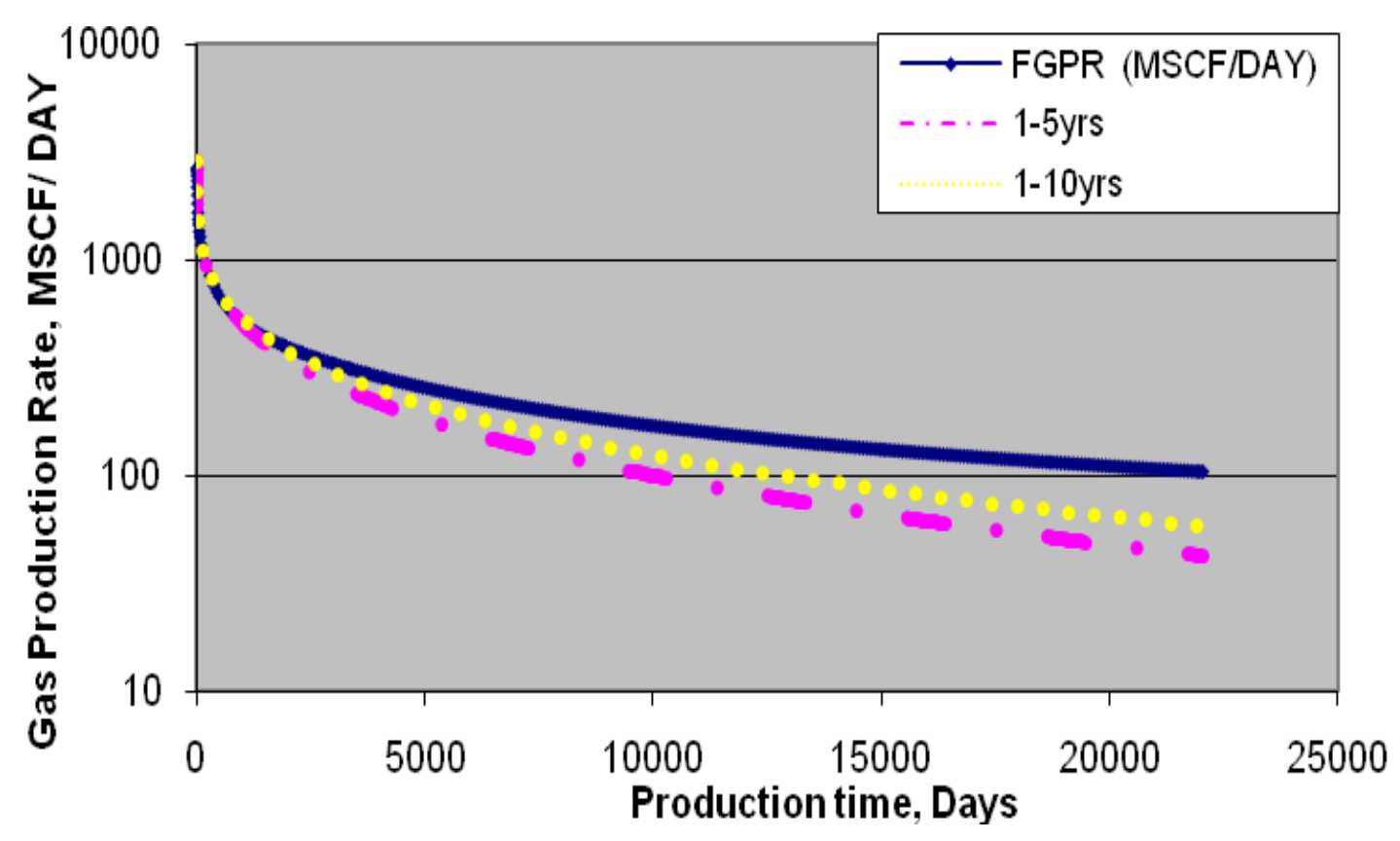

Figure 40: Semi-log showing Ilk Method (Using fracture half-length of 271ft). 
Table 21: Fracture half - length (Backward \& Ilk Method)

\begin{tabular}{|c|c|c|c|c|c|c|c|c|}
\hline $\begin{array}{l}\text { Start } \\
\mathrm{HM}, \mathrm{yr}\end{array}$ & $\begin{array}{l}\text { End } \\
\mathrm{HM}, \mathrm{yr}\end{array}$ & $\begin{array}{l}q_{i} \\
(\mathrm{Mscf} / \mathrm{D})\end{array}$ & $D_{i}$ & $\mathrm{n}$ & Dinfi & $\begin{array}{l}\text { CUM_cal } \\
\text { (Mscf) }\end{array}$ & $\begin{array}{l}\text { CUM_true } \\
\text { (Mscf) }\end{array}$ & $\begin{array}{l}\text { Error } \\
\text { (Fraction) }\end{array}$ \\
\hline 4 & 5 & 2874 & 0.462159 & 0.191 & 0.00001 & $3,696,732$ & $3,604,367$ & 0.02 \\
\hline 9 & 10 & 2924 & 0.419129 & 0.204 & 0.00001 & $2,896,691$ & $2,970,796$ & -0.02 \\
\hline
\end{tabular}

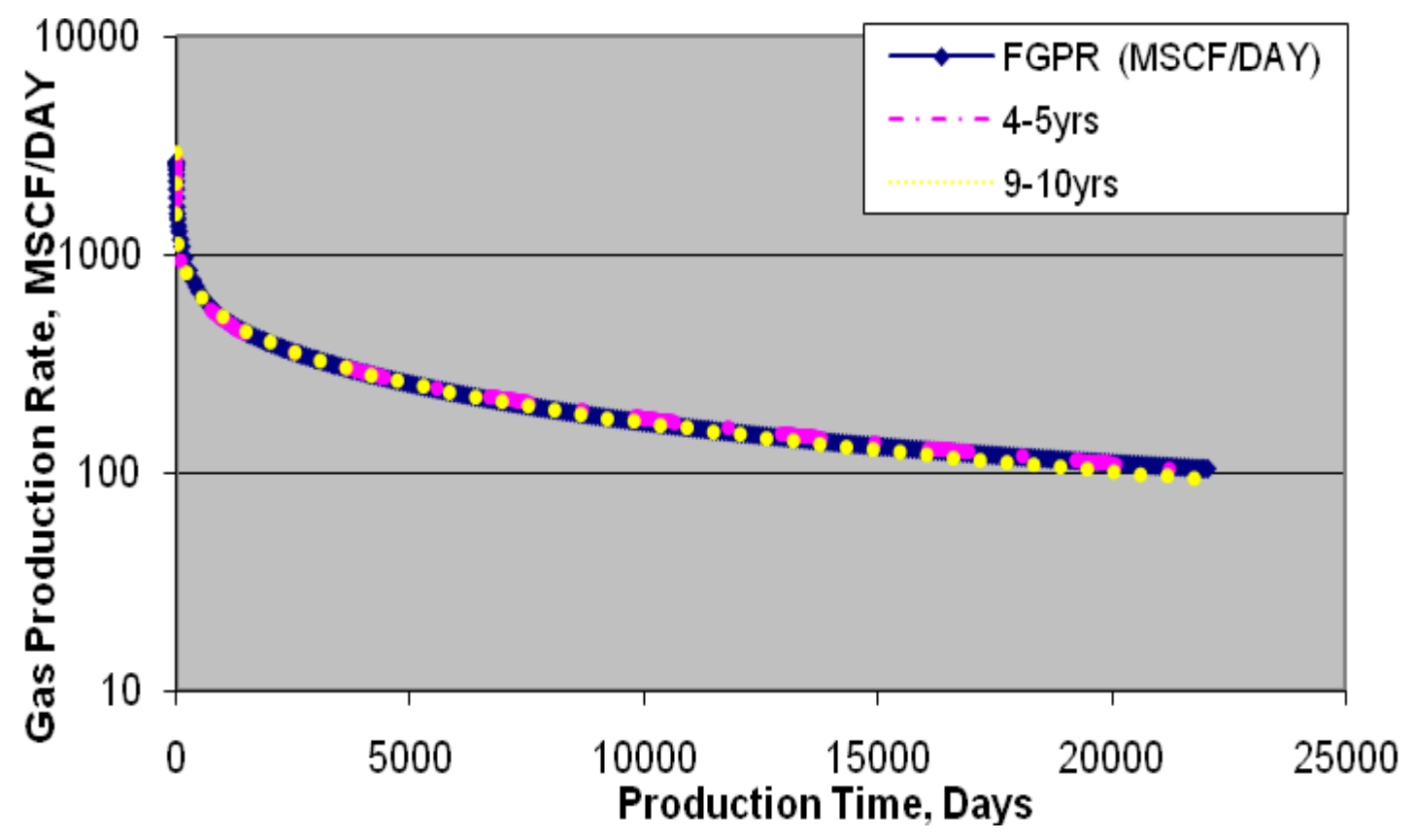

Figure 41: Semi-log showing Conventional Method (Using fracture half-length of 271ft). 


\section{SUMMARY AND CONCLUSIONS}

This research work has shown that production decline analysis can still be used to estimate ultimate reserves (EUR) of shale gas reservoirs using several methods like conventional decline curve analysis, backward method, Ilk method and Backward \& Ilk method, however, the conventional decline curve analysis method in shale gas reservoir is very problematical in forecasting long-term performance and is quite inaccurate in estimating reserves.

The Backward method from Cheng ${ }^{4}$ and Ilk method from Ilk D. et al ${ }^{14}$ were both reaffirmed in this work to be more accurate and a better estimator of reserves and predictor of future well performances in comparison to the traditional decline curve analysis method in shale gas reservoirs. Although, Ilk method is a good estimator of shale gas reserves, the backward method showed more consistency than the Ilk method throughout the different scenarios considered.

In the four scenarios considered, the maximum fractional error recorded were 1.21 (Conventional decline curve analysis method), 0.30 (Backward method10 years), 0.34 (Backward method 5 years), 0.51 (Ilk method) and 0.09 (Backward \& Ilk method), while the minimum fractional error recorded were 0.50 (Conventional decline curve analysis method), 0.09 (Backward method10 years), 0.18 (Backward method 5 years), 0.01 (Ilk method) and 0.01 (Backward \& Ilk method). Conventional decline curve analysis method had the maximum fractional error in all cases studied.

Furthermore, the new approach that was proposed, that is, the combination of the Backward \& Ilk method yielded superior results compared to all other production decline analysis methods used in this work. This method was validated using synthetic case 
studies for single-layer hydraulically fractured horizontal wells in different well-reservoir systems. From the different scenarios considered in this research work, accurate reserves and performance forecasts were obtained using the combination of the Backward \& Ilk method.

In addition, the proposed method provides a useful tool to estimate reserves and forecast future performance from production decline data in shale gas reservoirs. 


\section{RECOMMENDATION}

I would recommend that the combination of the Ilk \& Backward method be tried with most recent production data as it becomes more accurate in its reserve estimation prediction of future performances. 


\section{NOMENCLATURE}

$\mathrm{b}=$ the decline exponent

$C_{f D}=$ Dimensionless fracture conductivity

DCA = Decline Curve Analysis

$\mathrm{Di}=$ the initial decline rate

$D_{1}=$ Decline constant at 1 time unit $\mathrm{D}(\mathrm{t}=1$ day $)$

$D_{\infty}=$ Decline constant at "infinite time” $\mathrm{D}(\mathrm{t}=$ infinite $)$

$D_{i}=$ Decline constant where $D_{i}=D_{1} / \mathrm{n}$

FGPR $=$ Field Gas Production Rate

GPR $=$ Gas Production Rate

GPT $=$ Gas Production Total or Cumulative Production

$\mathrm{kf}_{\mathrm{f}}$ proppant pack permeability

$\mathrm{k}=$ formation permeability

$\mathrm{n}=$ Time exponent

$\mathrm{Np}=$ cumulative production

$\mathrm{P}=\mathrm{Gas}$ Pressure

$\mathrm{qi}=$ the initial production rate

$q_{i}=$ Rate $\mathrm{q}(\mathrm{t}=0)$ [this parameter differs from initial rate]

$\mathrm{q}(\mathrm{t})=$ production rate at time $\mathrm{t}$

$\mathrm{w}=$ fracture width

$\mathrm{Xf}=$ fracture half-length

$\theta=$ Percentage Coverage of the Surface

$\lambda=$ Langmuir constant 


\section{REFERENCES}

1. Arps, J. J.: "Analysis of Decline Curves," Published in Petroleum Transactions, AIME, 160 (1945): 230-250.

2. Cheng, Y et al.: "Improving Reserves Estimates from Decline- Curve Analysis of Tight and Multilayer Gas Wells,” SPE 108176 presented at the SPE Hydrocarbon Economics and Evaluation Symposium, Dallas, Texas, 1-3 April.

3. Cheng Y. et al.: "A New Approach for Reliable Estimation of Hydraulic Fracture Properties in Tight Gas,” SPE 105767 presented at the Hydraulic Fracturing Technology Conference in College station, Texas, 29-31 January 2007.

4. Cheng Y. et al.: "Practical Application of a Probabilistic Approach to Estimate Reserves Using Production Decline Data," SPE 95974 presented at the SPE Annual Technical Conference and Exhibition, Texas, 9-12 October 2005.

5. Cinco-Ley, H. and Meng, H.Z.: "Pressure Transient Analysis of Wells With Finite Conductivity Vertical Fractures in Double Porosity Reservoirs,” paper SPE 18172 presented at the $63^{\text {rd }}$ Annual Technical Conference and Exhibition, Houston, TX, Oct. 2-5, 1988.

6. Creties, D. J. et al.: “Coalbed and Shale Gas Reservoirs,” SPE 103514 (2008)

7. Fetkovich, M. J., E. J. Fetkovich, and M. D. Fetkovich: "Useful Concepts for Decline Curve Forecasting, Reserve Estimation, and Analysis," SPE 28628 presented at the SPE Annual Technical Conference \& Exhibition, New Orleans, September 25-28, 1994.

8. Fetkovich, M. J.: “Decline Curve Analysis Using Type Curves,” Journal of Petroleum Technology, Vol. 32, No. 6 (1980, June): 1065-77

9. “Flow Regimes,” www.fekete.com, http://www.fekete.com/software/welltest/media/webhelp/c-te-flowregimes.htm

10. Gidley, J.L. et al.: Recent Advances in Hydraulic Fracturing, Monograph Series, SPE, Richardson, Texas (1989) 12, 1 - 2, 83-89, 95-106

11. Hill, D. G., 2000, GIS compilation of gas potential of the New Albany Shale in the Illinois Basin

12. Holditch, S.A.: “Tight Gas Sands,” JPT (June 2006) 86.

13. Hong'en Don et al.: "Decline Analysis for Horizontal Wells of Intercampo Field, Venezuela," SPE 106440 presented at the SPE Production and Operations Symposium held in Oklahoma City, March 31- 3 April 2007. 
14. Ilk D. et al.: "Exponential Vs Hyperbolic Decline in Tight Gas Sands Understanding the Origin and Implications for Reserve Estimates Using Arp's Decline Curves,” SPE 116731 presented at the 2008 Annual Technical Conference and Exhibition held in Denver, Colorado, Sept. 21-24, 2008.

15. Joshi S.D. et al.: "Cost/Benefits of Horizontal Wells," SPE 83621 presented at the SPE Western Regional, AAPG Pacific Section Joint Meeting held in Long Beach, California, May 19-24, 2003.

16. Koziar Gregory.: "Devonian Shale Production Data Analysis Southwestern West Virginia,” SPE 14505 presented at the Eastern Regional Meeting held in Morgantown, West Virginia, November 6-8, 1985.

17. Kuuskraa, V.A.: “Natural Gas Resources, Unconventional,” Encyclopedia of Energy, Elsevier Academic Press, San Diego (2004) 4, 257.

18. Kuuskraa, V.A. et al.: “Technically Recoverable Devonian Shale Gas in Ohio, West Virginia, and Kentucky,” SPE 14503 presented at the Eastern Regional Meeting held in Morgantown, West Virginia, November 6-8, 1985.

19. "Marcellus shale - Appalachian Basin,” www.geology.com, http://geology.com/articles/marcellus-shale.shtml

20. Mavor, M.J. and Cinco-Ley, H.: "Transient Pressure Behavior of Naturally Fractured Reservoirs,” SPE 7977 presented at the 1979 California Regional Meeting of the SPE, Ventura, California, April 18-20, 1979.

21. Mcdaniel B.W. et al.: "Horiontal Wellbore Placement can Significantly Impact Hydraulic Fracturing,” SPE 105185 presented at the Hydraulic Fracturing Technology Conference in College station, Texas, 29-31 January 2007.

22. Mei Y. and Economides M.J.: “Transverse Hydraulic Fractures from a Horizontal Well," SPE 94671 presented at the Annual Technical Conference and Exhibition Dallas, Texas, 9-12 October 2005.

23. Miller M. J., Marshall Miller \& Associates: “Marcellus Shale Development Overview,” presented to Pennsylvania Independent Petroleum Producers Inc., March 2008.

24. Neil, C. D. et al.: “Applied Technology Helps Revitalize a Maturing Giant Gas Field: Learnings from the Cleveland Formation's Horizontal Well Redevelopment Program,”SPE 109948 presented at the Annual Technical Conference and Exhibition held in Anaheim, California, U.S.A., 11-14 November 2007. 
25. Paktinat, J, J.A Pinkhouse et al.: “Optimizing Hydraulic Fracturing Performance in Northeastern United States Fractured Shale Formations,” SPE 104306 presented at the SPE Eastern Regional Meeting held in Canton, Ohio, U.S.A., 1113 October 2006.

26. Soeder, D. J., SPE, Inst. Of Gas Technology: "Porosity and Permeability of Eastern Devonian Gas Shale,” SPE Formation Evaluation, March 1988.

27. Soliman, M. Y. et al.: "Fracturing Horizontal Wells in Gas Reservoirs," SPE 59096 (1999)

28. Sumi Lisa.: “Shale Gas: Focus on the Marcellus Shale,” May 2008.

29. Thakur P.C. and W.N. Poundstone: "Horizontal Drilling Technology for Advance Degasification,” June 1980.

30. Thompson Robert S. and Wright John D.: Oil Property Evaluation, $2^{\text {nd }}$ Edition, (1984)

31. Tschirhart, N.R.: “The Evaluation of Waterfrac Technology in Low-Permeability Gas Sands in the East Texas Basin,” MS thesis, Texas A\&M U., College Station, Texas (2005).

32. Walser, D.W. et al.: “ Making Mature Shale Gas Plays Commercial: Process Vs Natural Parameters,” SPE 110127 presented at the SPE Eastern Regional Meeting held in Lexington, Kentucky, U.S.A., 17-19 October 2007. 